\title{
Capacitively Coupled Resistivity Survey of Selected Irrigation Canals Within the North Platte River Valley, Western Nebraska and Eastern Wyoming, 2004 and 2007-2009
}

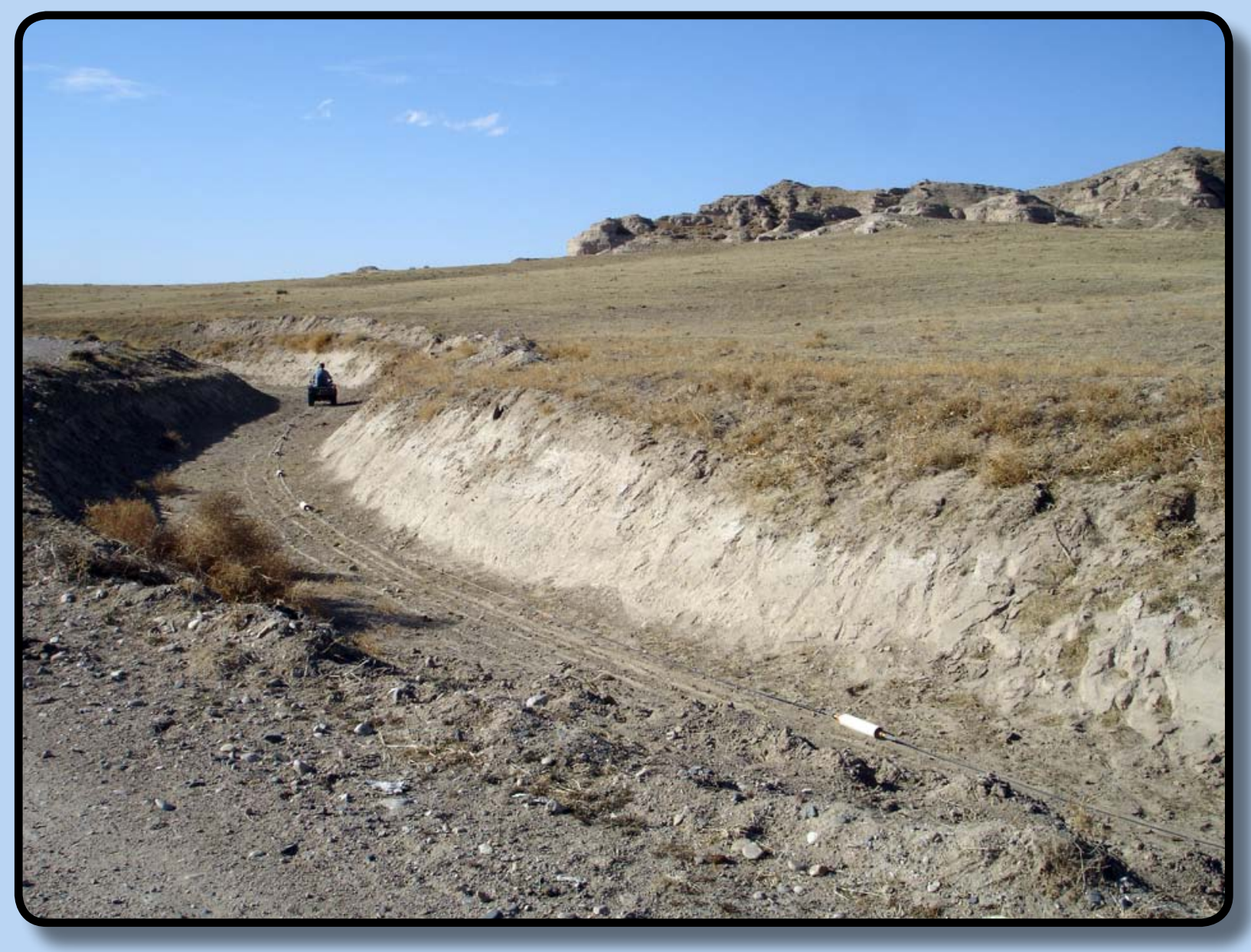

Scientific Investigations Report 2009-5194 



\section{Capacitively Coupled Resistivity Survey of Selected Irrigation Canals Within the North Platte River Valley, Western Nebraska and Eastern Wyoming, 2004 and 2007-2009}

By Bethany L. Burton, Michaela R. Johnson, Joseph Vrabel, Brian H. Imig, Jason D. Payne, and Ryan E. Tompkins

Prepared in cooperation with the North Platte Natural Resources District

Scientific Investigations Report 2009-5194

U.S. Department of the Interior

U.S. Geological Survey 


\title{
U.S. Department of the Interior \\ KEN SALAZAR, Secretary
}

\author{
U.S. Geological Survey \\ Suzette M. Kimball, Acting Director
}

U.S. Geological Survey, Reston, Virginia: 2009

For more information on the USGS--the Federal source for science about the Earth, its natural and living resources, natural hazards, and the environment: visit http://www.usgs.gov or call 1-888-ASK-USGS

For an overview of USGS information products, including maps, imagery, and publications, visit http://www.usgs.gov/pubprod

To order this and other USGS information products, visit http://www.store.usgs.gov

Any use of trade, product, or firm names is for descriptive purposes only and does not imply endorsement by the U.S. Government.

Although this report is in the public domain, permission must be secured from the individual copyright owners to reproduce any copyrighted materials contained within this report.

Suggested citation:

Burton, B.L., Johnson, M.R., Vrabel, Joseph, Imig, B.H., Payne, J.D., and Tompkins, R.E., 2009, Capacitively coupled resistivity survey of selected irrigation canals within the North Platte River valley, western Nebraska and eastern Wyoming, 2004 and 2007-2009: U.S. Geological Survey Scientific Investigations Report 2009-5194, 70 p. 


\section{Contents}

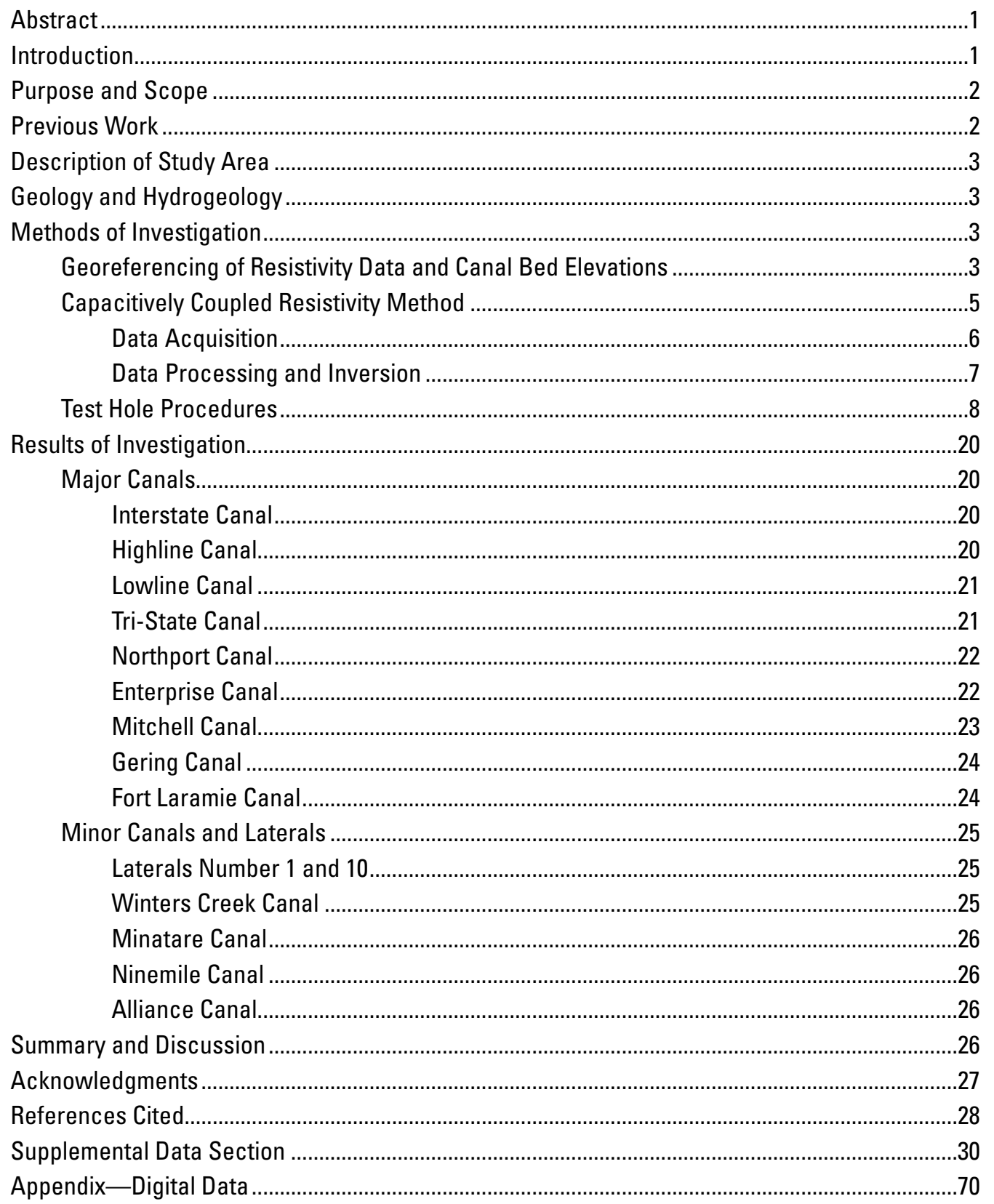




\section{Figures}

1. Map showing location of the capacitively coupled resistivity surveys from 2004 and 2007 through 2009 and location of test holes drilled in 2008 and 2009.

2. Schematic illustration showing the capacitively coupled resistivity-system setup and geometry

3-37. Comparisons of lithologic and electrical conductivity logs to inverted capacitively coupled resistivity sections and average resistivity curves from:

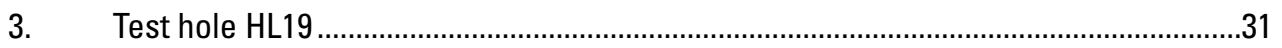

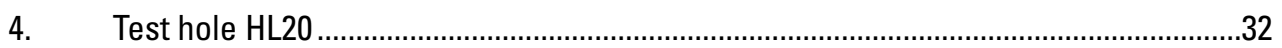

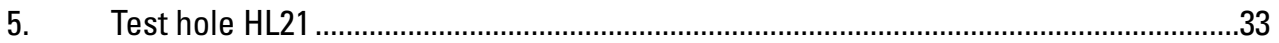

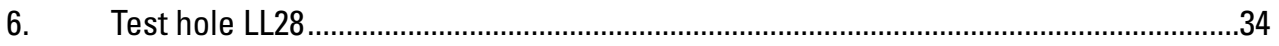

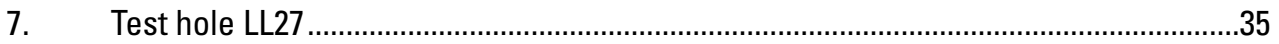

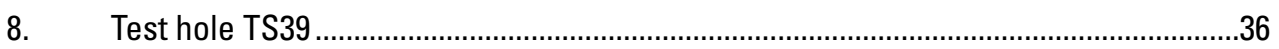

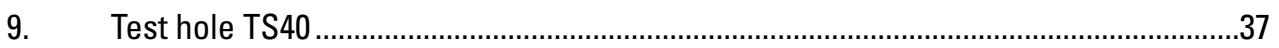

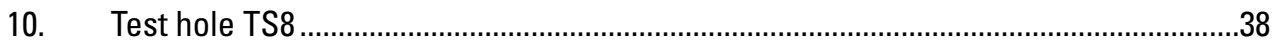

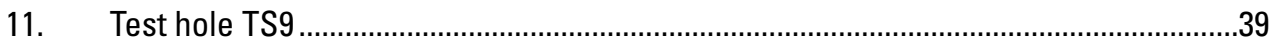

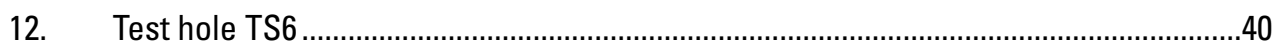

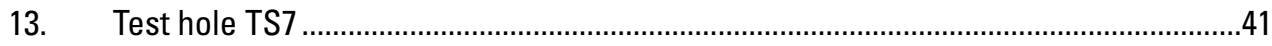

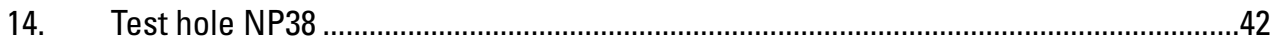

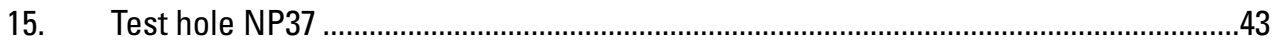

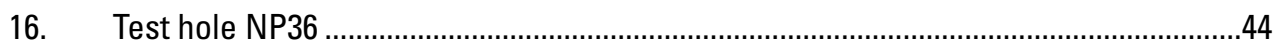

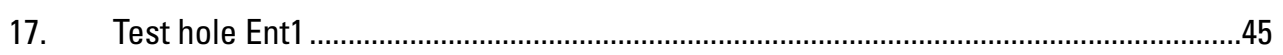

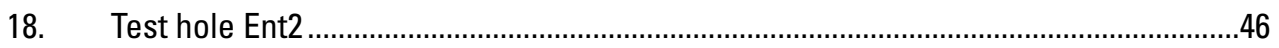

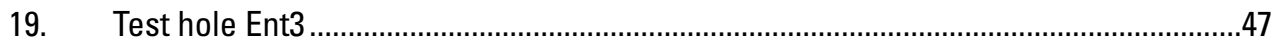

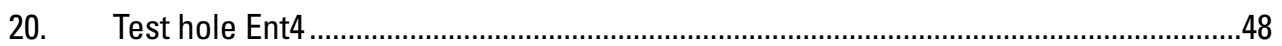

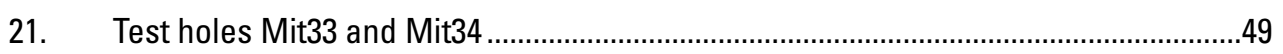

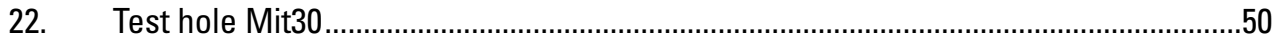

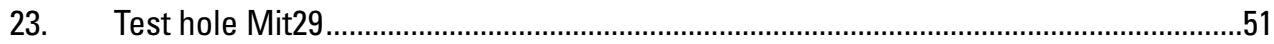

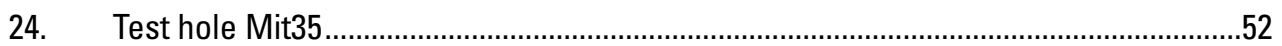

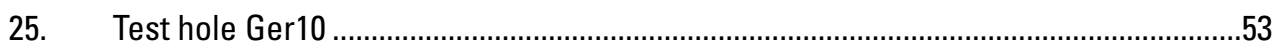

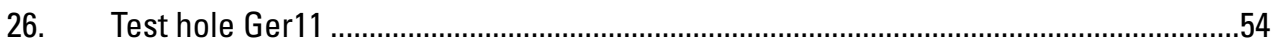

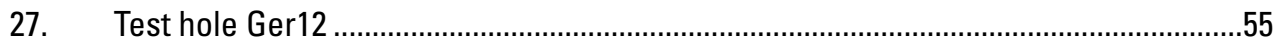

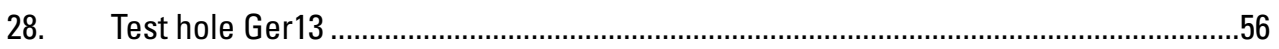

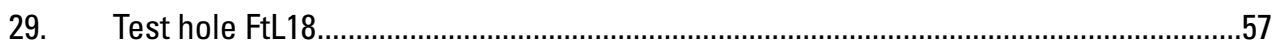

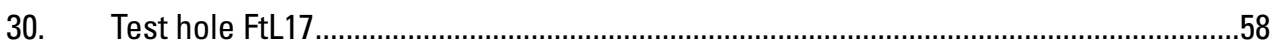

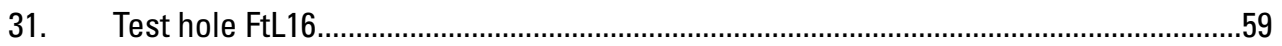

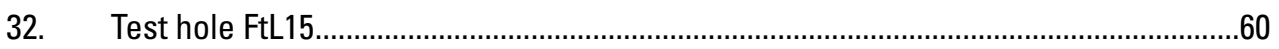

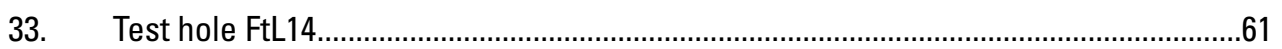

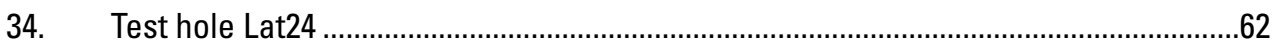

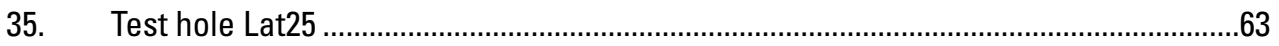

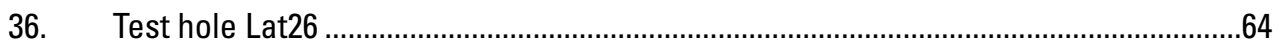

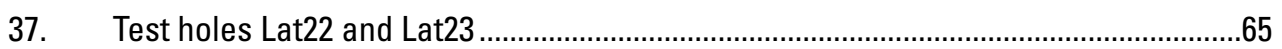


38-41. Sample inverted capacitively coupled resistivity sections and average resistivity curves from the:

38. Western and eastern surveyed sections of Winters Creek Canal.............................66

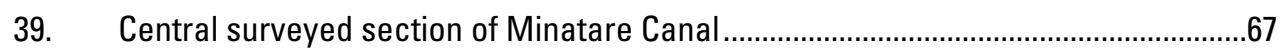

40. Central and eastern surveyed sections of Ninemile Canal ........................................68

41. Central and eastern surveyed sections of Alliance Canal .........................................69

\section{Tables}

1. Summary of capacitively coupled resistivity-survey-acquisition parameters ............7

2. Detailed lithologic descriptions from test holes acquired in 2008 and 2009 ................9 


\section{Conversion Factors}

\section{[SI to Inch/Pound]}

\begin{tabular}{lcl}
\hline Multiply & By & To obtain \\
\hline millimeter $(\mathrm{mm})$ & Length & \\
centimeter $(\mathrm{cm})$ & 0.03937 & inch (in) \\
meter $(\mathrm{m})$ & 0.3937 & inch (in) \\
kilometer $(\mathrm{km})$ & 3.281 & foot (ft) \\
meter $(\mathrm{m})$ & 0.6214 & mile (mi) \\
\hline & 1.094 & yard (yd) \\
\hline square meter $\left(\mathrm{m}^{2}\right)$ & Area & acre \\
square meter $\left(\mathrm{m}^{2}\right)$ & 0.0002471 & acre \\
hectare $(\mathrm{ha})$ & 2.471 & square mile $\left(\mathrm{mi} \mathrm{i}^{2}\right)$ \\
\hline & 0.003861 & \\
\hline kilometer per hour $(\mathrm{km} / \mathrm{h})$ & Flow rate & mile per hour $(\mathrm{mi} / \mathrm{h})$ \\
\hline & 0.6214 & foot per day $(\mathrm{ft} / \mathrm{d})$ \\
\hline meter per day $(\mathrm{m} / \mathrm{d})$ & Hydraulic conductivity & \\
\hline
\end{tabular}

Temperature in degrees Celsius $\left({ }^{\circ} \mathrm{C}\right)$ may be converted to degrees Fahrenheit $\left({ }^{\circ} \mathrm{F}\right)$ as follows:

$$
{ }^{\circ} \mathrm{F}=\left(1.8 x^{\circ} \mathrm{C}\right)+32
$$

Vertical coordinate information is referenced to North American Vertical Datum of 1988 (NAVD 88). Horizontal coordinate information is referenced to North American Datum of 1983 (NAD 83).

Elevation, as used in this report, refers to distance above the vertical datum. 


\title{
Capacitively Coupled Resistivity Survey of Selected Irrigation Canals Within the North Platte River Valley, Western Nebraska and Eastern Wyoming, 2004 and 2007-2009
}

\author{
By Bethany L. Burton, Michaela R. Johnson, Joseph Vrabel, Brian H. Imig, Jason D. Payne, and \\ Ryan E. Tompkins
}

\section{Abstract}

Due to water resources of portions of the North Platte River basin being designated as over-appropriated by the State of Nebraska Department of Natural Resources (DNR), the North Platte Natural Resources District (NPNRD), in cooperation with the DNR, is developing an Integrated Management Plan (IMP) for groundwater and surface water in the NPNRD. As part of the IMP, a three-dimensional numerical finite difference groundwater-flow model is being developed to evaluate the effectiveness of using leakage of water from selected irrigation canal systems to manage groundwater recharge. To determine the relative leakage potential of the upper $8 \mathrm{~m}$ of the selected irrigation canals within the North Platte River valley in western Nebraska and eastern Wyoming, the U.S. Geological Survey performed a land-based capacitively coupled (CC) resistivity survey along nearly $630 \mathrm{~km}$ of 13 canals and 2 laterals in 2004 and from 2007 to 2009. These 13 canals were selected from the 27 irrigation canals in the North Platte valley due to their location, size, irrigated area, and relation to the active North Platte valley flood plain and related paleochannels and terrace deposits where most of the saturated thickness in the alluvium exists. The resistivity data were then compared to continuous cores at 62 test holes down to a maximum depth of $8 \mathrm{~m}$. Borehole electrical conductivity (EC) measurements at 36 of those test holes were done to correlate resistivity values with grain sizes in order to determine potential vertical leakage along the canals as recharge to the underlying alluvial aquifer. The data acquired in 2004, as well as the 25 test hole cores from 2004, are presented elsewhere. These data were reprocessed using the same updated processing and inversion algorithms used on the 2007 through 2009 datasets, providing a consistent and complete dataset for all collection periods. Thirty-seven test hole cores and borehole electrical conductivity measurements were acquired based on the 2008 data. This report presents comparisons between the $\mathrm{CC}$ resistivity data and results from the 37 test holes and includes all binned and inverted CC resistivity datasets from all four years as well as the EC log data for the 37 test holes acquired in 2008 and 2009. The information gained from these data can help State and local water managers and scientists better understand the characteristics of the shallow subsurface underlying the irrigation canals so that the water resources can be managed more effectively.

\section{Introduction}

Water resources of portions of the North Platte River basin are designated as being over-appropriated by the State of Nebraska Department of Natural Resources (DNR). An over-appropriated basin designation means that the existing demand on the surface and hydrologically connected groundwater resources are greater than the supply, resulting in decreased surface-water flows and water-table levels. To comply with State law, the North Platte Natural Resources District (NPNRD), in cooperation with the DNR, is developing an Integrated Management Plan (IMP) for groundwater and surface water in the NPNRD (DNR, 2005; Kurtz, 2005). A necessary component of the IMP is a clear understanding of the groundwater and surface-water systems to be managed and the development of management tools that will be used by the participating agencies and the public. The study area lies within the Nebraska and Wyoming North Platte River valley upstream of the town of Lewellen in the Nebraska Panhandle. The majority of the study area is within the Nebraska portion of the valley. There are 27 irrigation districts that operate canals within the valley, delivering irrigation water to approximately 145,700 hectares. Recharge from these mostly unlined canals is a major source of groundwater for the area and in turn provides base flow to the valley streams, creating an intricate groundwater-surface-water relation.

As part of the IMP, a three-dimensional numerical finite difference groundwater-flow model is being developed to 
evaluate the effectiveness of incorporating leakage of water from selected irrigation canal systems to manage groundwater recharge. The U.S. Bureau of Reclamation estimates that canals in the area leak approximately 40-50 percent of their diversion into the aquifers (Verstraeten and others, 2001). Information on where this water is preferentially leaking will improve the recharge estimates for the groundwater-flow model and provide critical insight into the relation of groundwater and surface water. The results of the groundwater model will provide information that will be an integral part in developing the IMP and provide policy makers and planners with a better understanding of the effects of possible water management decisions.

In order for the groundwater-flow model to accurately simulate current or to predict future groundwater and surfacewater conditions in the NPNRD, input of specific variables such as stream bed conductance or leakage values of the canals is imperative. The values input into the model, however, are often estimated based on lithologic data collected from boreholes that can be several miles apart and distant from the canals. Moreover, these irrigation canals often transect areas underlain by laterally restricted or discontinuous sand and gravel or silt/clay deposits that are not observed in distant boreholes. These varied deposits affect the rate and volume of leakage. Because sand and gravel deposits are more transmissive than clay deposits, it is likely that areas containing sand and gravel deposits incised by irrigation canals will leak more than areas containing clay deposits. Further, because the input values of streambed conductance or leakage are based on data collected from distant sites, these data may not be representative of actual, local conditions. Large segments of canals are often assigned constant leakage rates due to a lack of nearby data. Although these constant values may be the best estimate given the available data, they will result in substantial errors that affect the groundwater-flow model. These effects are most noticeable when the model cell size is decreased from a large regional scale to a small local scale.

The drilling of boreholes, or test holes, is time-consuming and expensive. Nevertheless, the only means of obtaining additional lithologic information within canal systems has been through surficial mapping, drilling, and examination of borehole logs or through geophysical surveys. The preferred approach is to combine surface geophysical methods with a drilling program to provide greater spatial coverage requiring fewer test holes.

From 2004 and 2007 through 2009, the U.S. Geological Survey (USGS), in cooperation with the NPNRD and the University of Nebraska Conservation and Survey Division, acquired nearly $630 \mathrm{~km}$ of capacitively coupled (CC) resistivity data within and along 13 canals and 2 laterals, or small diversions, to determine lithologies to a depth of up to $8 \mathrm{~m}$. The canals surveyed are Alliance, Enterprise, Gering, Fort Laramie, Interstate, including Highline and Lowline Canals as well as Laterals Number 1 and 10, Minatare, Mitchell, Ninemile, Northport, Tri-State, and Winters Creek. These were selected from the 27 irrigation canals in the North Platte
River valley because of their location, size, irrigated area, and relation to the active North Platte valley flood plain and related paleochannels and terrace deposits where most of the saturated thickness exists. The resistivity data were then compared to continuous cores at 62 test holes down to a maximum depth of $8 \mathrm{~m}$. Borehole electrical conductivity measurements at 36 of those test holes were done to correlate resistivity values with lithologies, and ultimately grain sizes, in order to determine potential vertical leakage along the canals to estimate recharge to the underlying aquifer. The information gained from these data can help State and local water managers and scientists better understand the characteristics of the shallow subsurface underlying the irrigation canals so that the water resources can be managed more effectively.

\section{Purpose and Scope}

This report presents the final inverted results of nearly $630 \mathrm{~km}$ of CC resistivity data acquired in 2004 and from 2007 through 2009 along 13 irrigation canals and 2 laterals within the North Platte River valley. The results are presented as two-dimensional, layered-earth resistivity cross sections that extend to the maximum depth of investigation of approximately 8 meters below land surface (mbls). All data presented were acquired while the canals and laterals were dry. For consistency, the $2004 \mathrm{CC}$ resistivity data presented in Ball and others (2006) were reprocessed using updated processing and inversion algorithms as performed on the 2007 through 2009 data; this provides a consistent and complete dataset for all collection periods. An independent real-time kinematic (RTK) global positioning system (GPS) survey was done following each year's resistivity survey to acquire more accurate positions and elevations of the canal beds. The inverted resistivity models are compared with 37 test hole continuous cores and 36 borehole electrical conductivity (EC) measurements. All $\mathrm{CC}$ resistivity and test hole EC log data collected are provided as an appendix to this report in electronic text format.

\section{Previous Work}

This project is a continuation of the previous canal study performed by Ball and others (2006) on the Interstate and TriState canals during 2004. In the 2004 study, the selected sections of the Interstate and Tri-State canals were surveyed using both water-borne direct-current (DC) and land-based CC resistivity methods. Consequently, a comparison of the DC and CC methods could be made. Based on Ball and others (2006) findings, it was determined that the $\mathrm{CC}$ resistivity technique in the dry canals was a superior and more efficient technique for accomplishing the goals of this project for several reasons: (1) $\mathrm{CC}$ resistivity allows greater depth of investigation below the canal bed ( $8 \mathrm{~m}$ compared to 4-6 m), (2) CC resistivity provides a greater range of measured resistivity values, 
(3) data acquisition using the CC resistivity method is logistically easier in the presence of frequent obstructions (for example, bridges, concrete checks, and siphons), and (4) CC resistivity data collection reduces safety concerns because work is not performed in and around flowing water. For this report, these 2004 data were reprocessed using newly developed, in-house processing software, which was also used on the 2007 through 2009 datasets, that greatly aids in the quality control and analysis of large amounts of georeferenced data collected along a sinuous path.

\section{Description of Study Area}

The study area encompasses selected canals and laterals in the western and central regions of the NPNRD in Morrill, Scotts Bluff, and Sioux Counties in the Nebraska Panhandle and extends westward into Goshen County in eastern Wyoming to an extent similar to that of the western groundwatermodel unit of the Cooperative Hydrology Study (COHYST, 2004; fig. 1). The canals surveyed in 2004 and 2007 to 2009 encompass an area of about $1,850 \mathrm{~km}^{2}$. The east-west extent is approximately $10 \mathrm{~km}$ west of the Nebraska-Wyoming State line in the Interstate Canal to about $6.5 \mathrm{~km}$ northeast of Bridgeport, Nebr., in the Northport Canal. The north-south extent is about $16 \mathrm{~km}$ north of Henry, Nebr., in the Interstate Canal to about $5 \mathrm{~km}$ northwest of Bridgeport, Nebr., in the Alliance Canal.The study area is located in the High Plains section of the Great Plains physiographic province (Verstraeten and others, 1995). The majority of the land use is agricultural but also includes rangeland, urban, light industrial, recreational, wildlife refuges, and infrastructure (Verstraeten and others, 2001). The climate is typical for a mid-latitude, semiarid setting with a mean annual temperature of 9 degrees Celsius $\left({ }^{\circ} \mathrm{C}\right)$, a mean maximum of $32^{\circ} \mathrm{C}$ in July, a mean minimum of $-10^{\circ} \mathrm{C}$ in December and January, and a mean annual precipitation of 38.8 centimeters $(\mathrm{cm})$, based on data from the Scottsbluff weather station from 1961 to 1990 (The Weather Network, 2009).

\section{Geology and Hydrogeology}

There are numerous previous investigations that discuss in detail the geology and hydrogeology of the study area (Darton, 1903a,b; Wenzel and others, 1946; Babcock and Visher, 1951; Smith and Souders, 1975; Souders, 1986; Verstraeten and others, 1995; Steele and others, 2001; Verstraeten and others, 2001; Ball and others, 2006). In general, the near-surface geology consists of Quaternary age alluvial sand and gravel deposits with discontinuous lenses of silt and clay, Quaternary age residuum from sandstone and siltstone, and Quaternary age eolian sands all overlying the Tertiary age Brule Formation silt and mudstones. The surface eolian deposits are confined to localized areas that are located throughout the valley and near the surveyed canals. In some areas, the canals cut through these deposits, for example, Lateral Number 1 on the Interstate Canal. The Brule Formation is the local bedrock in the study area, and for the purposes of this study, is an aquitard (Verstraeten and others, 1995).

The alluvial, residuum, and eolian deposits vary in thickness and form an unconfined alluvial aquifer. There is a bedrock high just north of Tri-State Canal from the western edge of the study area to west of Mitchell, Nebr., that separates the unconfined alluvial aquifer into two halves; the northern aquifer is in the upland where the ancestral North Platte River valley paleochannels exist, and the southern aquifer is in the bottomland, as much as $30 \mathrm{~m}$ below the upland, where the present North Platte River valley exists. The depth to the water table in the northern aquifer ranges from 1.5 to $30 \mathrm{mbls}$ with a single, measured hydraulic conductivity of 91 meters/ day $(\mathrm{m} / \mathrm{d})$. The depth to the water table in the southern alluvial aquifer is shallower at $6 \mathrm{mbls}$ or less with measured hydraulic conductivities of $30 \mathrm{~m} / \mathrm{d}$ and $141 \mathrm{~m} / \mathrm{d}$ from two different boreholes (Verstraeten and others, 2001). The saturated thickness varies between $1.5 \mathrm{~m}$ near the valley walls to greater than 60 $m$ in the Dutch Flats area and near the present North Platte River (Verstraeten and others, 2001; Steele and others, 2001). The remainder of the alluvial aquifer in the central region of the NPNRD is described by Verstraeten and others (1995) as having a shallow water table and a maximum saturated thickness of $64 \mathrm{~m}$.

The direction of groundwater movement is typically toward the North Platte River (Verstraeten and others, 2001). The elevated bedrock along the south end of the Dutch Flats area creates local variations in the groundwater flow as the water must move around the obstacle. Multiple studies indicate that the North Platte River and the unconfined alluvial aquifer are hydraulically connected such that the river flow and groundwater levels are influenced by one another (Lappala and others, 1979; Hurr, 1981).

\section{Methods of Investigation}

\section{Georeferencing of Resistivity Data and Canal Bed Elevations}

All CC resistivity data were acquired using an integrated differential global positioning system (DGPS). The 2004 and 2007 data were collected using two different DGPS units, and the 2008 and 2009 data were collected using a newer DGPS unit, the Trimble DSM 232 (Trimble Navigation Ltd., Sunnyvale, Calif., U.S.A.) with the OmniSTAR (OmniSTAR, Inc., Houston, Tex., U.S.A.) High Precision (HP) subscription service. The vertical and horizontal accuracies provided by the HP service are typically less than $\pm 15 \mathrm{~cm}$ and $\pm 10 \mathrm{~cm}$, respectively (OmniSTAR, 2005).

Sections of data collected in 2008 and 2009 were acquired on the tow roads alongside the canals when access 


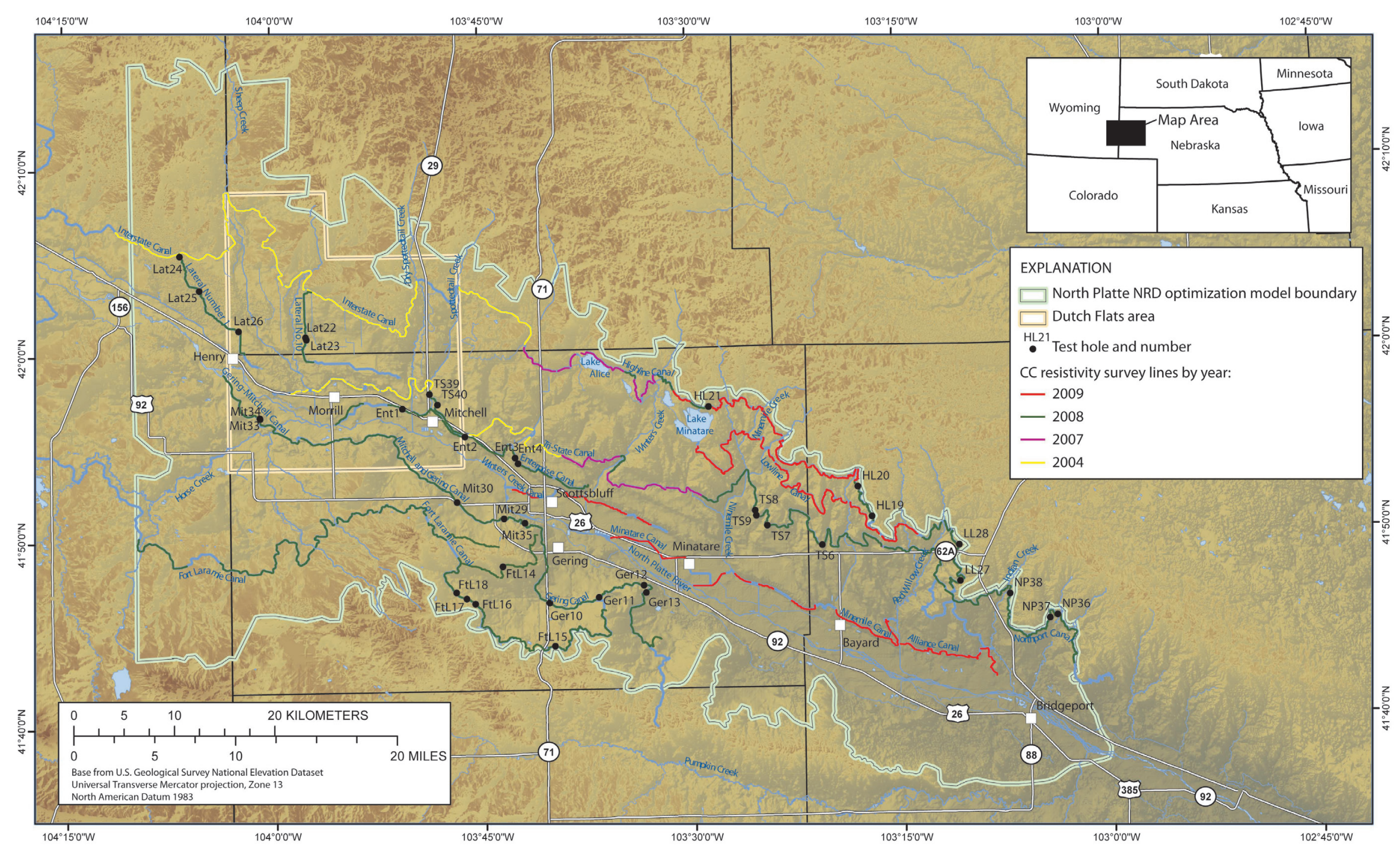

Figure 1. Map showing location of the capacitively coupled resistivity surveys performed in 2004 and 2007 through 2009 and location of test holes drilled in 2008 and 2009 . NRD, Natural Resources District; CC, capacitively coupled. Click to Enlarge 
within the canals was prohibited because of various obstacles such as large tumbleweed piles and snow drifts. For these tow road sections, a separate RTK GPS survey was performed after $\mathrm{CC}$ resistivity data collection before water was delivered to the canals. The canal bed elevations obtained were used to compare with the positioning of the CC resistivity data. In 2009, several sections of canals were already filled with water by the time the RTK GPS survey was done in early May. Consequently, $2 \mathrm{~km}$ of Highline Canal north of Lake Minatare, $2 \mathrm{~km}$ along the eastern half of Winters Creek Canal, and the western half of Ninemile Canal could not be surveyed by RTK GPS. For the RTK GPS survey, an Ashtech Z-Xtreme receiver and Geodetic IV revision A antenna (Magellan Corp., Santa Clara, Calif., U.S.A.) were used. The accuracy of this equipment is rated to be $1.6 \mathrm{~cm}+2$ parts per million (ppm) with five satellites and a position dilution of precision (PDOP) less than four (Ashtech Precision Products, 2001).

The RTK GPS uses the National Geodetic Survey (NGS) GEOID03 model, which is a geoid model of the conterminous United States. It is a hybrid geoid model combining GPS ellipsoid heights on benchmarks and gravimetric information (NGS, 2003). The data were collected in the Universal Transverse Mercator (UTM) projection, zone 13 North in meters. The horizontal datum used was North American Datum of 1983 (NAD83). Each GPS base station was positioned at a benchmark near the surveyed canal having an established location, and the collected data were processed through the NGS Online Positioning User Service (OPUS). The accuracy of these benchmark locations were reported to be within $5 \mathrm{~cm}$ horizontally and vertically. The OPUS service processes the base station data against three nearby continuously operating reference stations (CORS) with a two- to three-hour time span of data resulting in a peak-to-peak horizontal error of less than $2 \mathrm{~cm}$ and a vertical error of less than $3 \mathrm{~cm}$. The base station transmitted radio signals to the roving GPS unit to maintain the vertical and horizontal control during data collection.

When the 2008 data were collected, the OmniSTAR HP subscription was still utilizing the International Terrestrial Reference Frame of 2000 (ITRF00) for horizontal and vertical spatial reference. For the 2009 survey, however, the subscription service had been upgraded to the International Terrestrial Reference Frame of 2005 (ITRF05). During data collection for both the 2008 and 2009 surveys, the Trimble receiver output the National Marine Electronics Association (NMEA) GGA message string (includes time, position, and fix related data) to the $\mathrm{CC}$ resistivity data acquisition system, providing horizontal and vertical positioning and GPS quality factor information. The elevation recorded was the orthometric elevation determined by the Trimble receiver using the Model 332 geoid model - a manufacturer-installed, coarse $10^{\circ} \times 10^{\circ}$ grid (Dr. Lee Ott, written commun., July 8, 2005). This GGA orthometric elevation output from the Trimble receiver resulted in elevations that ranged from 2 to $5 \mathrm{~m}$ greater than the RTK GPS elevations. The GGA message elevations also exceeded elevations from existing sources, such as 7.5 minute USGS quadrangle maps.
Facilitating comparisons between the DGPS and RTK GPS datasets necessitated using a common spatial reference and geoid model. An adjustment factor using the raw coordinates collected with the DGPS was determined for all points using the following steps:

1. Remove the Trimble Model 332 geoid to obtain the ellipsoid height,

2. Convert from ITRF00 for the 2008 data (ITRF05 for the 2009 data) to NAD83, and

3. Determine the NGS GEOID03 model geoid heights from X, Y locations.

For step 1, the GGA message string contained the geoid separation height applied to each reading. For step 2, the Horizontal Time Dependent Positioning (HTDP) software (NGS, 2009a) was used to interactively transform positions between Horizontal Time Dependent Reference Frames. A set of locations was generated across the study area, and the elevation shift was determined for those points using HTDP. The resulting ITRF00 and ITRF05 to NAD83 adjustments were an addition to the elevation of less than a meter, with minimally changing values trending west to east. An adjustment grid was interpolated for the study area to generate a mesh of points. The values at the points nearest to the DGPS data collected were assigned to the DGPS points. The horizontal data were projected from ITRF00 and ITRF05 to WGS84 and from there to NAD83 using Environmental Systems Research Institute's ArcMap (Glennon and others, 2008). The horizontal geographic coordinates, after projecting to the geographic projection referenced to NAD83, were determined. For step 3, the GEOID03 heights were obtained using the NGS GEOID03 computation tool (NGS, 2009b). The $\mathrm{CC}$ resistivity data were assigned the adjustment elevation value determined for the nearest raw DGPS output coordinates. The value was calculated as the difference in the absolute values of the geoid heights and the ITRF00 and ITRF05 to NAD83 adjustment factor. The value was subtracted from the filtered, binned CC resistivity data.

\section{Capacitively Coupled Resistivity Method}

Resistivity is an intrinsic material property that is defined by resistance to the flow of electric current in that material. Measurements are made by injecting a known current into the subsurface using two current electrodes and measuring the resulting voltage difference between two potential electrodes. Based on Ohm's Law, the resistance is computed by taking the ratio of the measured voltage and the transmitted current. The apparent resistivity of the material, expressed in ohm-m, can then be determined by multiplying each resistance value by the corresponding geometric factor, which is based on the electrode geometry and spacing.

The main factors that affect the resistivity of a material are the amount of interconnected pore water present, the water quality (level of total dissolved solids, TDS), and the amount 
of mineralogical clay present. In the unsaturated zone, if no mineralogical clay is present, a fine-grained material (for example, silt or fine sand) will generally retain more interconnected water due to capillary forces than a coarse-grained material (for example, coarse sand or gravel). The fine-grained material will therefore have a lower resistivity compared to coarser grained materials. Water quality is an important factor because the concentration of ions in the water affects its ability to conduct electricity. Furthermore, materials containing water with high TDS will have a lower resistivity compared to materials containing water with low TDS. The presence of even a small amount of mineralogical clay minerals can dramatically decrease the overall bulk resistivity of a material because current is conducted both through the pore fluids (electrolytically) as well as through cation exchange (electronically). Because of the relation between grain size and resistivity, the resistivity method can be a useful tool in differentiating lithologies to determine relative levels of recharge to the unconfined, alluvial aquifer. Butler (2005), Reynolds (1997), and Sharma (1997) provide more detailed descriptions of the resistivity method and resistivity values for common geologic materials.

\section{Data Acquisition}

All CC resistivity datasets were acquired in the spring of 2004 and 2007 through 2009 before water delivery began in the canals to minimize the impact of groundwater level changes on the data. The $\mathrm{CC}$ resistivity data were acquired with the Geometrics OhmMapper TR5 (Geometrics, Inc., San Jose, Calif., U.S.A.) towed behind an all-terrain vehicle
(ATV). This dipole-dipole array system comprises five receiver dipoles, equivalent to five potential electrode pairs, and one transmitter dipole, equivalent to a current electrode pair (fig. 2). Each dipole consists of a 5-m cable attached to each end of an electronics unit, thereby creating dipole lengths of $10 \mathrm{~m}$. The resultant towed array length is on the order of $50 \mathrm{~m}$.

The transmitter, located at the rear of the array, is attached to the receivers by a nonconductive rope, and transmits an alternating current at a frequency of 16.5 kilohertz $(\mathrm{kHz})$. Current is transmitted into the ground through the use of capacitance; this negates the need for the electrodes to be in direct contact with the ground and thus allows for more efficient and faster data acquisition. The wire in each dipole cable and the ground act as the opposing conductor "plates" of a capacitor, and the insulating sheath of the wire and air between the dipole cable and the ground act as the insulator between the plates (Geometrics, 2001).

Each receiver dipole samples the subsurface to a particular depth based on its length and distance from the transmitter dipole. Based on the survey objective, the survey is designed for the optimal compromise between vertical and horizontal resolution and maximum depth of investigation by varying the geometry (dipole and rope lengths) of the array. The array geometry parameters used for each survey year are summarized in table 1 . Both the CC resistivity and DGPS data were acquired at a rate of $1 \mathrm{Hertz}(\mathrm{Hz})$ with the ATV traveling from 3 to $5 \mathrm{~km} / \mathrm{hr}$. For further details on the capacitively coupled resistivity method and acquisition system, refer to Ball and others (2006), Geometrics (2001), Lucius and others (2008), and Timofeev and others (1994).

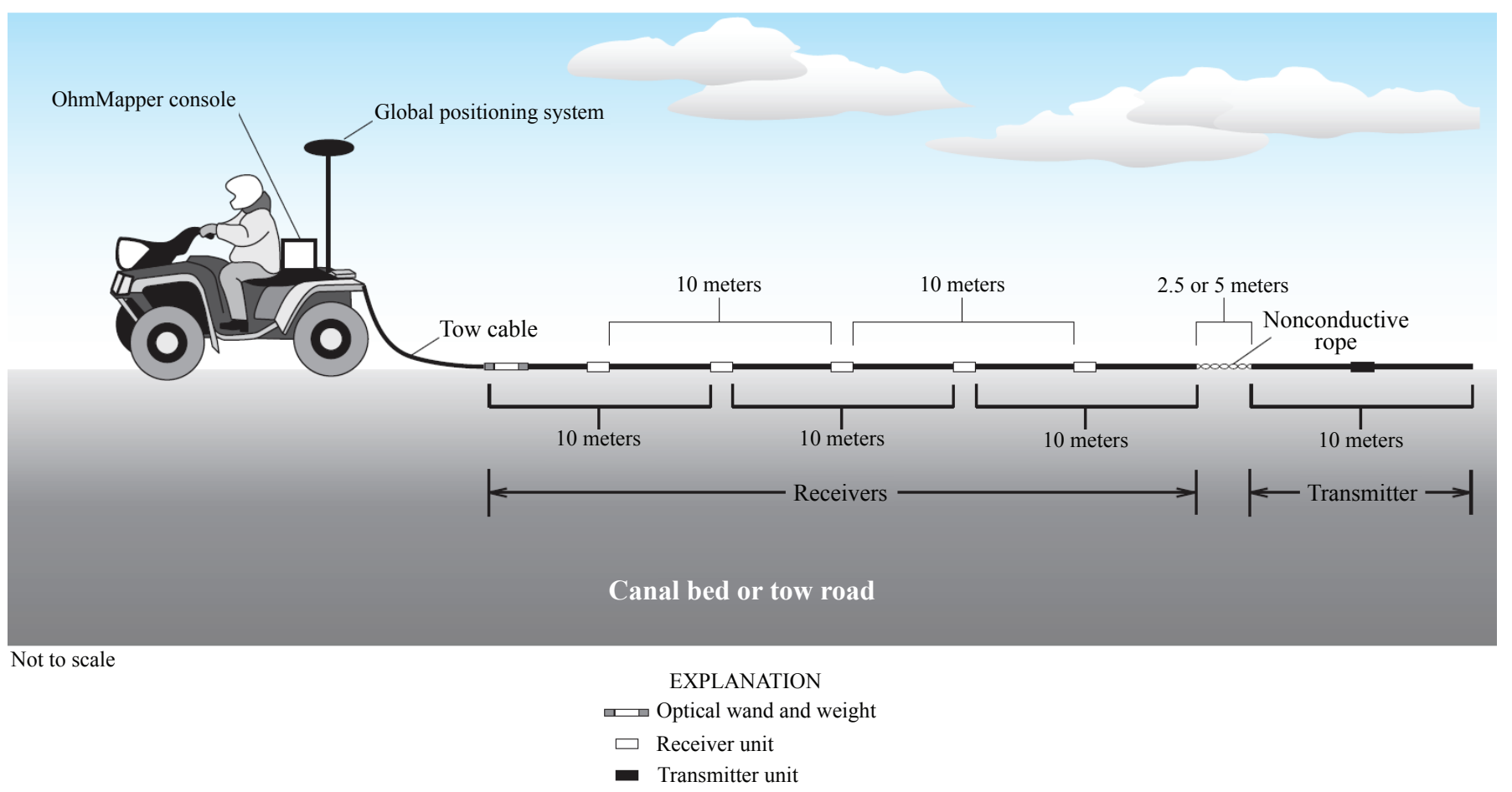

Figure 2. Schematic illustration showing the capacitively coupled resistivity-system setup and geometry (modified from Ball and others, 2006). 
There were several obstacles that impeded continuous data acquisition along many canals. For data acquired within the canals (as opposed to from the tow roads), the obstacles included large tumbleweed piles, snow drifts, concrete check structures (removable dams used to manage water levels in the canals) and gaging stations, low or impassible bridges, fences, underground siphons (located where canals cross surface drainage features), and extended sections of rough or sharp concrete blocks or trash that could cause damage to the system. If these obstacles were too frequent for time-efficient acquisition of data along an area within the canal, the survey was done along the tow road immediately adjacent to the canal. During the 2008 data acquisition, snow drifts within the canals were the most prevalent obstacle. Some drifting was such that an ATV operator could not safely drive atop the canal bed. Even with consistent and level snowpack in the canals, the ATV often could not get sufficient traction on the snow or underlying sediment. Data were acquired on the tow road in these situations. Large, extended tumbleweed piles within the canal were bypassed. If piles were relatively infrequent and small (50 $\mathrm{m}$ or less in length), then the survey crew would clear a path for the ATV such that the towed array remained on the ground surface, thereby minimizing noise in the data and maximizing data coverage. Standard operating procedures for concrete checks, gaging stations, and extended areas where it would be unsafe for the towed array to be pulled over (in instances when it was not necessary to winch the ATV out and back in on the other side) were to reel the array onto the back of the ATV, drive the ATV across the obstacle, and lay out the array on the other side. When a siphon was encountered, the section between the intake and outtake was bypassed. For acquisition along the tow roads, coverage gaps exist because of underground siphons, high-traffic road crossings, and the extreme sinuosity of some canals. If the canal was too sinuous, such that the towed array was no longer in a straight line behind the ATV or it was too difficult to keep the array on the tow road around the curves, then the section was bypassed. Larger omitted sections are located at the ends of Highline, Lowline, and Northport canals due to their sinuosity.

\section{Data Processing and Inversion}

The raw binary data files were downloaded from the OhmMapper instrument using several versions of Geometrics Magmap2000 software, including the latest available at the time of the 2009 survey, version 4.86 (Geometrics, 2009). The binary files were imported into a pair of USGS GPS and OhmMapper data processing software programs named GPSpathtool and OhmBin, respectively. Upon initial import of the raw binary file, GPSpathtool allows the user to enter the GPS antenna height mounted on the ATV, to define the nature of the survey (for example, a single pass with a single geometry or multiple passes over the same line with multiple geometries), and to edit the array geometry (for example, GPS-array offset, dipole lengths, or rope length) if entered incorrectly during acquisition. The geographic positions in the binary file are automatically projected to the appropriate NAD83 UTM zone in meters, and the position and elevation of the center of each transmitter-receiver pair for every measurement is interpolated and extrapolated from the GGA message strings. The user can reject GPS data based on the GPS quality factor or by graphically selecting data points. A single path is then fitted to the GPS data. The data are mapped, or projected, to the path fit and imported into the OhmBin program where the resistivity data can be viewed and processed. The typical processing procedure employed was to remove data with a GPS quality factor of zero (where there was a complete loss of signal because of overhead obstructions such as tree cover and bridges) and selective removal of data with a GPS quality factor of 2 (DGPS fix but has not converged to a horizontal accuracy under $30 \mathrm{~cm}$ ) based on their relative position to the general path trend. A quality factor of four is the optimal GPS quality factor indicating the horizontal accuracy ranges from 5 to $30 \mathrm{~cm}$.

Within the OhmBin program, the data can be viewed as either line plots for each receiver or as contoured pseudosections of the apparent resistivity, measured voltage, calculated resistance $(\mathrm{mV} / \mathrm{mA})$, and transmitted current levels. The data can be interactively edited to remove data spikes, clip data based on threshold values, smooth data, correct current tares

Table 1. Summary of capacitively coupled resistivity-survey-acquisition parameters.

\begin{tabular}{ccccc}
\hline Year & $\mathbf{2 0 0 4}$ & $\mathbf{2 0 0 7}$ & $\mathbf{2 0 0 8}$ & $\mathbf{2 0 0 9}$ \\
\hline Dipole length $(\mathbf{m})$ & 10 & 10 & 10 & 10 \\
Nonconductive tow-rope length (m) & 2.5 & 2.5 & 5 & 5 \\
Survey location & canal & canal & canal, tow road & canal, tow road \\
Acquisition rate & $1 \mathrm{~Hz}$ & $1 \mathrm{~Hz}$ & $1 \mathrm{~Hz}$ & $1 \mathrm{~Hz}$ \\
\hline
\end{tabular}


(occurring when there is a mismatch between the recorded current level and actual transmitted level), and bin, or average, the data. The typical processing scheme included the following:

1. Removal of apparent resistivity data spikes using a single data point spike width and factor of 1.5 ,

2. Manual removal of obvious data spikes in the current, voltage, and resistance data,

3. Correction of current tares by editing the current levels (not common),

4. Binning of data to a 5-m bin size, and

5. Export of the unbinned and binned data.

All binned data are available electronically with this report. Data formats are described in the appendix. The binned data is exported in a RES2DINV (Loke, 2009) data format that can also be read into Advanced Geosciences, Inc. (AGI), EarthImager 2D (AGI, 2008) inversion program. This format does not contain the true projected coordinates of the data, only the downline distance and elevation information. Upon export from OhmBin, an EarthImager 2D format elevation file is also created that is used during the optimized finite element inversion. All CC resistivity data were inverted using the robust inversion method in EarthImager 2D version 2.3.3 build 586. The robust method is based on the assumption of an exponential distribution of data errors and minimizes an L1-norm parameter that is a combination of the model data misfit and stabilizing function. The method typically performs well on noisy datasets and resolves resistivity boundaries well (AGI, 2008). The inversions were allowed to run a maximum of 10 iterations with a stop criterion of 3 percent or less rootmean-square (RMS) error between the measured and calculated forward model values or an L2-norm value of one or less. If neither of the stopping criteria were met, noisy data were removed using a percent-data misfit threshold of typically under 15 percent. This threshold varied depending on the noise levels of the data and on the overall percentage of data that would be removed at those data misfit levels. The inversion was then run a second time with the edited data.

The 2004 data were reprocessed using the new processing software programs and reinverted using the same inversion software as the 2007 through 2009 data to incorporate the improved method developed since 2004 and so that a more direct comparison could be made between all datasets. All inverted data are available with this report in electronic form. See the appendix for a description of the file formats.

Once a final inversion was achieved, the data were exported in an electronic text format and imported into Geosoft Oasis montaj versions 7.0.1 and 7.1 (Geosoft, Inc., Toronto, Ontario, Canada). Using an additional text file containing position information exported from OhmBin, the inverted data were rejoined with the easting and northing projected coordinates based on the downline distance field. For visual display of the data in both two-dimensional and three-dimensional space, the data were reformatted for import into Encom Profile Analyst (Encom Technology Pty Limited, North Sydney, Australia).

\section{Test Hole Procedures}

Test holes were drilled on two occasions based on the 2004 and $2008 \mathrm{CC}$ resistivity datasets. From Ball and others (2006), in November 2004, continuous core samples were acquired from 25 test holes using a track-mounted Geoprobe system (Geoprobe Systems, Salina, Kans., U.S.A.). Maximum depth of investigation is approximately $8 \mathrm{mbls}$. The first 20 test holes were randomly chosen, and comparisons of the results of these test holes to the nearby $\mathrm{CC}$ resistivity profiles determined the location of the remaining five test holes to ensure repeated sampling of all major types of resistivity features. All test holes were drilled from the canal bed while it was dry (Ball and others, 2006). Refer to Ball and others (2006) for the 2004 test-hole results, including core descriptions and comparison to the CC and water-borne DC inverted resistivity models.

Forty new test-hole locations were chosen in reference to the $2008 \mathrm{CC}$ resistivity dataset to sample different resistivity features and structures observed throughout all surveyed canals and laterals. Because of time and access limitations, 36 test holes were fully completed and one test hole, NP38, was only partially cored and no borehole EC (electrical conductivity) $\log$ acquired (fig. 1). All were drilled using a similar Geoprobe system used in 2004, but mounted to a four-wheeldrive tractor to acquire continuous core samples to a maximum depth of 8 mbls. Each test hole was either drilled on the tow road or in the canal, corresponding to where the resistivity data were acquired. Two exceptions, however, are test holes Mit33 and Mit34 that were drilled from the tow road and not in the canal where the $\mathrm{CC}$ resistivity data were acquired, because the steep canal walls in this area prevented access. Table 2 provides the detailed lithologic descriptions for all 37 test holes.

After each core was completed, a direct-push electrical conductivity log was acquired using the Direct Image EC System attached to the Geoprobe. The EC logging tool measures soil conductivity and probing speed simultaneously. A sensor is attached to the end of a steel drive rod, which is driven into the subsurface using a percussion hammer and a hydraulic slide. The employed sensor consists of a four-electrode Wenner array configuration with a total array length of $76 \mathrm{~mm}$. The vertical resolution is $2 \mathrm{~cm}$ with a $20-\mathrm{Hz}$ sampling rate (Kejr, 2009).

For the first and last log collected during a day, a standard quality-control test was performed on both the field computer and the EC probe, consisting of an instrument calibration test and probe continuity and isolation tests. Before and after each test hole, an EC load test was done using a test jig that simulates three different soil electrical conductivity values. The threshold limit for a successful test, indicating the probe was functioning properly, was \pm 5 percent of each load value. 
Table 2. Detailed lithologic descriptions from test holes acquired in 2008 and 2009.

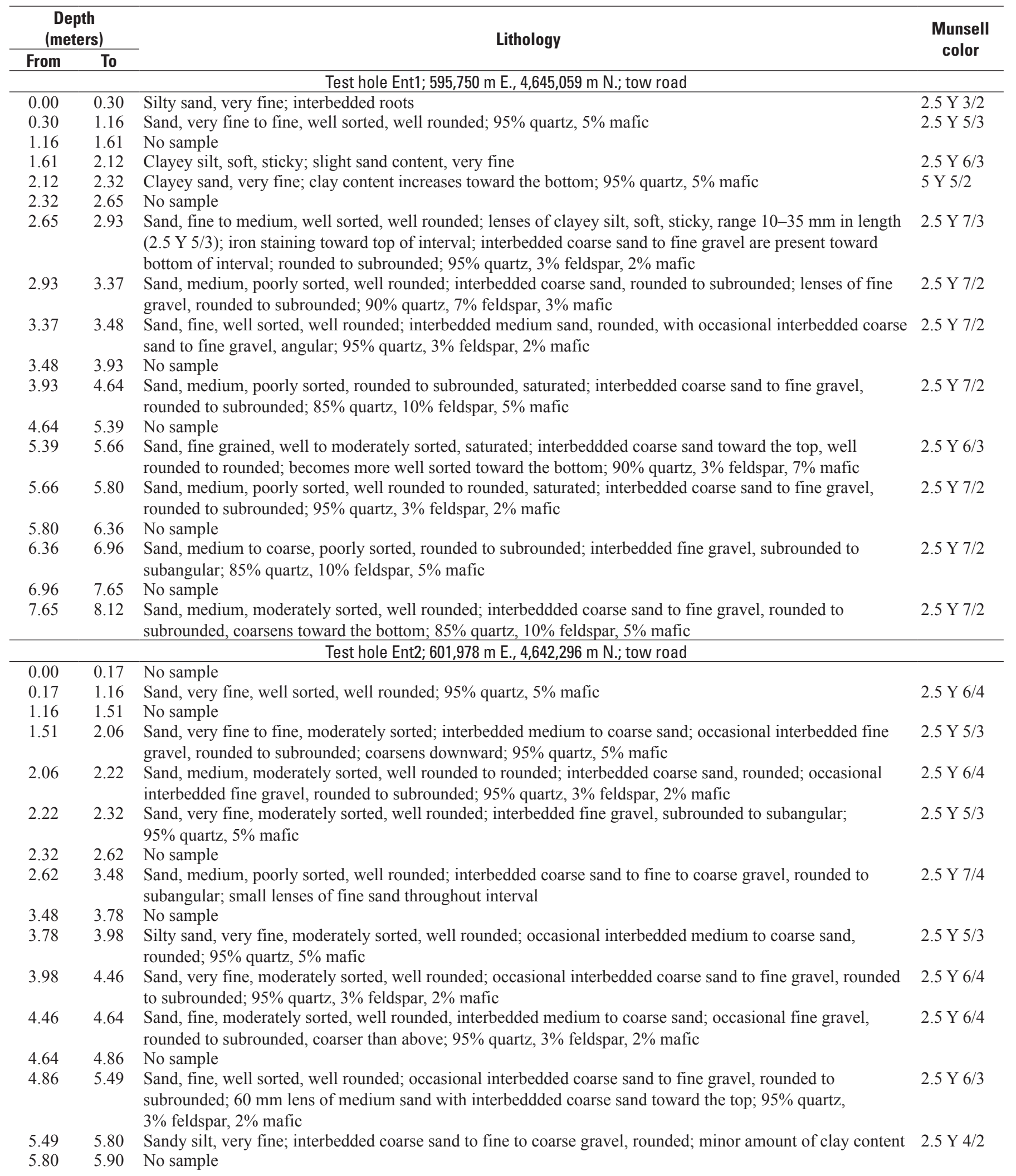


Table 2. Detailed lithologic descriptions from test holes acquired in 2008 and 2009._Continued

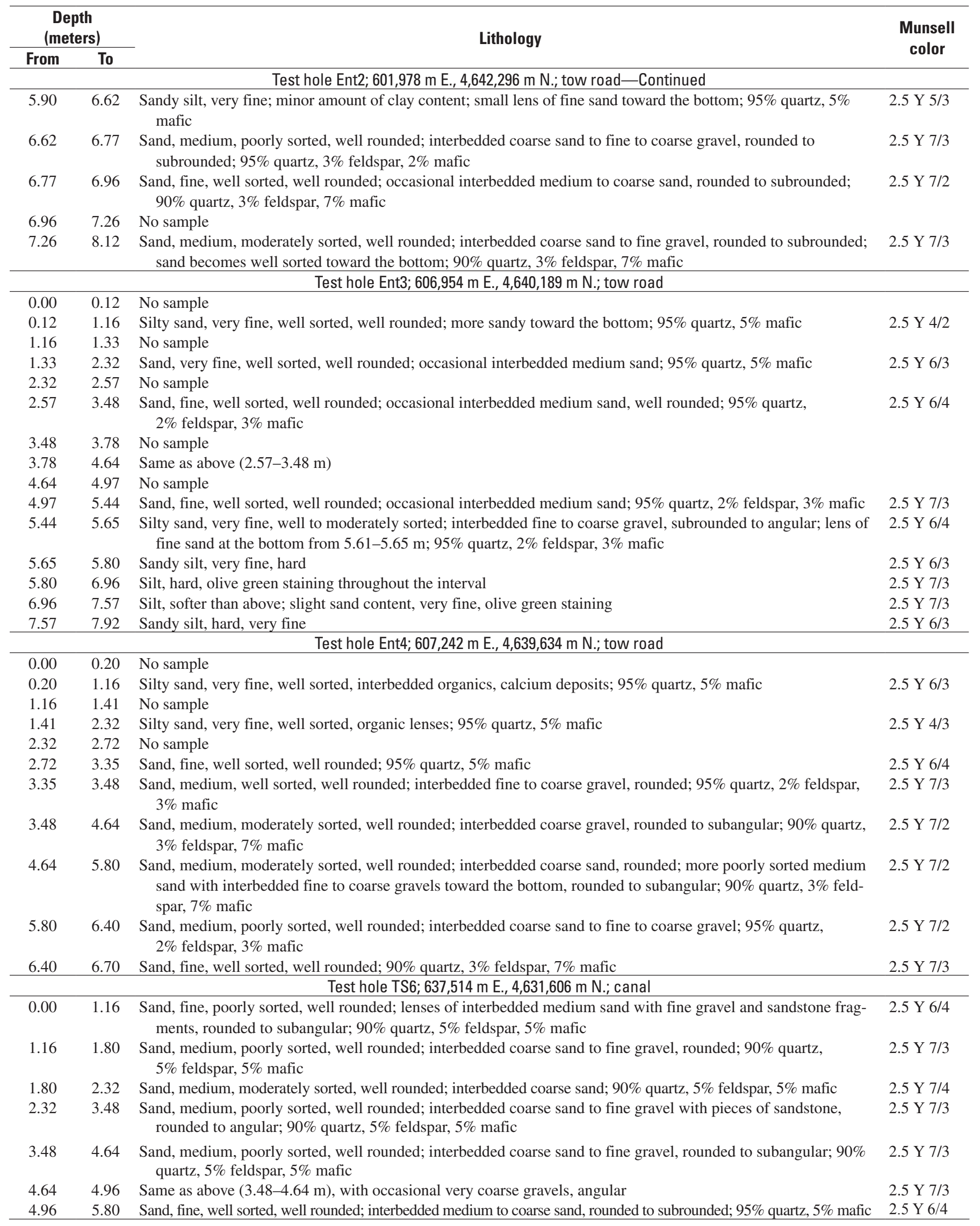


Table 2. Detailed lithologic descriptions from test holes acquired in 2008 and 2009.-Continued

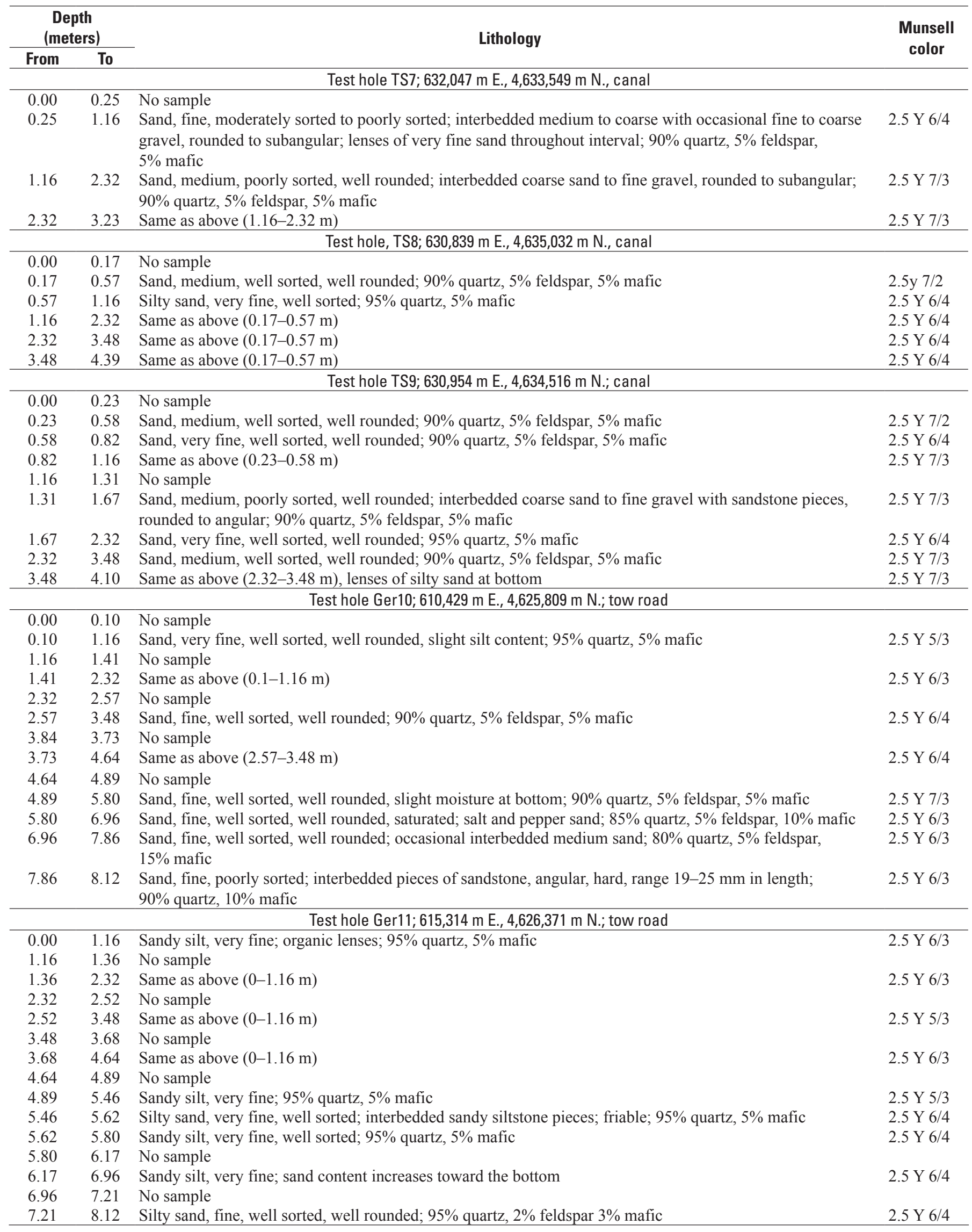


Table 2. Detailed lithologic descriptions from test holes acquired in 2008 and 2009._Continued

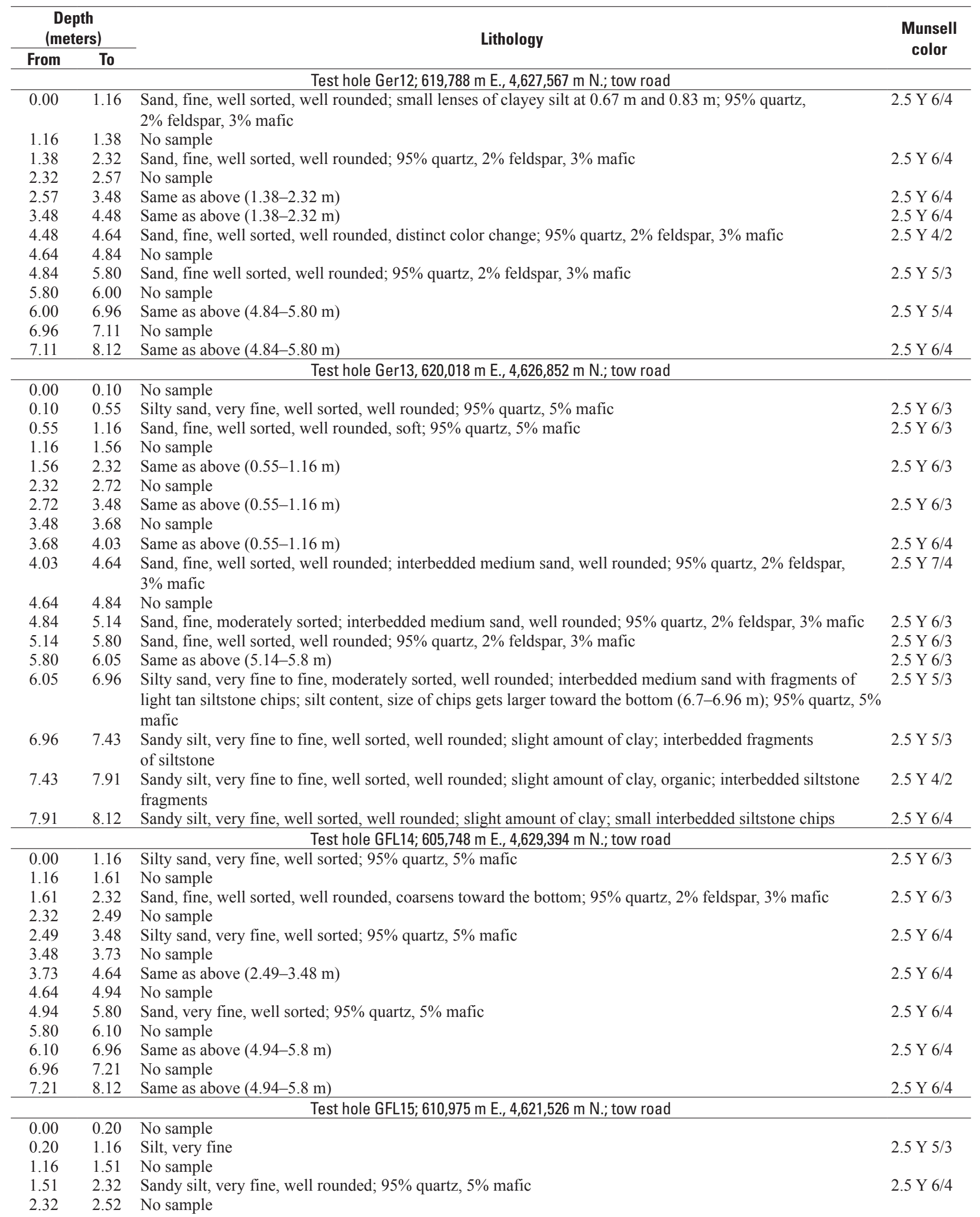


Table 2. Detailed lithologic descriptions from test holes acquired in 2008 and 2009.-Continued

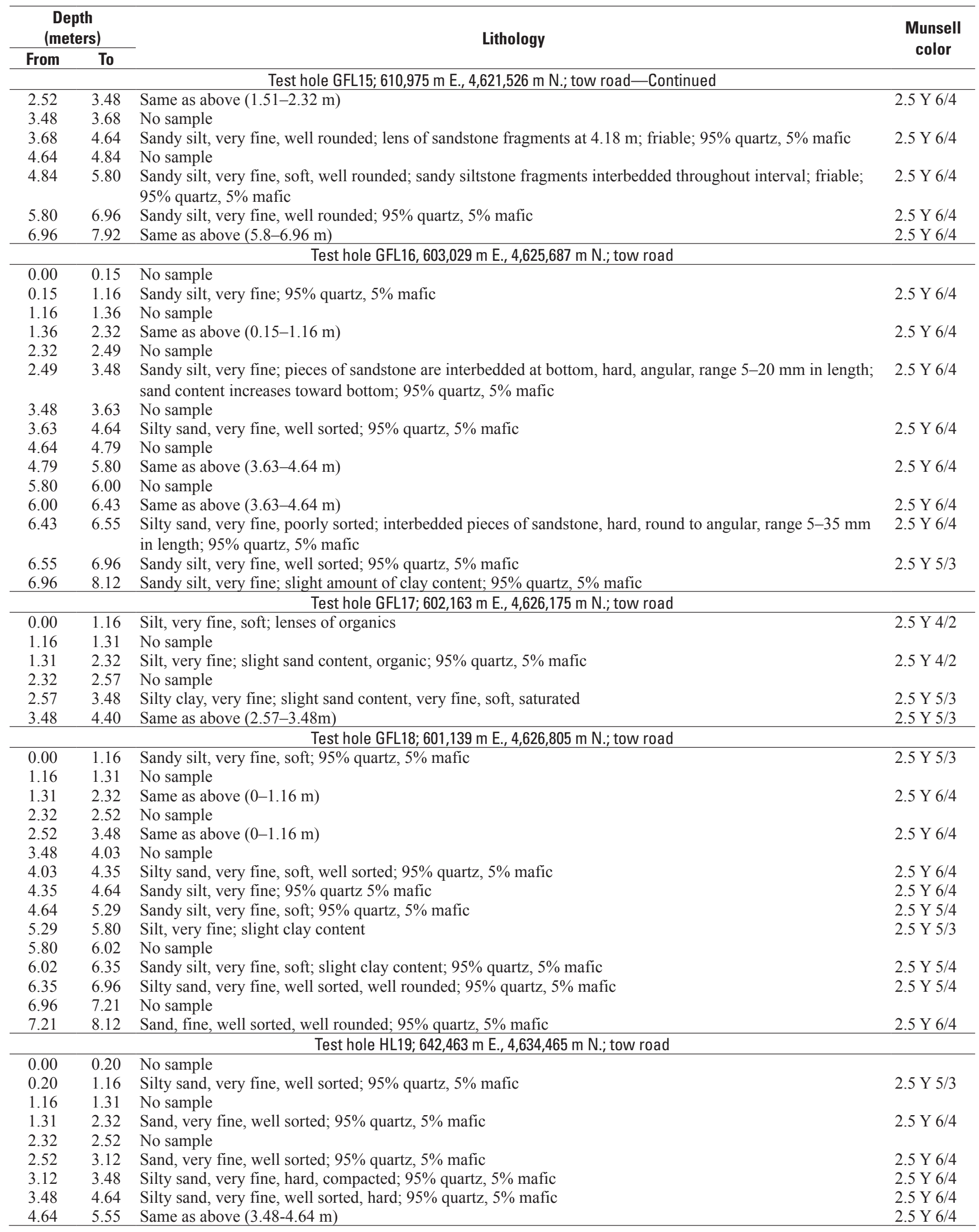


Table 2. Detailed lithologic descriptions from test holes acquired in 2008 and 2009._Continued

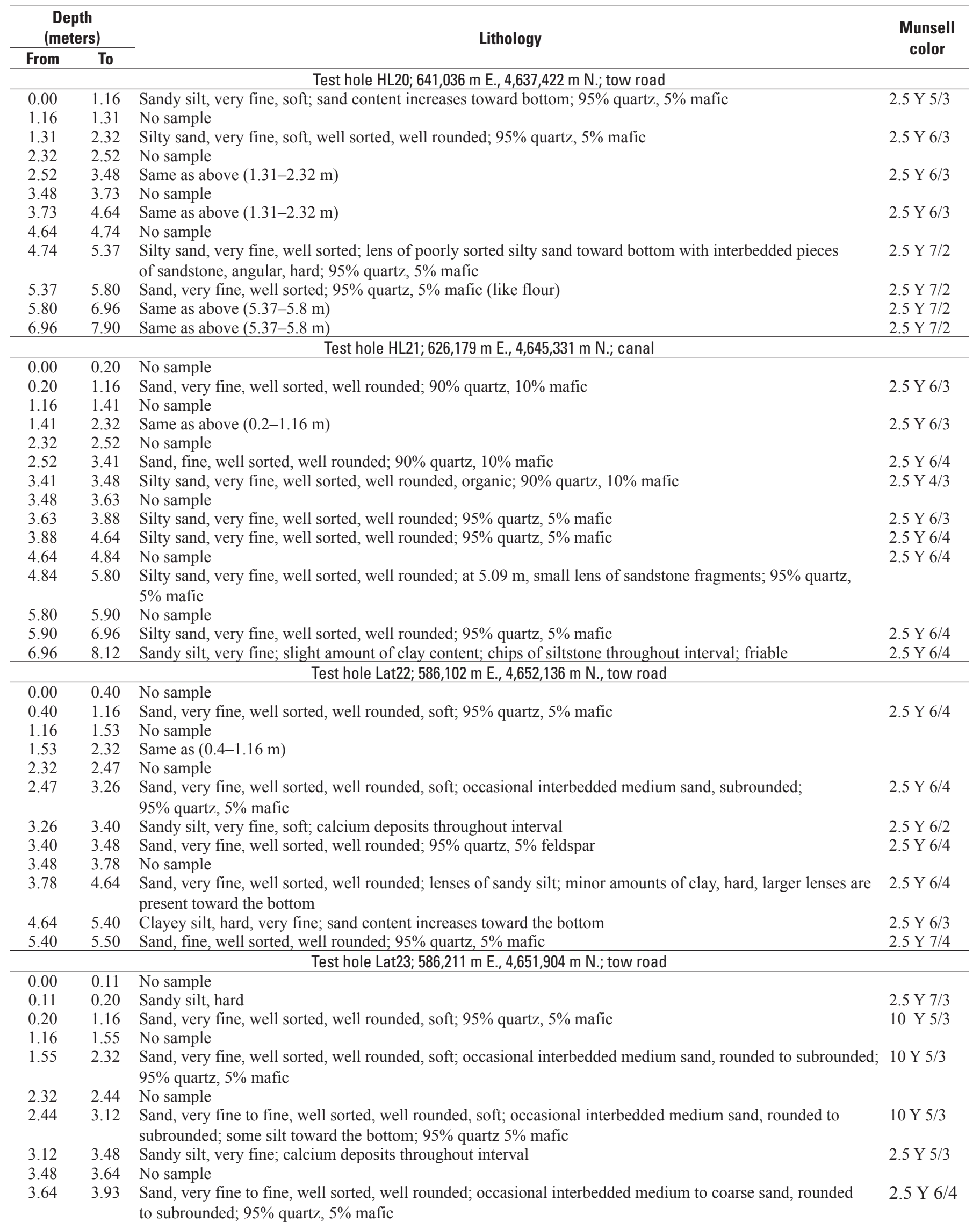


Table 2. Detailed lithologic descriptions from test holes acquired in 2008 and 2009._Continued

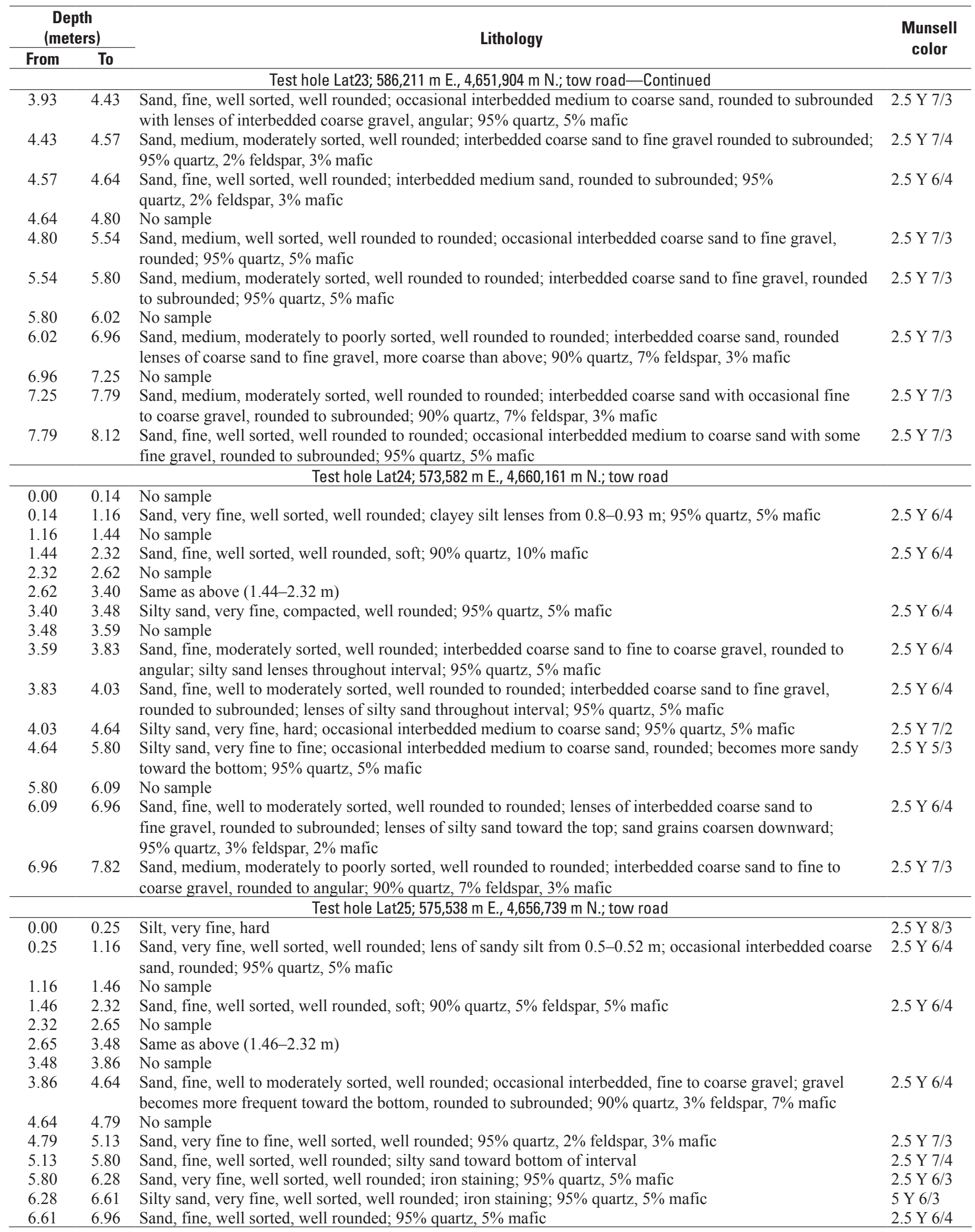


Table 2. Detailed lithologic descriptions from test holes acquired in 2008 and 2009._Continued

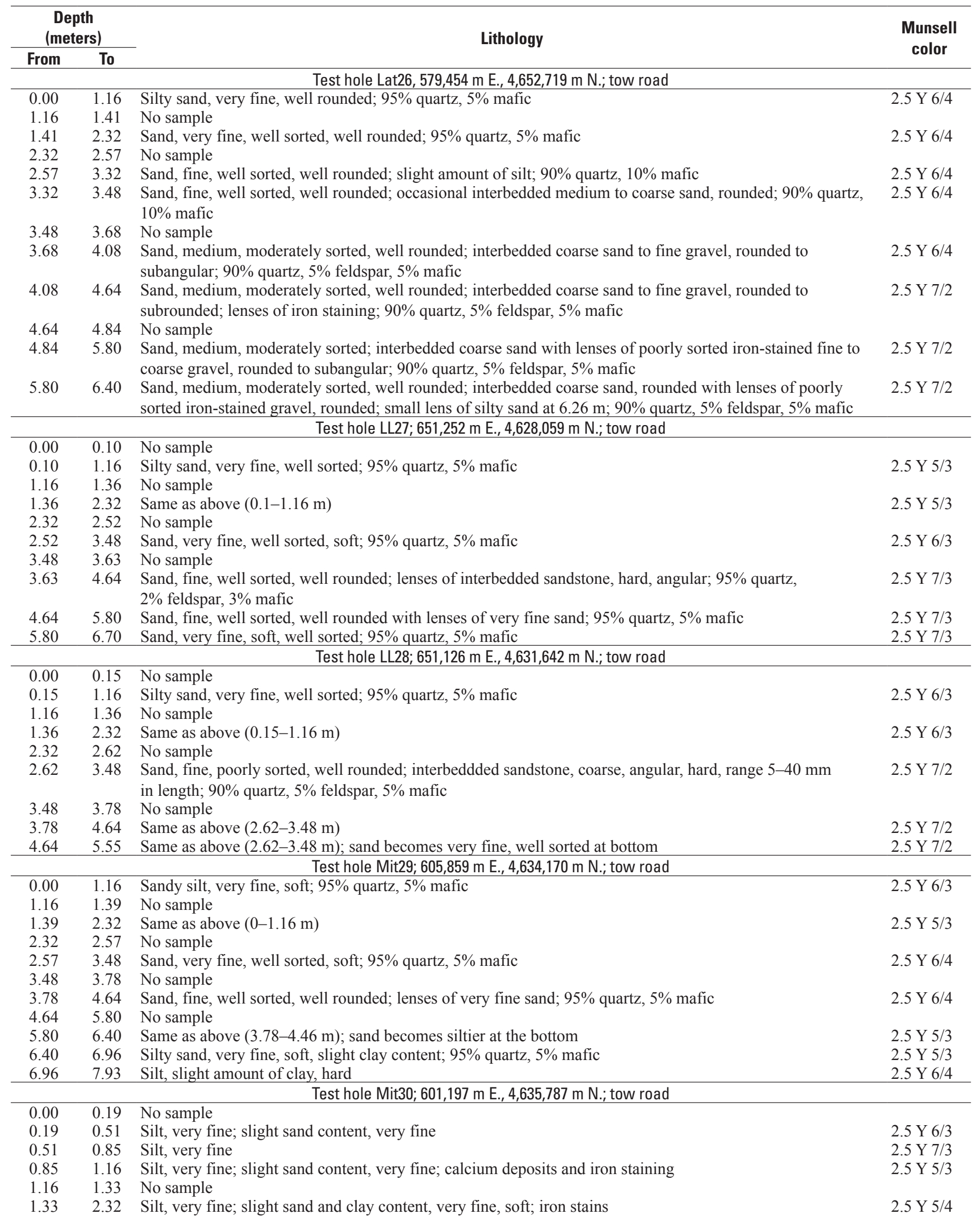


Table 2. Detailed lithologic descriptions from test holes acquired in 2008 and 2009._Continued

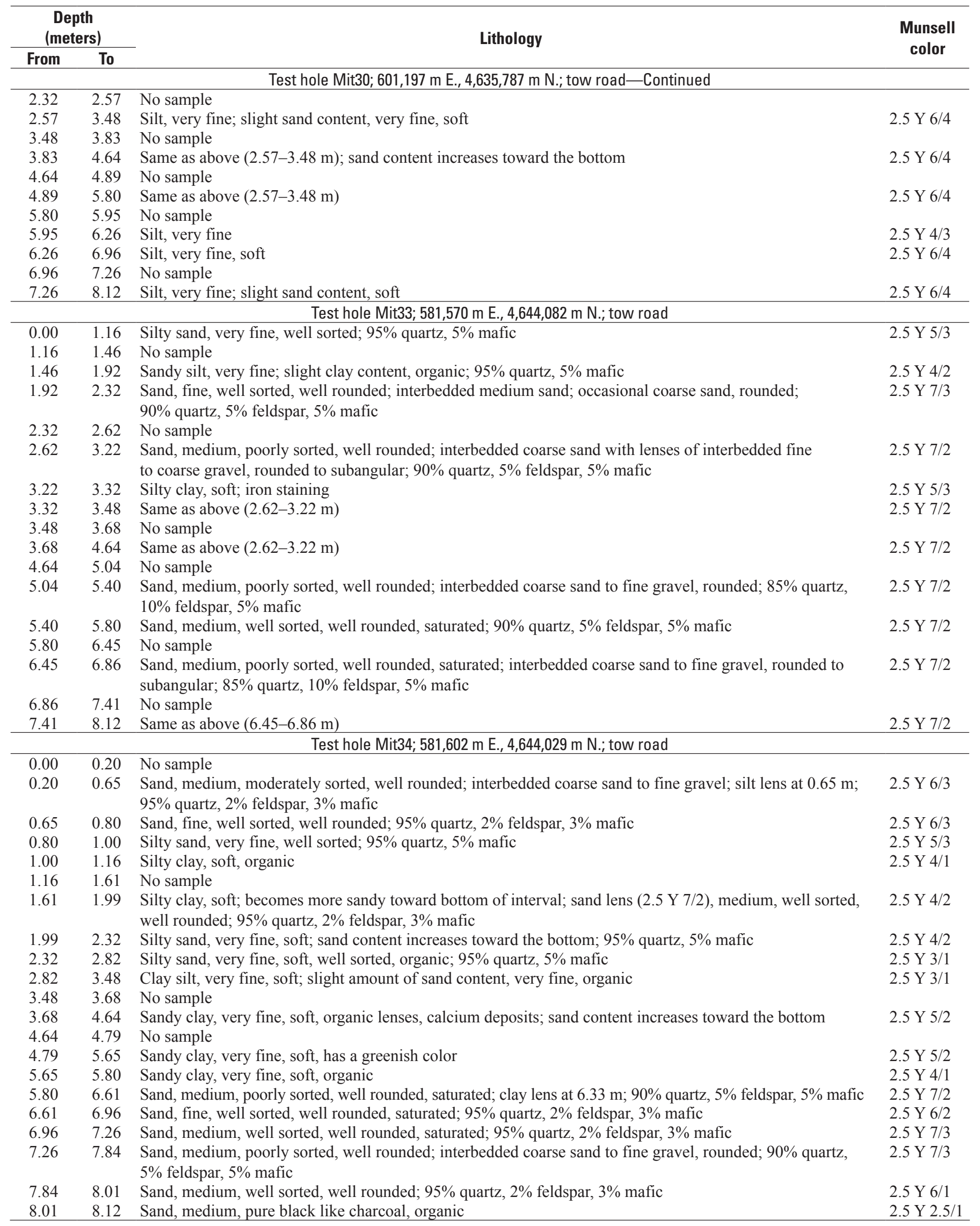


Table 2. Detailed lithologic descriptions from test holes acquired in 2008 and 2009._Continued

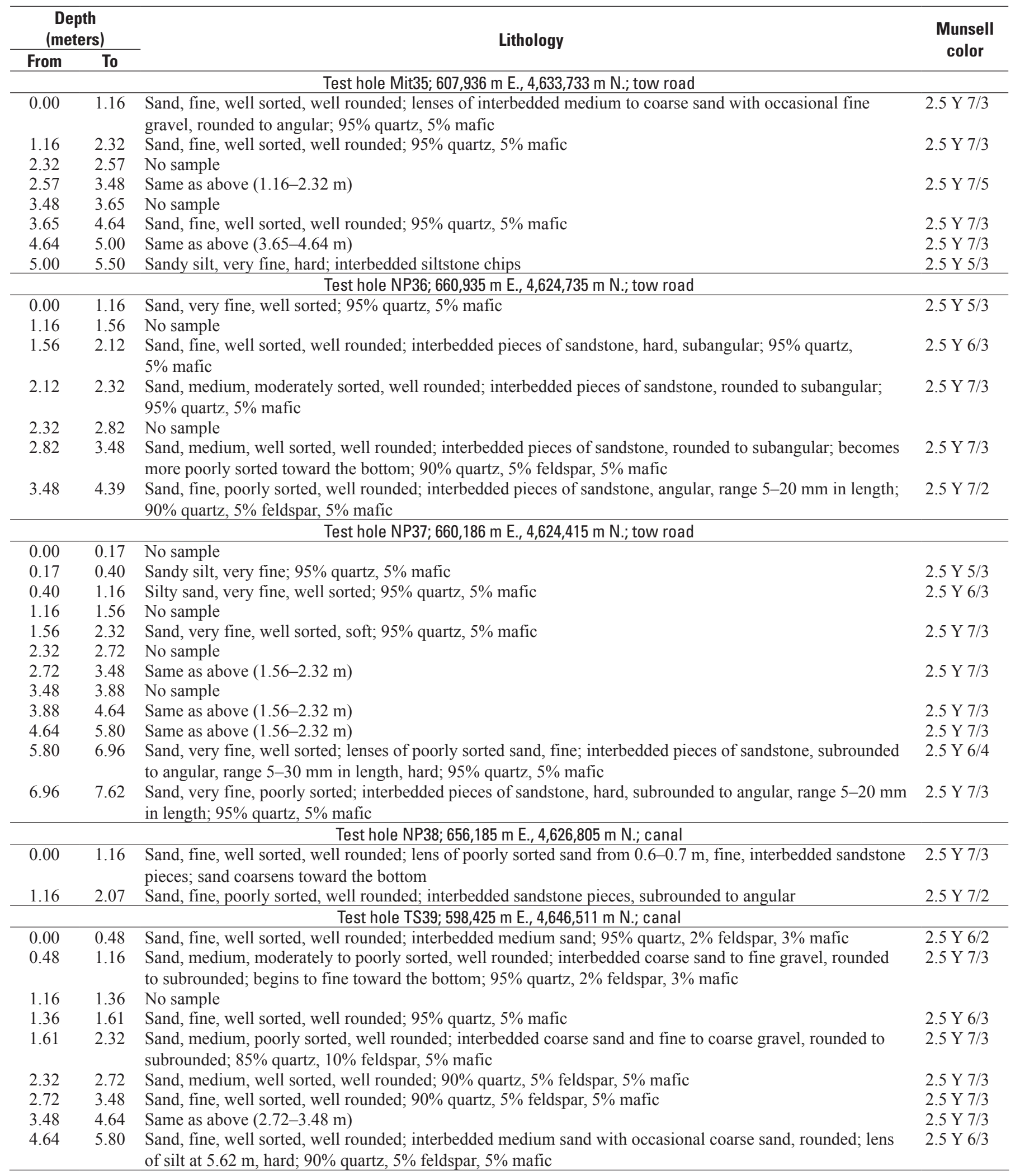


Table 2. Detailed lithologic descriptions from test holes acquired in 2008 and 2009._Continued

\begin{tabular}{|c|c|c|c|}
\hline \multicolumn{2}{|c|}{$\begin{array}{c}\text { Depth } \\
\text { (meters) }\end{array}$} & Lithology & $\begin{array}{c}\text { Munsel } \\
\text { color }\end{array}$ \\
\hline \multicolumn{4}{|c|}{ Test hole TS40; 599,239 m E., 4,645,470 m N.; canal } \\
\hline 0.13 & 0.91 & Sand, fine to medium, well sorted, well rounded; $90 \%$ quartz, $3 \%$ feldspar, $7 \%$ mafic & $2.5 \mathrm{Y} 6 / 3$ \\
\hline 0.91 & 1.16 & $\begin{array}{l}\text { Sandy silt, very fine; lens of organic sandy silt from } 0.92-0.95 \mathrm{~m} \text {; slight clay content throughout interval; } \\
95 \% \text { quartz, } 5 \% \text { mafic }\end{array}$ & 2.5 Y $5 / 3$ \\
\hline 2.32 & 2.75 & No sample & \\
\hline 2.75 & 3.48 & Sandy silt, very fine; lens of coarse sand to fine gravel at $3.12 \mathrm{~m} ; 95 \%$ quartz, $5 \%$ mafic & $2.5 \mathrm{Y} 5 / 3$ \\
\hline 3.48 & 3.73 & No sample & \\
\hline 3.73 & 4.64 & $\begin{array}{l}\text { Sandy silt, very fine; lenses of poorly sorted fine to medium sand with interbedded coarse sand to fine gravel, } \\
\text { rounded; sand content increases toward the bottom; } 95 \% \text { quartz, } 5 \% \text { mafic }\end{array}$ & 2.5 Y $5 / 3$ \\
\hline 4.64 & 4.84 & No sample & \\
\hline 6.60 & 6.70 & $\begin{array}{l}\text { Sand, medium, poorly sorted, well rounded; interbedded coarse sand to fine gravel; } 95 \% \text { quartz, } 2 \% \text { feldspar, } \\
3 \% \text { mafic }\end{array}$ & $2.5 \mathrm{Y} 6 / 3$ \\
\hline
\end{tabular}


The conductivity log was converted to resistivity by taking the reciprocal of the conductivity values for a better direct comparison with the $\mathrm{CC}$ resistivity data. The results for all lithology and reciprocated EC logs are shown alongside the corresponding CC resistivity data in figures 3 to 37 in the Supplemental Data Section at the end of this report. The EC log data from the test holes drilled in 2008 and 2009 are included in the appendix.

\section{Results of Investigation}

For organizational purposes, the canals were split into two categories: major and minor canals. The distinction between major and minor was based on total canal length, with a cutoff threshold of $40 \mathrm{~km}$. The major canals are presented first, and all data presented are shown alongside nearby test holes. The presentation order of the canals is from north to south, following each major canal along its entire length. The minor canals are also presented from north to south, or in the downstream direction along the valley, with only selected, representative results of the $\mathrm{CC}$ resistivity data along each canal. Each canal is described from west to east.

A vertical average was also calculated for all $\mathrm{CC}$ resistivity data to aid in the generalized description of the observed structure and to serve as a simple comparison tool. The average includes all data in a section, including the vertical extent from the tow road to the canal bed level for all data acquired along the tow roads. This was the method used by Ball and others (2006) to determine relative leakage potential along the canals, which is a simple qualitative method. Based on this method, a material with a low average resistivity is interpreted as having a low leakage potential. This is because low resistivities are often associated with finer grained materials (such as clay and silt) and have lower hydraulic conductivities. Highly resistive materials, on the other hand, are interpreted to have high leakage potential because of the assumption that they are associated with coarse-grained materials such as coarse sand and gravel.

A more sophisticated method for estimating leakage potential is to take into consideration the relative local lithologic heterogeneity, which can have a major effect on the actual level of recharge to the underlying aquifer (Teeple and others, in press). For example, a strong resistor (coarse sand or gravel) at the surface underlain by a strong conductor (clay) would combine for a moderate average resistivity that would indicate a moderate leakage potential. In reality, the presence of the clay at depth would impede recharge, and the section should be characterized as having a low leakage potential.

The CC resistivity data and borehole EC logs typically match well. In general, the EC logs show greater detail than the $\mathrm{CC}$ resistivity data can fully resolve. The test-hole data are detailed logs at a particular location with EC log data acquired at depth increments of $1.5 \mathrm{~cm}$. Conversely, the $\mathrm{CC}$ resistivity data comprise five data points over an 8-m depth range, and each data point is a lateral average across $5 \mathrm{~m}$. This relatively coarse sampling has a "smearing" effect on the positioning of the resistivity boundaries.

As was done with the 2004 test-hole cores, the detailed lithologic descriptions were combined into broader categories to aid in the visual comparison with and interpretation of the $\mathrm{CC}$ resistivity and EC log results. The following nine lithologic categories follow the same classification scheme that was used in Ball and others (2006): clay, silt and clay, sand and clay, silt, hard silt, very fine sand, fine sand, sand, and moderately to poorly sorted mixed sand. These categories are used for all of the lithology logs presented in figures 3 through 37 in the Supplemental Data Section at the end of this report.

\section{Major Canals}

\section{Interstate Canal}

Interstate Canal is operated by the Pathfinder Irrigation District and diverts water from the North Platte River about $55 \mathrm{~km}$ west of the Wyoming-Nebraska border at the Whalen Diversion Dam and ends at its delivery point to the Highline Canal and Lake Alice (Ball and others, 2006). The majority of this canal was surveyed in 2004. When combined with additional CC resistivity data acquired in 2007, a total of $77 \mathrm{~km}$ was surveyed. A several-kilometer-long section between Dry Spottedtail Creek and Spottedtail Creek was bypassed due to standing water in the canal. No additional test holes have been drilled in this canal since the 2004 survey. The 2004 resistivity and test-hole data are presented in Ball and others (2006).

In summary, the first section of Interstate Canal that was surveyed is very highly resistive (greater than $500 \mathrm{ohm}-\mathrm{m}$ ) and becomes more moderately to highly resistive ( 150 to 425 ohm-m) beyond the intersection with Lateral Number 1. A deep conductor (less than 10 to $50 \mathrm{ohm}-\mathrm{m}$ ) appears to the west of the Highway 79A intersection and continues to just north of the SG Road canal intersection east of S4 Road. The conductor ranges in depth from 2 to 4 mbls and is overlain by a moderately resistive layer (100 to $300 \mathrm{ohm}-\mathrm{m})$. Where the conductor disappears, the resistivity section becomes moderately to highly resistive again, becoming increasingly resistive east of Lateral Number 14 . The section abruptly becomes more conductive approximately where SD and S13 Roads intersect immediately west of Highway 29 and continues for the remainder of the canal. A moderate, and at times intermittent, 2- to 5-m-thick surface layer overlies a low-resistivity to very low resistivity (less than 10 to 75 ohm-m) layer. When the upper moderate layer is absent, the entire section is characterized as having a low to very low resistivity.

\section{Highline Canal}

Highline Canal, which is part of Interstate Canal system, is also operated by the Pathfinder Irrigation District and extends 56 km southeast from Lake Alice (U.S. Bureau of Reclamation, USBR, 2009). Fifty-four kilometers of CC resistivity 
data were acquired from 2007 through 2009, collected both on the tow road and in the canal. Small gaps in data coverage exist because of underground siphons and frequent tumbleweed piles and concrete checks in the canals. Three test holes, HL19, HL20, and HL21 (fig. 1), were drilled within this canal.

The CC resistivity data show that the first eighty percent of the canal is typified by a 2-layer very low to moderate-resistivity structure (less than $10 \mathrm{ohm}-\mathrm{m}$ to $325 \mathrm{ohm}-\mathrm{m}$ ). There is a 1- to 7-m-thick upper layer that shows more moderate resistivity values (150 to $325 \mathrm{ohm}-\mathrm{m}$ ) overlying a strong conductive layer (less than 10 to $75 \mathrm{ohm}-\mathrm{m}$ ). In the last twenty percent of the canal, starting just east of Road 75, the resistivity becomes consistently moderate with very little indication of a conductor at depth.

Test holes HL19 and HL20 were both drilled in this more moderate resistivity zone toward the eastern end of the canal. Both test holes indicate very fine sand throughout with relatively little change in character in the EC curves, except for a gradual decrease in resistivity with depth (figs. 3 and 4). Test hole HL21, however, was drilled to the west where there is a dominant conductive lower layer in the CC resistivity data. Although the lithology log indicates only very fine and fine sand throughout, the first decrease in the resistivity at about $1,267-\mathrm{m}$ elevation correlates with a change from fine to very fine sand with another abrupt decrease at 1,263.5-m elevation (fig. 5). According to the detailed lithology description (table 2), the lower very fine sand unit in the lithology log is silty; the presence of a finer grained material would explain the observed decrease in resistivity in the EC log. The second decrease in resistivity near the bottom of the test hole can be attributed to the small amount of clay noted in the sample. The observed change in the CC resistivity data is most likely a combination of both of these lithologic changes that cannot be resolved as well as with the EC log.

\section{Lowline Canal}

Lowline Canal is also part of the Interstate Canal system and extends from Lake Minatare to the southeast for $71 \mathrm{~km}$. The canal is operated by the Pathfinder Irrigation District. Between 2008 and 2009, $59 \mathrm{~km}$ were surveyed both in the canal and along the tow road. There are several small gaps in data coverage because of underground siphons and frequent, large tumbleweed piles that could not be cleared. The survey along the canal began on the south side of a gaging station to the south of County Road G, approximately $0.3 \mathrm{~km}$ from the Lake Minatare outlet. The $0.3-\mathrm{km}$ section was omitted due to frequent obstacles in a short distance. The last couple of kilometers could not be surveyed, because of a lack of a tow road, and that section of the canal was too narrow to acquire data along the bed. Two test holes, LL27 and LL28 (fig. 1), were drilled in the easternmost section of the canal for comparison to the $2008 \mathrm{CC}$ resistivity data.

The Lowline Canal is relatively uniform and has a very low to moderate resistivity character, similar to Highline
Canal. Average resistivities along the first three-quarters of the canal typically range from less than $10 \mathrm{ohm}-\mathrm{m}$ to approximately $50 \mathrm{ohm}-\mathrm{m}$, except for a few small sections that show a higher overall resistivity. There generally appears to be two layers of resistivity: an upper, low- to moderate-resistivity layer (50 to $350 \mathrm{ohm}-\mathrm{m}$ ) that extends 4 to $7 \mathrm{mbls}$ and a lower, highly conductive layer (less than $10 \mathrm{ohm}-\mathrm{m}$ ). The first kilometer surveyed, closest to Lake Minatare, is an anomalous section with the upper layer showing resistivity values near $500 \mathrm{ohm}-\mathrm{m}$. This section appears to overlie the same strong conductive layer that is present throughout much of the canal. A second anomalous section is the $1.5-\mathrm{km}$-long U-shaped curve south of Highland Road. The CC resistivity profiles do not show a strong conductor at depth; instead, the entire section shows moderate resistivities (100 to $450 \mathrm{ohm}-\mathrm{m}$ ) throughout. The last one-quarter of the surveyed canal, beginning just southeast of the intersection of County Road N and Road 85, shows a more moderate-resistivity structure (50 to $150 \mathrm{ohm}-\mathrm{m}$ average resistivity) with a thicker upper, moderate-resistivity layer and typically only an indication at the base of the profiles of an underlying conductor.

Test hole LL28 was drilled in one of the more resistive surface features located between Red Willow Creek and Highway 385 north of Highway 62A (fig. 6). The logs show a 2-m-thick very fine sand overlying a more resistive moderately to poorly sorted mixed sand unit. The lithology log does not extend below the mixed sand unit due to the hard ground, but the EC log was recorded to a slightly deeper depth and indicates a more conductive unit below the mixed sand, which corresponds to the resistivity structure in the $\mathrm{CC}$ resistivity profile. Test hole LL27 is located near the eastern end of Lowline Canal south of Highway 62A and samples another moderately resistive section (fig. 7). The moderate resistivity observed in the majority of this CC resistivity section correlates with a very fine sand, and 2-m-thick fine sand correlates with the slightly more resistive lenses observed in the CC resistivity profile. Although there are no test holes that sample the upper section of Lowline Canal where the conductive sections dominate, it is assumed that these sections are clay-rich units, due to the extremely low resistivity values. This would result in a low leakage potential.

\section{Tri-State Canal}

Tri-State Canal, operated by the Farmers Irrigation District, extends for $129 \mathrm{~km}$ (USBR, 2009). Water is diverted from the North Platte River about $10 \mathrm{~km}$ northwest of Morrill, Nebr., and ends at its delivery point to the start of the Northport Canal (Ball and others, 2006). During the 2004, 2007, and 2008 surveys, more than $130 \mathrm{~km}$ were surveyed with the $\mathrm{CC}$ resistivity method. Refer to Ball and others (2006) for the 2004 CC resistivity and test-hole data. Data were acquired only within the canal, and six test holes were drilled for comparison with the CC resistivity data: TS6 through TS9, TS39, and TS40 (fig. 1). 
Generally, the CC resistivity data show a low- to moderate-resistivity structure (50 to $375 \mathrm{ohm}-\mathrm{m}$ ) from the headgate of the canal to where it crosses Highway 29, north of Mitchell, except for a 3-km-long section between County Roads 11 and 13, which contains discrete highly resistive (greater than $500 \mathrm{ohm}-\mathrm{m}$ ) lenses. East of Highway 29, the resistive lenses become increasingly more frequent and more extensive. North of Mitchell, where the canal turns toward the southwest immediately before it begins to parallel Enterprise Canal, the section becomes more homogeneously highly resistive (greater than 500 ohm-m) until the Sunflower Drain crossing. These data correlate well with water-borne DC resistivity data acquired in 2004. Continuing east of the Sunflower Drain, the resistivity section becomes alternately moderately (175 to 325 $\mathrm{ohm}-\mathrm{m}$ ) and highly (greater than $500 \mathrm{ohm}-\mathrm{m}$ ) resistive. A very conductive layer (less than $10 \mathrm{ohm}-\mathrm{m}$ ) appears at depth (5 to 7 mbls) overlain by a more moderately resistive layer (75 to 300 ohm-m) throughout the stretch of canal that turns north around Ninemile Creek, to the east of County Road 32. When the canal crosses County Road 34, the resistivity structure becomes more heterogeneous with the conductor at depth becoming more intermittently present and occasional high to very high (400 to greater than $500 \mathrm{ohm}-\mathrm{m}$ ) resistivity lenses in the upper 2 to $6 \mathrm{~m}$ approximately until the canal crosses County Road $\mathrm{N}$ for the first time. Beyond this point, Tri-State Canal remains a more consistently two-layer resistivity model with a moderately resistive (75 to $300 \mathrm{ohm}-\mathrm{m}$ ) 3- to 7 -m-thick layer overlying a very low resistivity layer (less than $10 \mathrm{ohm}-$ m) until it ends at the Northport Canal headgate.

Test hole TS39 sampled a resistive lens overlying a more moderately resistive unit, based on the $\mathrm{CC}$ resistivity data (fig. $8)$. The resistive lens correlates with a gravelly medium-size sand, and the underlying more conductive unit corresponds to a well-sorted fine sand. Test hole TS40 samples an anomalously moderate resistivity unit that is within a typically very high resistivity section. In the $\mathrm{CC}$ resistivity data, the moderately resistive unit extends about $4.5 \mathrm{mbls}$ and is underlain by a more resistive unit (fig. 9). The moderate resistivity (100 to $300 \mathrm{ohm}-\mathrm{m}$ ) correlates with a very fine sandy silt that grades into a medium sand with interbedded coarse sand and fine gravel over the last meter of the core.

Test holes TS6 through TS9 sampled more low to moderately resistive sections farther down the canal. Test holes TS8 and TS9 are located within $1 \mathrm{~km}$ of each other, and both indicate very fine and medium sand are present (figs. 10 and 11), correlating with the moderate resistivities observed in the $\mathrm{CC}$ resistivity sections. The highly resistive lens that test hole (TH) TS9 samples is interpreted to be due to the presence of the medium sand with interbedded coarse sand to fine gravel (table 2). Test holes TS6 and TS7 are within the more heterogeneous area of the canal. They both sample highly resistive lenses of varying thicknesses and resistivities that correspond to fine to medium sands with interbedded fine to coarse gravels (figs. 12 and 13). Although neither of the lithology logs extend to an equivalent depth as the $\mathrm{CC}$ resistivity data, the
EC logs sampled to a greater depth and correlate well with the resistivity structure observed in the $\mathrm{CC}$ resistivity profiles.

\section{Northport Canal}

Northport Canal is operated by the Northport Irrigation District and is a 44-km-long direct extension of the Tri-State Canal with no control structure (USBR, 2009). It begins approximately $10 \mathrm{~km}$ northeast of Bayard, Nebr. In 2008, 29 $\mathrm{km}$ were surveyed both in the canal and along the tow road. The remaining $15 \mathrm{~km}$ at the east end were either inaccessible or too sinuous for the instrument array to remain in a straight line behind the ATV to be able to make accurate measurements.

Northport Canal typically shows a very low to moderate resistivity structure (10 ohm-m or less to $300 \mathrm{ohm}-\mathrm{m}$ ) except for a few relatively short sections with a shallow, high-resistivity layer. A lower resistivity layer is present at depth throughout with a varying top layer resistivity. Test hole NP38 was drilled in one of the more moderately resistive sections with a relatively high resistivity at depth (fig. 14). An EC log was not acquired because of an equipment malfunction, and only about $2 \mathrm{~m}$ of core were collected because of the extremely hard ground. The limited core that was taken indicates a fine sand within one meter of the surface underlain by a mixed sand, assumed to be the more resistive unit observed in the CC resistivity profile.

The resistivity structure is particularly low from the surface to depth beginning just south of Road 106, where the canal approaches Highway 385 almost due east of Bayard. With an average resistivity of only about $10 \mathrm{ohm}-\mathrm{m}$, this section stretches for slightly more than $2 \mathrm{~km}$. Further downstream, starting near TH NP36, a more consistent, high-resistivity surface layer (300 ohm-m and greater) is present and extends about 4 to $5 \mathrm{mbls}$. This layer becomes more intermittent again along the final $2 \mathrm{~km}$ of the surveyed length of the canal.

Test holes NP36 and NP37 (fig. 1) were drilled within $2 \mathrm{~km}$ of each other, sampling different resistivity structures observed in the CC resistivity data. Test hole NP37 was drilled into a moderately resistive section comprising almost $7 \mathrm{~m}$ of conductive very fine sand underlain by more resistive mixed sand (fig. 15). The $\mathrm{CC}$ resistivity data cannot resolve this relatively thin mixed sand, but they do correlate at depth with the conductive layer at the bottom of the EC log. The lithology and EC logs from test hole NP36 and the CC resistivity data correlate well (fig. 16). There is a shallow, low-resistivity layer (very fine and fine sand) underlain by a more resistive 2-m-thick layer (sand) and a low- to moderate-resistivity mixed sand at the base.

\section{Enterprise Canal}

Enterprise Canal runs roughly parallel to the North Platte River and starts about $3 \mathrm{~km}$ south of Morrill, Nebr. It extends 
for $33 \mathrm{~km}$ to the southeast, passing through the town of Mitchell and the northern part of Scottsbluff. In total, $28 \mathrm{~km}$ were surveyed, with a couple of small and one 2.5-km-long data coverage gaps due to restricted access. All data were acquired along the tow road, and there are four test holes with lithology and $\mathrm{EC}$ logs that can be compared with the $\mathrm{CC}$ resistivity data.

Acquisition began close to the diversion point from the North Platte River, and the data show a moderately resistive surface layer (100 to $300 \mathrm{ohm}-\mathrm{m}$ ) underlain by a highly resistive layer (325 ohm-m and greater) that varies in thickness. This resistive layer at depth continues until just before the canal begins to parallel the Tri-State Canal and Spottedtail Creek north of Highway 26. Test hole Ent1 (fig. 1) is located within this section with the resistive lower layer and shows very fine sand, silt, and clay in the top $2.5 \mathrm{~m}$ with lenses of fine and moderately to poorly sorted mixed sand below (fig. 17). At the time of drilling, the water level was estimated to be 4 mbls, which explains the difference in resistivity values observed on the EC log between the sand layers above and below 1,204-m elevation. Generally, the logs and CC resistivity data correspond well, but the $\mathrm{CC}$ resistivity data appear to be less sensitive to the water content than the EC log.

Where the lower resistive layer disappears, the $\mathrm{CC}$ resistivity data becomes moderately resistive from the surface to the maximum depth of penetration. Thin (lateral extent of 5 to $20 \mathrm{~m}$ ) resistive patches, with varying vertical extents, become increasingly frequent as the canal parallels Tri-State Canal. Test hole Ent2 is located near the divergence of Enterprise and Tri-State Canals (fig. 1) and shows that the resistivity structure is caused by multiple layers of very fine, fine, and mixed sand throughout (fig. 18). Beyond the divergence, the average resistivity continues to increase until the canal turns north at the Tub Springs Drain, which originates at Lake Alice. Low- to moderate-resistivity values dominate the section that parallels the Tub Springs Drain and turns back toward Highway 26. Test hole Ent3, located near the turn back toward the southwest, indicates very fine and fine sand overlying a more conductive hard silt (fig. 19).

Once the canal resumes its southwesterly trend parallel to Highway 26, a strong resistive layer (greater than $500 \mathrm{ohm}-\mathrm{m}$ ) appears that initially extends throughout the vertical section and becomes continually deeper until it disappears completely where the canal becomes a tunnel and continues underground near the hospital in Scottsbluff. Located at the initial appearance of this strong resistor, TH Ent 4 shows more conductive very fine and fine sands overlying a highly resistive mixed sand (fig. 20). Where the tunnel ends and the canal resurfaces, the resistivity values are low to moderate (50 to $350 \mathrm{ohm}-\mathrm{m}$ ) until a rapid change occurs in the last kilometer where frequent, discontinuous, and extremely high resistive lenses are present ranging from 10 to $100 \mathrm{~m}$ in lateral extent.

\section{Mitchell Canal}

For the purposes of this report, the Gering-Mitchell Canal and Mitchell and Gering Canal (fig. 1) are collectively referred to as the Mitchell Canal. The Mitchell Canal diversion from the North Platte River is about $3 \mathrm{~km}$ southwest of Henry, Nebr., and extends to the immediate west of Gering, Nebr., where it connects to Gering Canal within the Scotts Bluff National Monument. This canal extends for a total of about $45 \mathrm{~km}$ and is operated by the Mitchell Irrigation District. The entire canal length was surveyed in 2008 , both on the tow road and in the canal, with no notable data coverage gaps other than road crossings. Test holes Mit29, Mit30, Mit33, Mit34, and Mit35 were drilled along this canal (fig. 1). Test holes Mit31 and Mit32 were planned but not drilled, because of construction on the canal in those locations.

The first several kilometers are characterized by moderate to high resistivities (100 to greater than $500 \mathrm{ohm}-\mathrm{m}$ ). The first kilometer is dominated by moderate resistivities with a discontinuous, increasingly resistive upper layer appearing over the next kilometer. This variable resistive layer is typically vertically centered about 2 mbls but extends to the full depth of the section in some areas. The resistivity abruptly changes to show a very strong conductor (less than $10 \mathrm{ohm}-\mathrm{m}$ ) at depth that quickly becomes shallower and dominates much of the section where the canal parallels County Road F. This transition begins at an oxbow curve between County Roads 5 and 6 south of County Road F, approximately $5 \mathrm{~km}$ southwest of Morrill, Nebr. As the Mitchell Canal turns south away from County Road F, the resistivity of the upper layer becomes more moderate ( 75 to $325 \mathrm{ohm}-\mathrm{m}$ ), but the strong conductor at depth continues and varies in depth. Between Rifle Site Road and Hunt Dairy Road west of Gering, the resistivities become increasingly moderate with only slight indications of a conductor at depth. East of Hunt Dairy Road, the strong conductor appears again and continues into Gering Canal.

Test holes Mit33 and Mit34 were drilled within $100 \mathrm{~m}$ of each other, in a very heterogeneous section of Mitchell Canal. These two test holes sample different resistivity structures observed in the $\mathrm{CC}$ resistivity data. Although the $\mathrm{CC}$ resistivity data were acquired in the canal in this area, both test holes were acquired on the tow road because the canal walls were too steep to get the tractor into the canal. A discontinuous, shallow, strong resistor is sampled by test hole Mit33 (fig. 21). The resistor corresponds to a poorly sorted, mixed medium-size sand with interbedded gravel (table 2). The abrupt decrease in resistivity observed on the EC log is caused by an increase in water content; the core sample near 1,221-m elevation is described as the same medium-size sand as above but is saturated. There is also an indication in the $\mathrm{CC}$ resistivity data of a decrease in resistivity, but it is not as abrupt. This is most likely caused by a relatively low vertical resolution in these data as compared to the EC log. Test hole Mit34 samples a more moderate resistivity structure immediately south of TH Mit33. The shallow conductive unit comprises silty sand and silty clay, overlying more moderately resistive fine and medium sands (fig. 21).

Test hole Mit30 was drilled in a low to moderately resistive section (fig. 1). The entire core is described as silt, and the EC curve is featureless, indicating a relatively homogeneous 
unit (fig. 22). Further downstream, TH Mit29 was drilled near Hunt Dairy Road. The upper layer moderate resistivities in the $\mathrm{CC}$ resistivity section and on the EC curve are caused by a very fine sand. Beginning at 1,208.5-m elevation, the decrease in resistivity is caused by a sand with a slight clay content overlying a hard silt (fig. 23). Test hole Mit35 was the farthest east test hole drilled in this canal. The moderately resistive top $5 \mathrm{~m}$ are fine sands with occasional interbedded fine gravels overlying very fine sandy silt with siltstone chips (fig. 24). This lower layer could also be categorized as a hard silt, based on the very low resistivity at the base of both resistivity datasets.

\section{Gering Canal}

Gering Canal, operated by the Gering Irrigation District, is a continuation of Mitchell Canal that extends for approximately $33 \mathrm{~km}$. The canal runs through the western edge of Gering, Nebr. Acquired in 2008, all CC resistivity data were collected along the tow road with only a few kilometers at the end not surveyed due to limited access. Test holes Ger10 through Ger13 (fig. 1) were drilled along the canal.

Gering Canal, like the end of Mitchell Canal, shows a strong conductor at depth (less than $10 \mathrm{ohm}-\mathrm{m}$ ) underlying a low to moderately resistive upper layer (50 to $325 \mathrm{ohm}-\mathrm{m}$ ) that varies in thickness. Except for one section that extends from east of County Road 26 to the intersection of the canal with County Road 27 just south of County Road S, the resistivity structure remains consistent throughout the remainder of the canal. Along the noted exception, the upper layer becomes moderately to highly resistive (175 to $425 \mathrm{ohm}-\mathrm{m}$ ) with discontinuous lenses of high resistivity. The strong conductor remains at the base of the resistivity sections, but is more consistent at 6 to 8 mbls.

Test hole Ger10 was drilled in one of the predominantly moderate-resistivity structures where the conductive lower layer is below the maximum depth of investigation (fig. 1). This moderately resistive layer is only $350 \mathrm{~m}$ in length in the $\mathrm{CC}$ resistivity profile. The lithology $\log$ shows $2.5 \mathrm{~m}$ of very fine sand at the surface overlying $2 \mathrm{~m}$ of sand, almost $3 \mathrm{~m}$ of fine sand, and finally a moderately to poorly sorted mixed sand at the bottom (fig. 25). The EC curve shows a gradual decrease in resistivity with very little character. Although the absolute values of the EC log and CC resistivities do not agree, the presence of sands of various grain size throughout the sample correlate with a generally featureless EC log and $\mathrm{CC}$ resistivity profile. The detailed lithologic descriptions (table 2), however, indicate that the sample is saturated at about 7 mbls (1,205-m elevation), which corresponds to a slight decrease in both the EC log and in the CC resistivity data. Test hole Ger11 samples the typical resistivity structure that dominates much of the canal (fig. 1). The lithologic log indicates $7 \mathrm{~m}$ of very fine sand overlying fine sand, all of which are described as being silty (fig. 26, table 2). As with test hole Ger10, there is not much change in character in the
EC log. The fining downward of the sediments is assumed to cause the observed decrease in resistivity at depth.

Test holes Ger12 and Ger13 were drilled within $2 \mathrm{~km}$ of one another in the section containing the moderately to highly resistive upper layer. Both test holes show fine sand throughout, with test hole Ger13 displaying a thin layer of very fine sand at the top and bottom (figs. 27 and 28). The only indication of a change in lithology (table 2) is a distinct soil color change at about 1,203-m elevation, which corresponds to a decrease in resistivity in the $\mathrm{CC}$ resistivity profile as well as a change to a steadier EC curve at that depth. In test hole Ger13, there is a high correlation between the logs and the $\mathrm{CC}$ resistivity data. The decrease in resistivity at 1,200.5-m elevation corresponds to the presence of silty sand with a slight amount of clay and siltstone chips.

\section{Fort Laramie Canal}

Fort Laramie Canal is operated by the Gering-Fort Laramie Irrigation District. Ninety-eight kilometers were surveyed in 2008. Data were acquired both within the canal and along the tow road. For descriptive purposes, the canal can be divided into four segments: (1) the main canal originating in Wyoming and continuing to the north end of the Fort Laramie Irrigation Tunnel (10 km west of Gering), (2) the approximately 6-km-long diversion east of the tunnel intake referred to as the Scotts Bluff Lateral, (3) the western leg of the canal on the south side of the tunnel, and (4) the eastern leg of the canal on the south side of the tunnel referred to as the Gering Lateral, which is approximately $13 \mathrm{~km}$. A 4.5-km-long section along segment 1 was not surveyed because of standing water in the canal in both 2008 and 2009. Several kilometers were not surveyed at the end of segment 3 , because the canal became too sinuous in this area to continue the survey along the tow road, and the canal is too narrow to survey along the bed. Test holes FtL14 through FtL18 (fig. 1) were drilled in various sections of the canal.

Segment 1 is typified by a very low resistivity (less than 10 ohm-m) throughout with low (25 to 75 ohm-m) or moderate $(75$ to $325 \mathrm{ohm}-\mathrm{m})$ discontinuous lenses in the upper 4 to $6 \mathrm{~m}$ that vary in frequency and lateral extent. There is a 2-km-long section immediately east of the Wyoming-Nebraska border where highly resistive lenses (greater than $450 \mathrm{ohm}-\mathrm{m}$ ), ranging in lateral extent from 10 to $40 \mathrm{~m}$, are in the upper $4 \mathrm{~m}$. No test holes were drilled along this segment.

Segments 2 and 3 are consistently conductive (less than $10 \mathrm{ohm}-\mathrm{m}$ ) down to $8 \mathrm{mbls}$. Moderately resistive (75 to 300 ohm-m) lenses ranging in thickness from 4 to $7 \mathrm{~m}$ occur and vary considerably in lateral extent. Test holes FtL15 through FtL18 were drilled along segment 3. Test hole FtL18, closest to the south side of the tunnel, was drilled in a more moderately resistive section that is one of only a few areas that does not have a strong conductor at depth (fig. 29). The lithology log shows that the majority of the core is very fine silty sand with a small silt unit between 1,270- and 1,271-m elevation. Test hole FtL17 shows the very conductive units 
in this area are silt and saturated silty clay (fig. 30). This most likely correlates with the strong conductor prominent at depth and throughout segment $1 \mathrm{CC}$ resistivity data. Test hole FtL16 shows a section comprising mostly very fine sand that becomes siltier with a slight amount of clay with depth, correlating with the gradual decrease in resistivity in the EC $\log$ (fig. 31). The two obvious resistive spikes in the EC log correlate with the presence of interbedded sandstone pieces observed in the cores (table 2). Farther down the segment, test hole FtL15 was drilled into $1 \mathrm{~m}$ of silt at the surface overlying sandy silt throughout the rest of the core (fig. 32). This corresponds well with the resistivities and lithologies described for test hole FtL18 (fig. 29).

Segment 4 continues with a similar resistivity structure defined for segments 2 and 3: moderate-resistivity lenses ranging in thickness from 4 to $7 \mathrm{mbls}$ within a strongly conductive unit. There were several siphons throughout the last $10 \mathrm{~km}$ of this segment with large decreases in elevation as the canal continued through the Scotts Bluff National Monument north of Highway 92. Test hole FtL14 was drilled along this segment (fig. 33).

\section{Minor Canals and Laterals}

\section{Laterals Number 1 and 10}

Laterals Number 1 and 10 are diversions from the Interstate Canal. The north-south trending Lateral Number 1 diversion is about $4.5 \mathrm{~km}$ west of the Wyoming-Nebraska border and has a total surveyed length of just over $14 \mathrm{~km}$. All CC resistivity data were acquired on the tow road (fig. 1).

Generally, resistivity is high with the majority of the values greater than $600 \mathrm{ohm}-\mathrm{m}$, with a general trend of increased resistivity with depth. This lateral is in a region known to contain sand dunes, and the high-resistivity values indicate that the lateral does indeed intersect them. The first $1 \mathrm{~km}$ after the diversion from the Interstate Canal shows the lowest overall resistivity, with an average of about $80 \mathrm{ohm}-\mathrm{m}$. Test hole Lat 24 was drilled in this relatively low resistivity section and shows multiple layers of very fine and fine sand overlying a more resistive mixed sand at the base (fig. 34). There is a 2-km-long section that ends near test hole Lat25 with an extremely high resistivity bottom layer with an average resistivity ranging from 500 to near 1,000 ohm-m. The general trends of the EC log from test hole Lat 25 correspond well with the nearby resistivity structure of the $\mathrm{CC}$ resistivity data (fig. 35). The more highly resistive surface layer and less resistive underlying layer are both described as very fine sand and sand layers. Although not mentioned in the drilling log, the decrease in resistivity may be caused by increased water, or possibly clay, content below 1,274-m elevation.

Test hole Lat26 is located where Lateral 1 makes an abrupt turn to the south and where another strong resistor is present on the lower half of the CC resistivity profiles (fig. 1). The lithology log shows very fine sand and sand layers overly- ing much more resistive moderately to poorly sorted mixed sand (fig. 36). This lower sand unit could be coarser grained and/or have a lower clay content.

The Lateral Number 10 diversion is located approximately $8 \mathrm{~km}$ east of the Wyoming-Nebraska State line. The surveyed length along the tow road is almost $9 \mathrm{~km}$ (fig. 1). This lateral typically has a more moderate to high-resistivity structure as compared with Lateral 1. This lateral is in a more alluvium-rich region. There is a discontinuous, varying highresistivity layer (325 to $475 \mathrm{ohm}-\mathrm{m}$ ) along the bottom half of the majority of the $\mathrm{CC}$ resistivity profiles with frequent, isolated conductive and resistive lenses throughout. Test holes Lat 22 and Lat 23 were drilled within $300 \mathrm{~m}$ of each other and sample two substantially different areas. Test hole Lat22 samples a low- to moderate-resistivity section (100 to $350 \mathrm{ohm}-\mathrm{m}$ ) and shows mostly very fine sand in the top $4.5 \mathrm{~m}$ underlain by a more conductive silt and clay (fig. 37). The more resistive section below the silt and clay observed in both the CC resistivity and EC log data was not sampled with the core. Like the top of test hole Lat22, the lithology log of test hole Lat23 also shows mostly very fine sand in the top $3.5 \mathrm{~m}$ but is underlain by a more resistive sand and mixed sand (fig. 37 ).

\section{Winters Creek Canal}

Winters Creek Canal extends for $19 \mathrm{~km}$, located north of and paralleling the North Platte River. The canal, run by Winters Creek Irrigation District, passes through Scottsbluff, Nebr. Gaps in data coverage exist along this canal because of limited access in certain areas and because the canal extends underground as a tunnel. In addition, much of the canal through Scottsbluff was lined with concrete and could not be surveyed. Approximately $12 \mathrm{~km}$ were surveyed. No test holes are available for comparison with these $\mathrm{CC}$ resistivity data. All data were acquired along the tow road.

The canal is characterized by moderate resistivities (100 to $300 \mathrm{ohm}-\mathrm{m}$ ) with a couple of varying sections. Acquisition began on the east side of County Road 19 along irrigated crop fields for about $1.5 \mathrm{~km}$ to Highway 71 . This section displayed moderate resistivities with several discontinuous higher resistivity lenses (325 to $450 \mathrm{ohm}-\mathrm{m}$ ). The next section was acquired on the other side of Highway 71 along a thickly forested, ill-maintained tow road and ended where the concretelined canal began. The resistivities along this section are all extremely high, with average resistivities becoming increasingly greater eastward and nearing 1,000 ohm-m. The CC resistivity profile is dominated by a highly resistive layer 2 to 3 mbls. There is no indication in the raw data that the system was not functioning properly, and there is some indication at the eastern end of the previous section on the other side of the road that more resistive materials were present.

The survey resumed on the other side of downtown Scottsbluff where the canal continues above ground with no concrete lining. The data show low to moderate resistivities (10 to $300 \mathrm{ohm}-\mathrm{m}$ ) with indications of the presence of low 
resistivity at the bottom of the profiles and discontinuous, thin lenses throughout the sections (fig. 38B). Beginning south of the Highland Road crossing, an increasingly more consistent resistive layer ( 325 to $450 \mathrm{ohm}-\mathrm{m}$ ) is present that extends from the surface down to 4 to 6 mbls and continues eastward throughout the remainder of the accessible areas (fig. 38C).

\section{Minatare Canal}

Minatare Canal begins about $5 \mathrm{~km}$ southeast of Scottsbluff and extends southeast for $16 \mathrm{~km}$ through the town of Minatare, Nebr. The canal is run by the Minatare Irrigation District and intersects the western edge of Ninemile Canal near its end. A total of $8 \mathrm{~km}$ was surveyed along the western two-thirds of the canal. Small sections were bypassed due to access constraints though the town of Minatare. The eastern section of the canal was not completed due to time constraints but should be possible to survey in the future. There were no test holes drilled along this canal. Resistivity data were acquired both in the canal and along the tow road.

The canal is typified by consistently moderate resistivity values (150 to $325 \mathrm{ohm}-\mathrm{m}$ ). There are discontinuous low- and high-resistivity lenses, which are more prevalent on the eastern end of the surveyed area. A 2.5-km-long section, beginning north of the second Highway 26 crossing and continuing to where the canal begins to parallel the highway, shows a more resistive lower half (350 to $450 \mathrm{ohm}-\mathrm{m}$ ), indicating a coarser grained or less clay-rich deposit (fig. 39).

\section{Ninemile Canal}

Ninemile Canal is $31 \mathrm{~km}$ long and is operated by the Ninemile Irrigation District. The canal begins approximately $2 \mathrm{~km}$ south of Minatare, Nebr., and parallels the North Platte River to the southeast. Because of limited access to the canal in some sections, $21 \mathrm{~km}$ were surveyed in discontinuous sections with gaps up to $2 \mathrm{~km}$ long. No test holes were drilled in this canal. The majority of the resistivity data was acquired along the tow road, except for the westernmost 3-km section, which was collected in the canal.

The first three western surveyed sections have moderate resistivity (125 to $300 \mathrm{ohm}-\mathrm{m}$ ) with infrequent isolated lenses of higher resistivity typically 10 to $20 \mathrm{~m}$ in lateral extent and only several meters thick. Unfortunately, it is not possible to identify the continuity of these lenses in the plane perpendicular to the canal. The section extending between County Road 36 and midway between County Roads 37 and 73 is characterized by higher resistivities (350 to $450 \mathrm{ohm}-\mathrm{m}$ ) in the upper $6 \mathrm{mbls}$, indicating either larger grain sizes or lower clay content (fig. $40 \mathrm{~B}$ ). In the next section that begins just west of Bayard, Nebr., and passes through the town, the first $2 \mathrm{~km}$ are moderately resistive but then abruptly becomes highly resistive (average values near 1,000 ohm-m) throughout the lower half of the section and extending to the surface for much of the next $4 \mathrm{~km}$ (fig. 40C). The rest of the canal becomes more moderately resistive with another 800-m-long section with a very high resistor at depth just after the canal turns toward the north.

\section{Alliance Canal}

Alliance Canal, operated by the Alliance Irrigation District, is located north of and parallels the North Platte River, extending for $24 \mathrm{~km}$. The eastern two-thirds were surveyed, totaling $15 \mathrm{~km}$, but access was limited west of Red Willow Creek where the canal begins to parallel Ninemile Canal. Between the two datasets acquired along Alliance and Minatare Canals, there is continuous coverage from west to east along the river corridor (fig. 1). All data along this canal were acquired along the tow road.

Alliance Canal generally shows a moderate resistivity (150 to $300 \mathrm{ohm}-\mathrm{m}$ ) with discontinuous lenses of very high resistivity (500 ohm-m or greater) and sections with low resistivity (80 ohm-m or less) at the base. Eastward from Red Willow Creek, the resistivities are moderate with an increasing occurrence of highly resistive lenses that have a lateral range of approximately 10 to $80 \mathrm{~m}$ with vertical extents that do not appear to extend to the full depth of investigation (fig. $41 B$ ). About $10 \mathrm{~km}$ along the surveyed canal length, overall resistivity begins to decrease and discontinuous conductive layers begin to appear at depth. East of the short north-south omitted section that parallels County Road 93, the conductive layer becomes more continuous and thicker, approaching the surface at the very eastern end of the canal (fig. 41C).

\section{Summary and Discussion}

The NPNRD, in cooperation with the DNR, is developing an Integrated Management Plan for groundwater and surface water in the NPNRD as a result of portions of the North Platte River valley being designated as over-appropriated. As part of the IMP, a three-dimensional numerical finite difference groundwater-flow model is being developed to evaluate the effectiveness of using leakage of water from selected irrigation canal systems to manage groundwater recharge. The U.S. Geological Survey performed a land-based CC resistivity survey along nearly $630 \mathrm{~km}$ of 13 canals and 2 laterals from 2004 and 2007 through 2009 to determine the relative leakage potential of the upper $8 \mathrm{~m}$ of the selected irrigation canals within the valley in western Nebraska and eastern Wyoming. The resistivity data were then compared to continuous cores at 62 test holes down to a maximum depth of $8 \mathrm{~m}$. Borehole electrical conductivity measurements at 36 of those test holes were done to correlate resistivity values with grain sizes and lithologies to determine potential vertical leakage along the canals as recharge to the underlying aquifer. The original 2004 CC resistivity results and 25 test holes are presented in Ball and others (2006). The CC resistivity data were reprocessed and inverted using the same updated methods and available software with 
which the 2007 through 2009 datasets were completed. This provides a consistent and complete dataset for all collection periods. Thirty-seven test-hole cores and borehole electrical conductivity measurements were acquired based on observed variations in the resistivity structure in the 2008 data.

Overall, the CC resistivity and borehole EC logs match well. The EC logs generally show greater detail than the $\mathrm{CC}$ resistivity data can fully resolve. The test-hole data are detailed $\operatorname{logs}$ at a particular location with EC log data acquired at depth increments of $1.5 \mathrm{~cm}$. Conversely, the $\mathrm{CC}$ resistivity data comprise five data points over an 8-m-depth range, and each data point is a lateral average across $5 \mathrm{~m}$. This relatively coarse sampling has a "smearing" effect on the positioning of the resistivity boundaries.

The development of the in-house GPSpathtool and OhmBin programs were essential for properly positioning and processing this large amount of CC resistivity data collected continuously along sinuous paths. Data acquisition efficiency was greatly increased because it was not limited to straightline segments when the curves in the canals were wide enough to accommodate a relatively straight array. The quality control and data editing procedures that these programs included also provided higher confidence in the quality of the inverted resistivity sections. These programs will be published and made publicly available in the future.

There are a couple of modifications that can be made both in the acquisition setup and data processing that would help streamline the GPS data processing scheme. One example is related to the NMEA string output by the GPS unit. It was determined that the capacitively coupled acquisition system can accept a NMEA GGK message string (includes time, position, position type, and dilution of precision (DOP) values) that could be used in place of the GGA string. The GGK string outputs only the ellipsoid height, whereas the GGA string outputs the orthometric height if there is a geoid model loaded onto the GPS. Currently, the GPSpathtool program only recognizes the GGA string, but it should be easy to modify the program to also accept the GGK string. This would allow for more consistent data processing since it would ensure that only the ellipsoid height is recorded, regardless of the GPS unit and loaded geoid models.

In areas where the canal became too sinuous to continue the $\mathrm{CC}$ resistivity survey along the tow road and where the canal is too narrow to survey along the bed (for example, the ends of Fort Laramie and Northport Canals), other geophysical methods could be used to measure the resistivity of the subsur- face. These methods include frequency- and time-domain electromagnetic techniques that have acquisition systems that can be hand-carried or towed behind an ATV to create continuous resistivity profiles. The measurement systems are typically more compact than the 50-m-long CC resistivity array and could be towed more readily behind an ATV on sinuous tow roads.

Future work includes the development of a more sophisticated method of estimating canal leakage that incorporates both CC resistivity profiles and test-hole data. Sixty-two test holes were drilled throughout the study area, and sieve analyses of the collected cores were performed. Sieve analysis, comprised of passing the core sediments through screens of varying mesh sizes, is a method to determine the grain-size distribution of the recovered test-hole materials. Hydraulic conductivity, defining the rate of water movement through the subsurface, can be readily estimated from sediment grain size using standard reference tables. In addition to test-hole cores, the EC log data can be used to associate sediment grain size with electrical resistivity. Using statistical techniques to correlate the sieve and EC log data, a relation between grain size and electrical resistivity can be established that would be site-specific to the hydrogeologic conditions of the study area. The relation can then be applied to the $\mathrm{CC}$ resistivity profiles to obtain a 2-dimensional "mapping" of sediment grain size, and hence estimated hydraulic conductivity, beneath the canal beds.

\section{Acknowledgments}

This project was performed in cooperation with the North Platte Natural Resources Department (NPNRD) and the University of Nebraska Conservation and Survey Division. The authors would like to thank Roy Lyles, NPNRD, for his help in obtaining permissions for our work in the canals and for providing a workspace from which to base our field operations. Our appreciation is extended to Justin Krahulik, Theresa Rademacker, and Bill Sellers, USGS, for their help in field operations during the 2007 through 2009 field seasons and to Lyndsay Ball and Renee Bowers, USGS, for creating the test-hole description databases. The authors wish to thank James Cannia and Jared Abraham, USGS, for their extensive contributions during the project and for their critical reviews of this report. Special appreciation is also extended to the canal companies for granting access to the canals. 


\section{References Cited}

AGI [Advanced Geosciences, Inc.], 2008, Instruction manual for EarthImager 2D version 2.3.0 - resistivity and IP inversion software: Austin, Tex., Advanced Geosciences, Inc., $139 \mathrm{p}$.

Ashtech Precision Products, 2001, Technical reference manual Z-Xtreme: Santa Clara, Calif., Magellan Corporation.

Babcock, H.M., and Visher, F.N., 1951, Ground-water conditions in the Dutch Flats area, Scotts Bluff and Sioux Counties, Nebraska, with a section on Chemical quality of the ground water, by W.H. Durum: U.S. Geological Survey Circular 126, 51 p. [available online at http://pubs.er.usgs. gov/usgspubs/cir/cir126].

Ball, L.B., Kress, W.H., Steele, G.V., Cannia, J.C., and Andersen, M.J., 2006, Determination of canal leakage potential using continuous resistivity profiling techniques, Interstate and Tri-State Canals, western Nebraska and eastern Wyoming, 2004: U.S. Geological Survey Scientific Investigations Report 2006-5032, 53 p. [available online at http:// pubs.usgs.gov/sir/2006/5032/].

Butler, D.K, ed., 2005, Near-surface geophysics; Investigations in geophysics No. 13: Tulsa, Okla., Society of Exploration Geophysicists, $732 \mathrm{p}$.

COHYST [Cooperative Hydrology Study], 2004, Overview of the objectives, processes, and products of the COHYST project, September 21, 2004 technical committee final draft: The Nebraska Environmental Trust, 27 p. [accessed June 2009 at http://cohyst.dnr.ne.gov/document/dc012overview_04.doc].

Darton, N.H., 1903a, Geologic atlas of the United States, Scotts Bluff folio, Nebraska: U.S. Geological Survey Folio 88,5 p.

Darton, N.H., 1903b, Preliminary report on the geology and water resources of Nebraska west of the one hundred and third meridian: U.S. Geological Survey Professional Paper 17, 69 p., 43 pls.

DNR [State of Nebraska Department of Natural Resources], 2005, What is the meaning of LB 962's fully-appropriated basin designation?: Nebraska Department of Natural Resources Information Sheet, 4 p. [accessed June 2009 at http://www.dnr.state.ne.us/LB962/Newsletter/FullyAppropriatedDesignation_0905A.pdf].

Geometrics, 2001, OhmMapper TR1 Operation Manual rev. F: San Jose, Calif., Geometrics, Inc., 147 p. [accessed May 2009 at ftp://geom.geometrics.com/pub/GeoElectric/Manuals/OhmMapper-Manual-TRN-2004.PDF].
Geometrics, 2009, Magmap 20004.0 user guide rev. H: San Jose, Calif., Geometrics, Inc., 235 p. [accessed May 2009 at http://www.geometrics.com/geometrics-products/geometrics-magnetometers/download-magnetometer-software/.

Glennon, R., Harlow, M., Minami, M., and Booth, B., 2008, ArcGIS 9 ArcMap Tutorial: Redlands, Calif., ESRI, 58 p. [accessed May 2009 at http://webhelp.esri.com/arcgisdesktop/9.3/pdf/ArcMap_Tutorial.pdf].

Hurr, R.T., 1981, Ground-water hydrology of the Mormon Island Crane Meadows Wildlife Area near Grand Island, Hall County, Nebraska: U.S. Geological Survey Open-File Report 81-1109, 43 p.

Kejr, Inc., 2009, Direct Image_-Geoprobe Systems: Kejr, Inc. [conductivity system and probe specification website, accessed May 2009 at http://geoprobe-di.com/content/ view/20/30/].

Kurtz, T., 2005, 2005 LB 962 update: Nebraska Department of Natural Resources Nebraska Resources Newsletter, issue 18, 6 p. [accessed June 2009 at http://www.dnr.state.ne.us/ dnrnews/news2005/December2005Screen.pdf].

Lappala, E.G., Emery, P.A., and Otradovsky, F.J., 1979, Simulated changes in ground-water levels and streamflow resulting from future development (1970-2020) in the Platte River basin, Nebraska: U.S. Geological Survey WaterResources Investigations Report 79-26, 82 p.

Loke, M.H., 2009, RES2DINV ver. 3.58 manual—Rapid 2D resistivity and IP inversion using the least-squares method: Penang, Malaysia, Geotome Software, 151 p. [accessed May 2009 at http://www.geoelectrical.com/downloads.php].

Lucius, J.E., Abraham, J.D., and Burton, B.L., 2008, Resistivity profiling for mapping gravel layers that may control contaminant migration at the Amargosa Desert Research Site, Nevada: U.S. Geological Survey Scientific Investigations Report 2008-5091, 30 p. [available online at http:// pubs.usgs.gov/sir/2008/5091/.

NGS [National Geodetic Survey], 2003, Technical information page for USGG2003 and GEOID03: National Geodetic Survey website [accessed May 2009 at http://www.ngs.noaa. gov/GEOID/GEOID03/tech.html].

NGS [National Geodetic Survey], 2009a, HTDP-Horizontal time dependent positioning: National Geodetic Survey software website [accessed May 2009 at http://www.ngs.noaa. gov/cgi-bin/HTDP/htdp.prl?fl=4\&f2=1].

NGS [National Geodetic Survey], 2009b, Computation of Geoid03 geoid height: National Geodetic Survey software website [accessed May 2009 at http://www.ngs.noaa.gov/ cgi-bin/GEOID_STUFF/geoid03_prompt1.prl]. 
OmniSTAR, 2005, High precision subscription service: Houston, Tex., OmniSTAR, Inc., website [accessed May 2009 at http://www.omnistar.com/faq.html].

Reynolds, J.M., 1997, An introduction to applied and environmental geophysics: Chichester, England, Wiley, 796 p.

Sharma, P.V., 1997, Environmental and engineering geophysics: Cambridge, United Kingdom, Cambridge University Press, $475 \mathrm{p}$.

Smith, F.A., and Souders, V.L., 1975, Groundwater geology of Banner County, Nebraska: Nebraska Water Survey Paper $39,96 \mathrm{p}$.

Souders, V.L., 1986, Geologic sections, ground-water maps, and logs of test holes, Morrill County, Nebraska: University of Nebraska-Lincoln, Conservation and Survey Division, Open-File Report, 90 p.

Steele, G.V., Verstraeten, I.M., and Cannia, J.C., 2001, Surface-water/ground-water interaction and implications for ground-water sustainability in the Dutch Flats area, western Nebraska: U.S. Geological Survey Fact Sheet 074-01, 4 p. [available online at http://pubs.er.usgs.gov/usgspubs/fs/ fs07401].

Teeple, A.P., Vrabel, Joseph, Kress, W.H., and Cannia, J.C., in press, Apparent resistivity and estimated interaction potential of surface water and groundwater along selected canals and streams in the Elkhorn-Loup Model study area, north-central Nebraska, 2006-07: U.S. Geological Survey Scientific Investigations Report 2009-5171, 66 p.
The Weather Network, 2009, Scottsbluff, Nebraska, weather statistics, 1961 to 1990: The Weather Network website [accessed May 2009 at http://www.theweathernetwork.com/ statistics/C02858/usne0436].

Timofeev, V.M., Rogozinski, A.W., Hunter, J.A., and Douma, M., 1994, A new ground resistivity method for engineering and environmental geophysics: Proceedings of the Symposium on the Application of Geophysics to Engineering and Environmental Problems, EEGS, p. 701-715.

USBR [U.S. Bureau of Reclamation], 2009, North Platte Project-Nebraska and Wyoming: U.S. Bureau of Reclamation website [accessed May 2009 at http://www.usbr.gov/ dataweb/html/northplatte.html\#general].

Verstraeten, I.M., Sibray, S.S., Cannia, J.C., and Tanner, D.Q., 1995, Reconnaissance of ground-water quality in the North Platte Natural Resources District, western Nebraska, JuneJuly 1991: U.S. Geological Survey Water-Resources Investigations Report 94-4057, 114 p. [available online at $h t t p: / /$ pubs.er.usgs.gov/usgspubs/wri/wri944057].

Verstraeten, I.M., Steele, G.V., Cannia, J.C., Hitch, D.E., Scripter, K.G., Böhlke, J.K., Kraemer, T.F., and Stanton, J.S., 2001, Interaction of surface water and ground water in the Dutch Flats area, western Nebraska, 1995-99: U.S. Geological Survey Water-Resources Investigations Report 01-4070, 56 p. [available online at http://pubs.er.usgs.gov/ usgspubs/wri/wri014070].

Wenzel, L.K., Cady, R.C., and Waite, H.A., 1946, Geology and ground-water resources of Scotts Bluff County, Nebraska: U.S. Geological Survey Water-Supply Paper 943, 150 p. [available online at http://pubs.er.usgs.gov/usgspubs/wsp/ wsp943/]. 


\section{Supplemental Data Section}

Comparisons of lithologic and electrical conductivity logs to inverted capacitively coupled resistivity sections and average resistivity curves are provided in figures 3 through 37 . Figures 38 through 41 show representative inverted capacitively coupled resistivity sections and average resistivity curves from the minor canals surveyed in 2009. Because of the sinuosity of the canals, some distortion of the inverted resistivity sections may occur when displayed in a two-dimensional environment. Test holes have been plotted with respect to their relation to the downline distance along the inverted resistivity sections and not the displayed geographic coordinate due to the plotting distortion. 


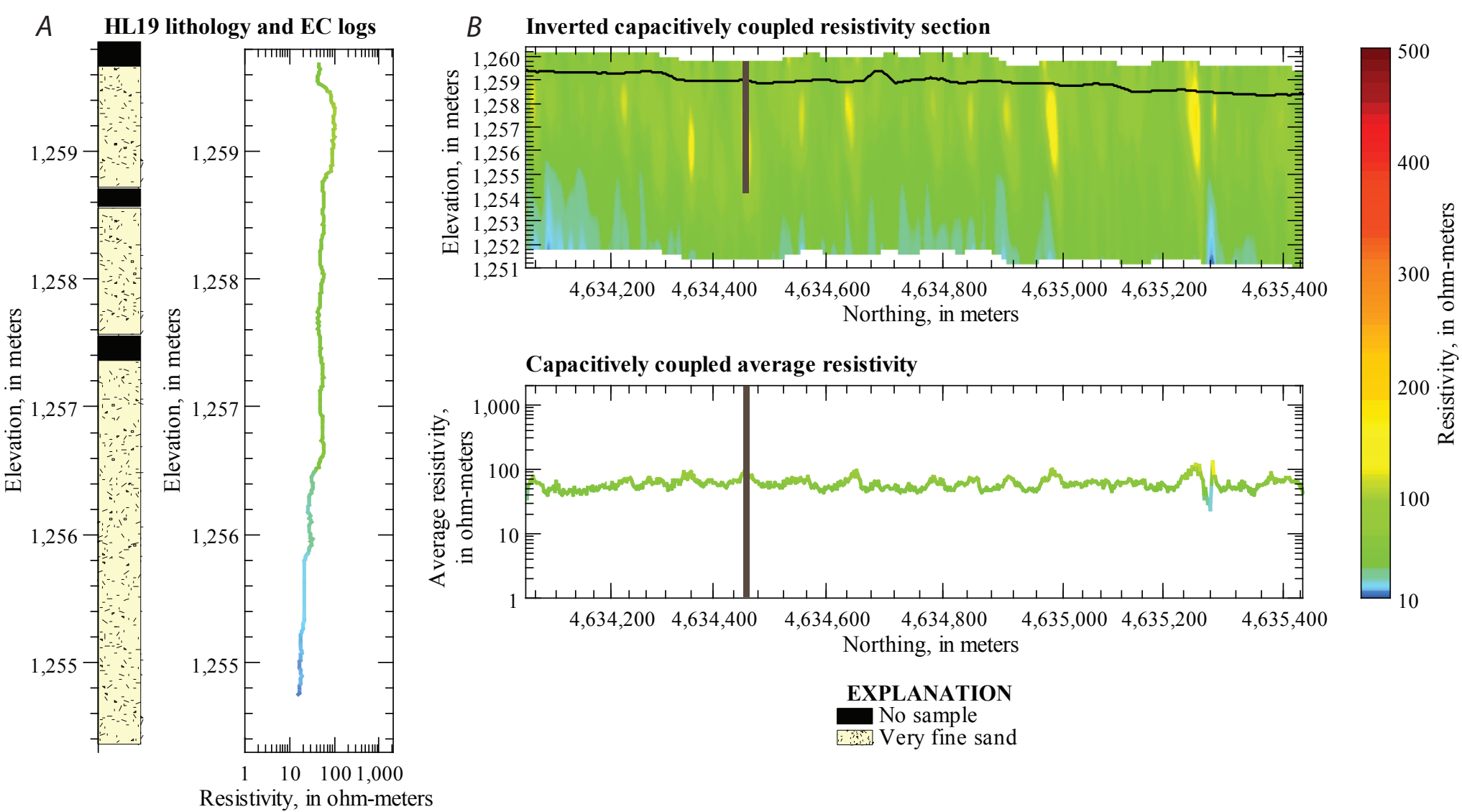

Figure 3. Comparison of $(A)$ lithologic and electrical conductivity log data from test hole HL19 drilled along the tow road of Highline Canal to $(B)$ an inverted capacitively coupled resistivity section and average resistivity curve. The horizontal black line on the inverted resistivity section is the canal bed elevation, and the vertical gray line on the inverted resistivity section and average resistivity curve plots is the location of test hole HL19. 


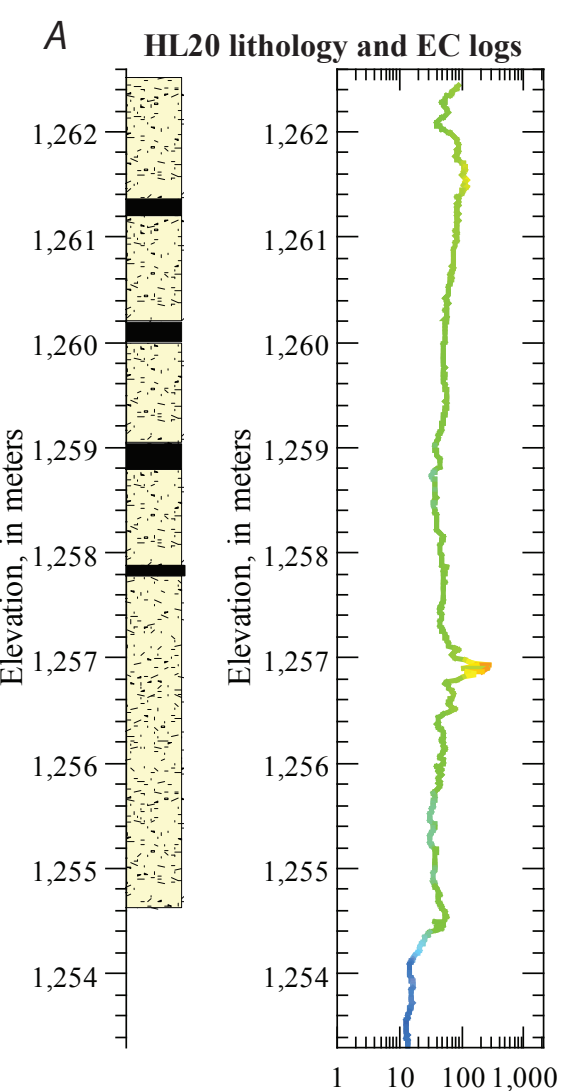

$B \quad$ Inverted capacitively coupled resistivity section
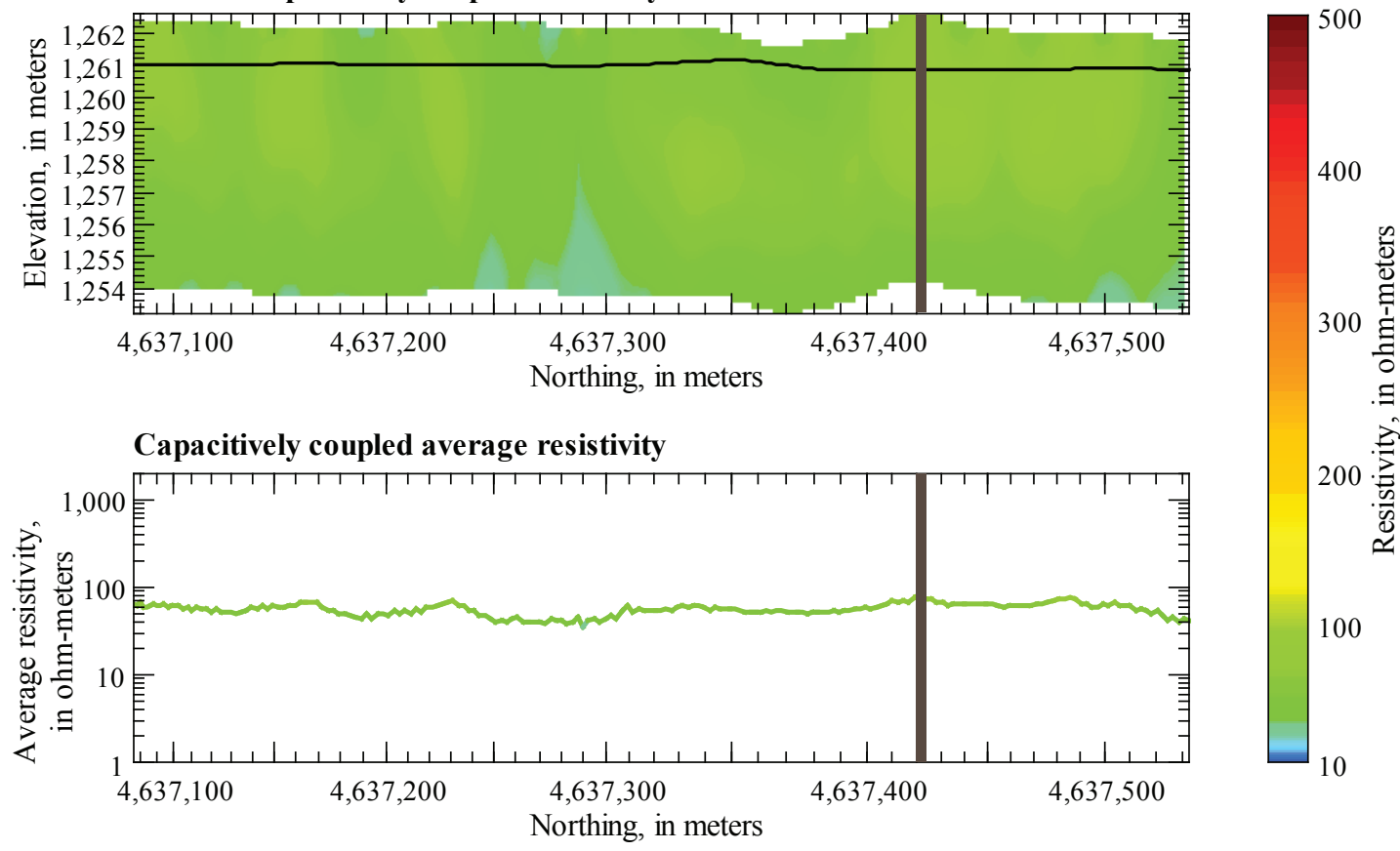

Figure 4. Comparison of (A) lithologic and electrical conductivity log data from test hole HL20 drilled along the tow road of Highline Canal to $(B)$ an inverted capacitively coupled resistivity section and average resistivity curve. The horizontal black line on the inverted resistivity section is the canal bed elevation, and the vertical gray line on the inverted resistivity section and average resistivity curve plots is the location of test hole HL20. 


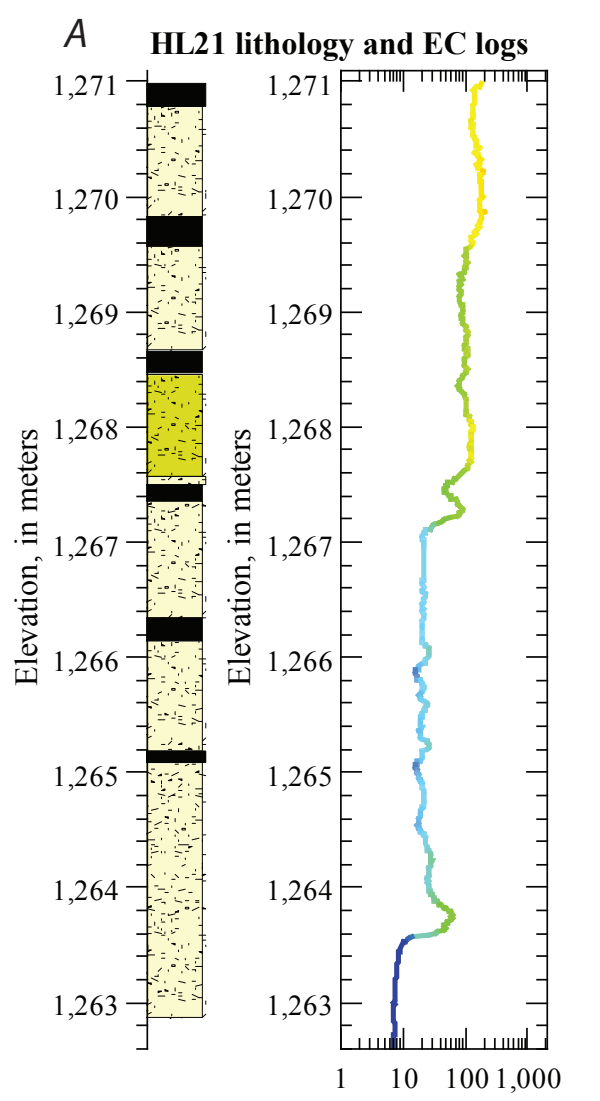

$B \quad$ Inverted capacitively coupled resistivity section

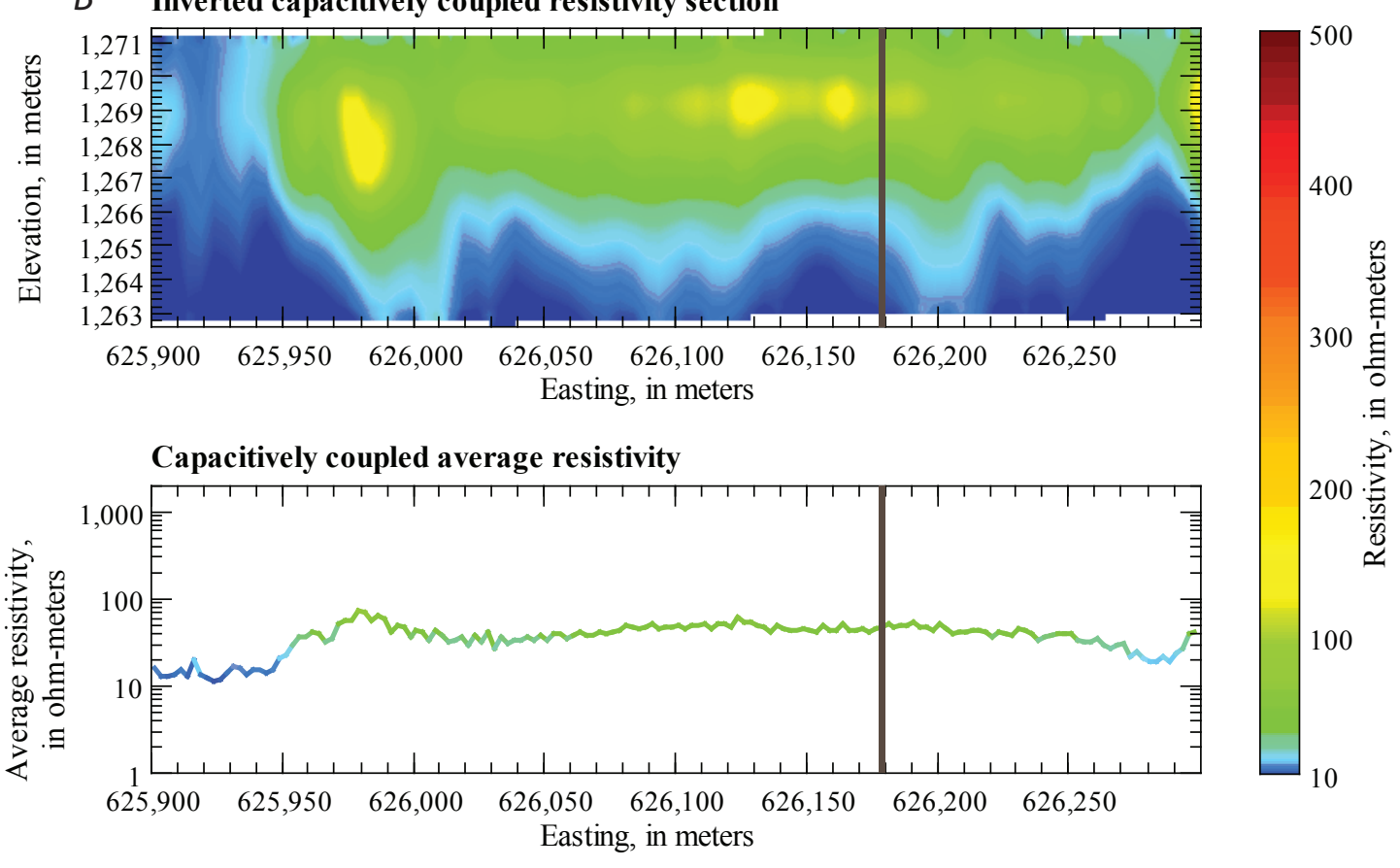

EXPLANATION

No sample

Very fine sand

Resistivity, in ohm-meters

Figure 5. Comparison of ( $A$ ) lithologic and electrical conductivity log data from test hole HL21 drilled in the bed of Highline Canal to (B) an inverted capacitively coupled resistivity section and average resistivity curve. The vertical gray line on the inverted resistivity section and average resistivity curve plots is the location of test hole HL21. 


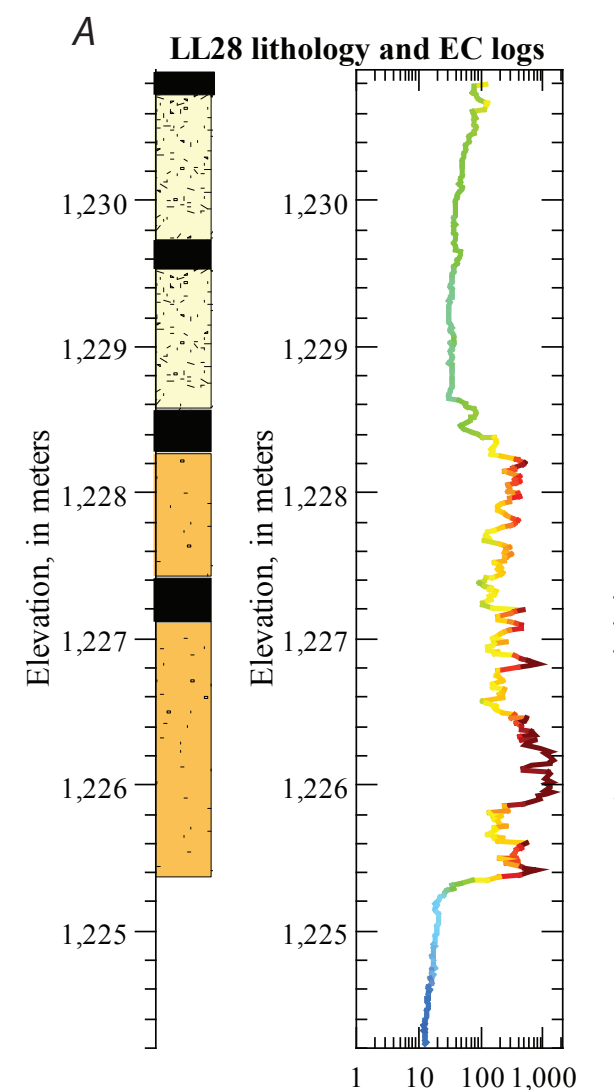

$B$ Inverted capacitively coupled resistivity section

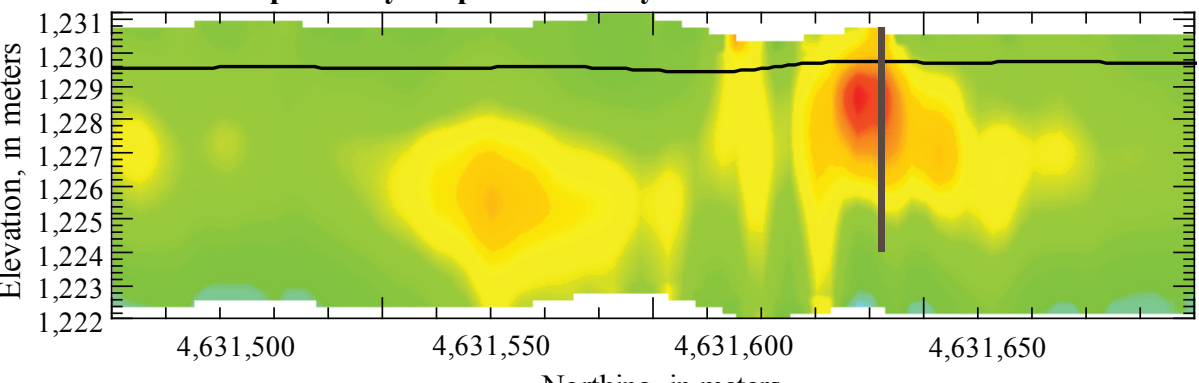

500

400

$300 \stackrel{\text { I }}{g}$

Resistivity, in ohm-meters

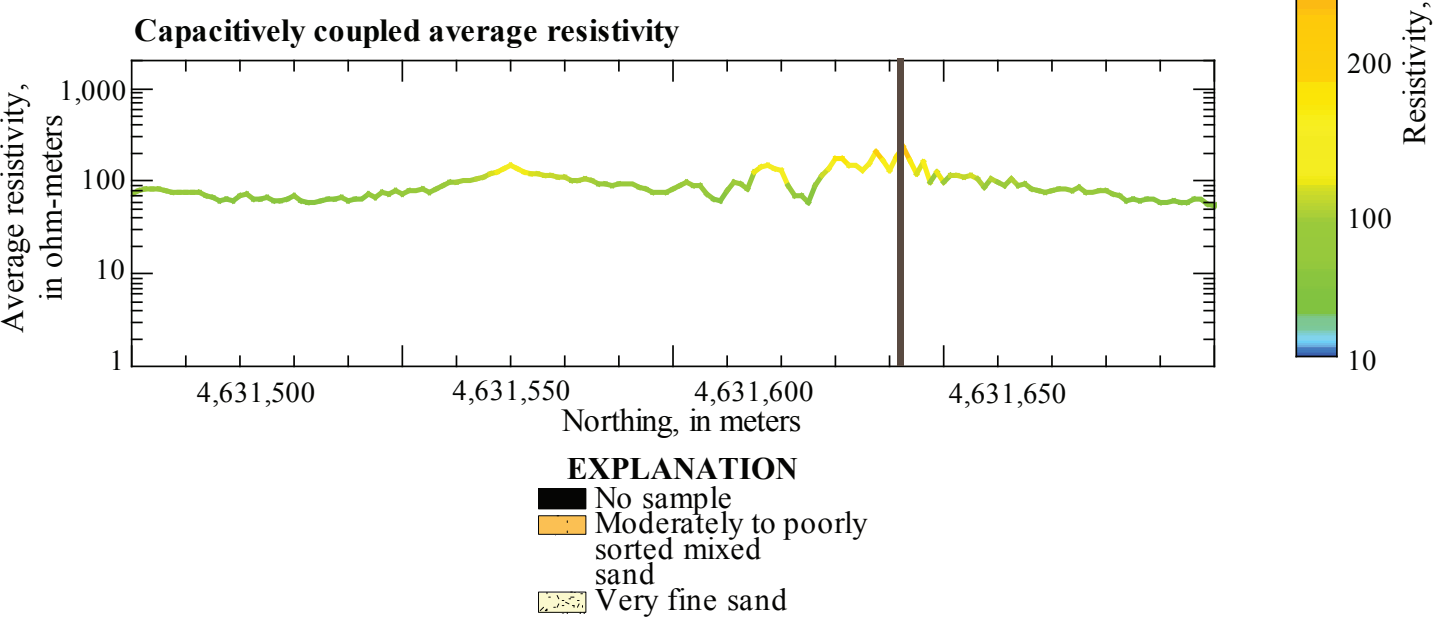

Figure 6. Comparison of $(A)$ lithologic and electrical conductivity log data from test hole LL28 drilled along the tow road of Lowline Canal to $(B)$ an inverted capacitively coupled resistivity section and average resistivity curve. The horizontal black line on the inverted resistivity section is the canal bed elevation, and the vertical gray line on the inverted resistivity section and average resistivity curve plots is the location of test hole LL28. 

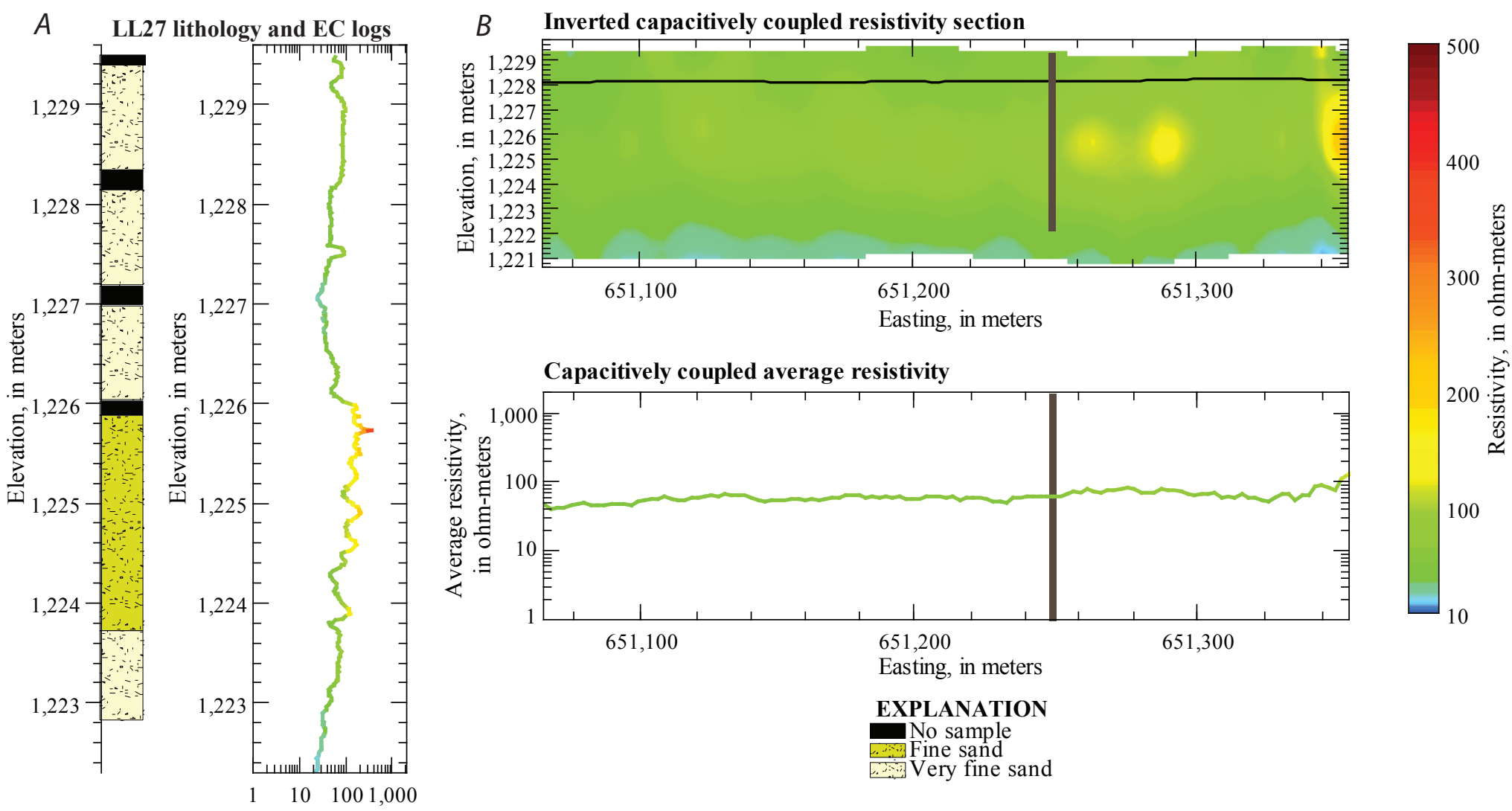

Resistivity, in ohm-meters

Figure 7. Comparison of ( $A$ ) lithologic and electrical conductivity log data from test hole LL27 drilled along the tow road of Lowline Canal to $(B)$ an inverted capacitively coupled resistivity section and average resistivity curve. The horizontal black line on the inverted resistivity section is the canal bed elevation, and the vertical gray line on the inverted resistivity section and average resistivity curve plots is the location of test hole LL27. 

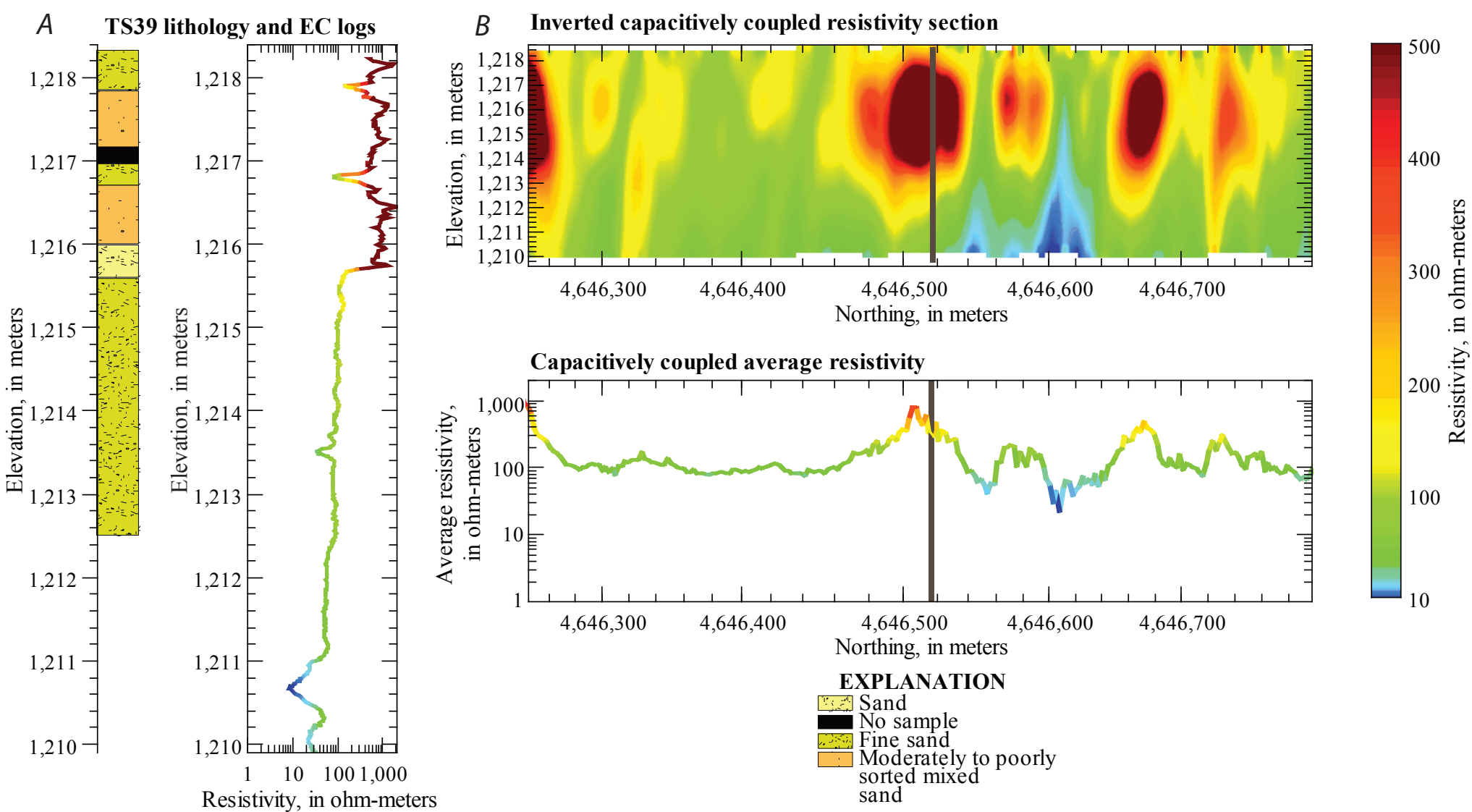

Figure 8. Comparison of $(A)$ lithologic and electrical conductivity log data from test hole TS39 drilled in the bed of Tri-State Canal to $(B)$ an inverted capacitively coupled resistivity section and average resistivity curve. The vertical gray line on the inverted resistivity section and average resistivity curve plots is the location of test hole TS39. 


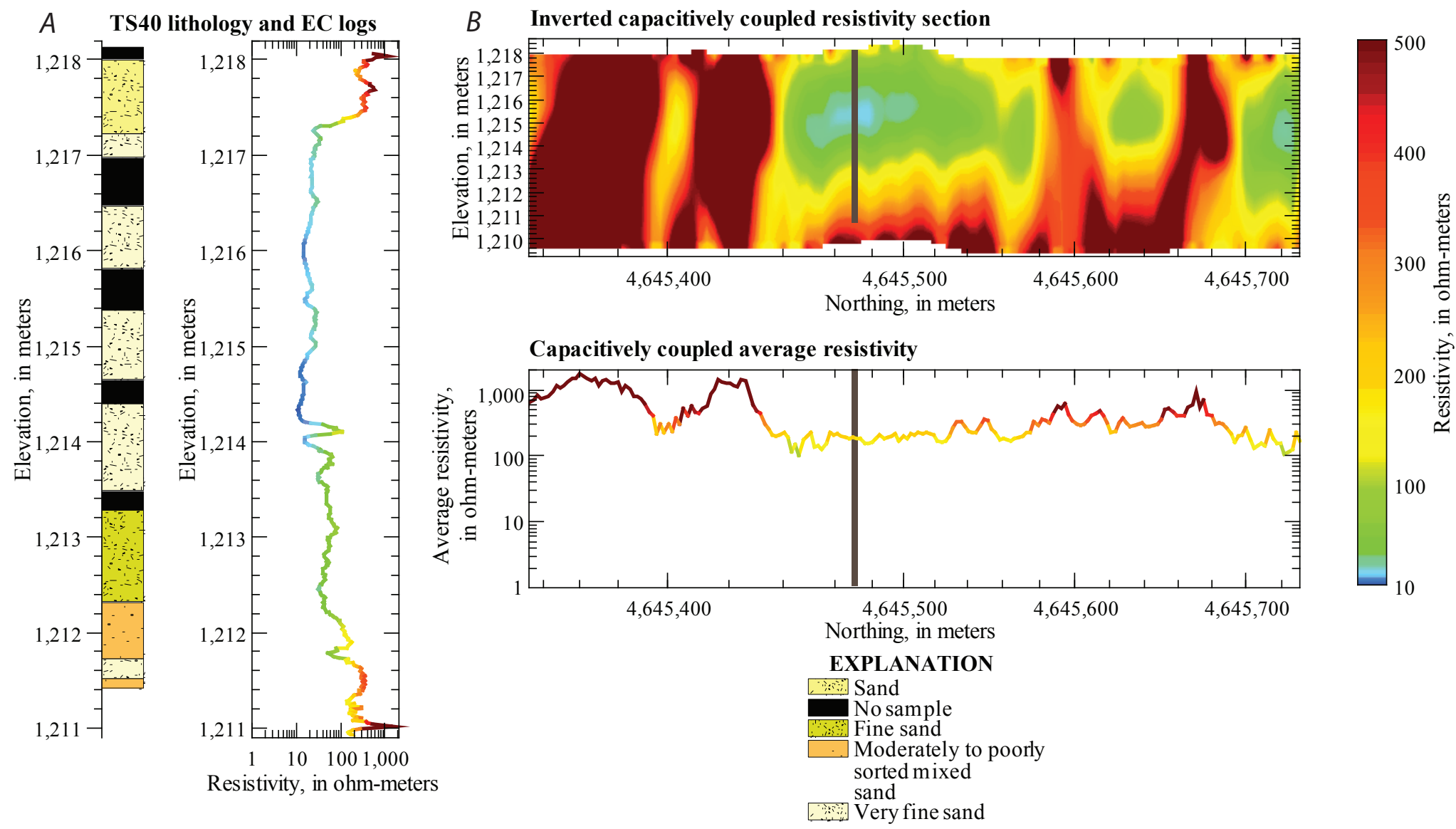

Figure 9. Comparison of ( $A$ ) lithologic and electrical conductivity log data from test hole TS40 drilled in the bed of Tri-State Canal to (B) an inverted capacitively coupled resistivity section and average resistivity curve. The vertical gray line on the inverted resistivity section and average resistivity curve plots is the location of test hole TS40. 

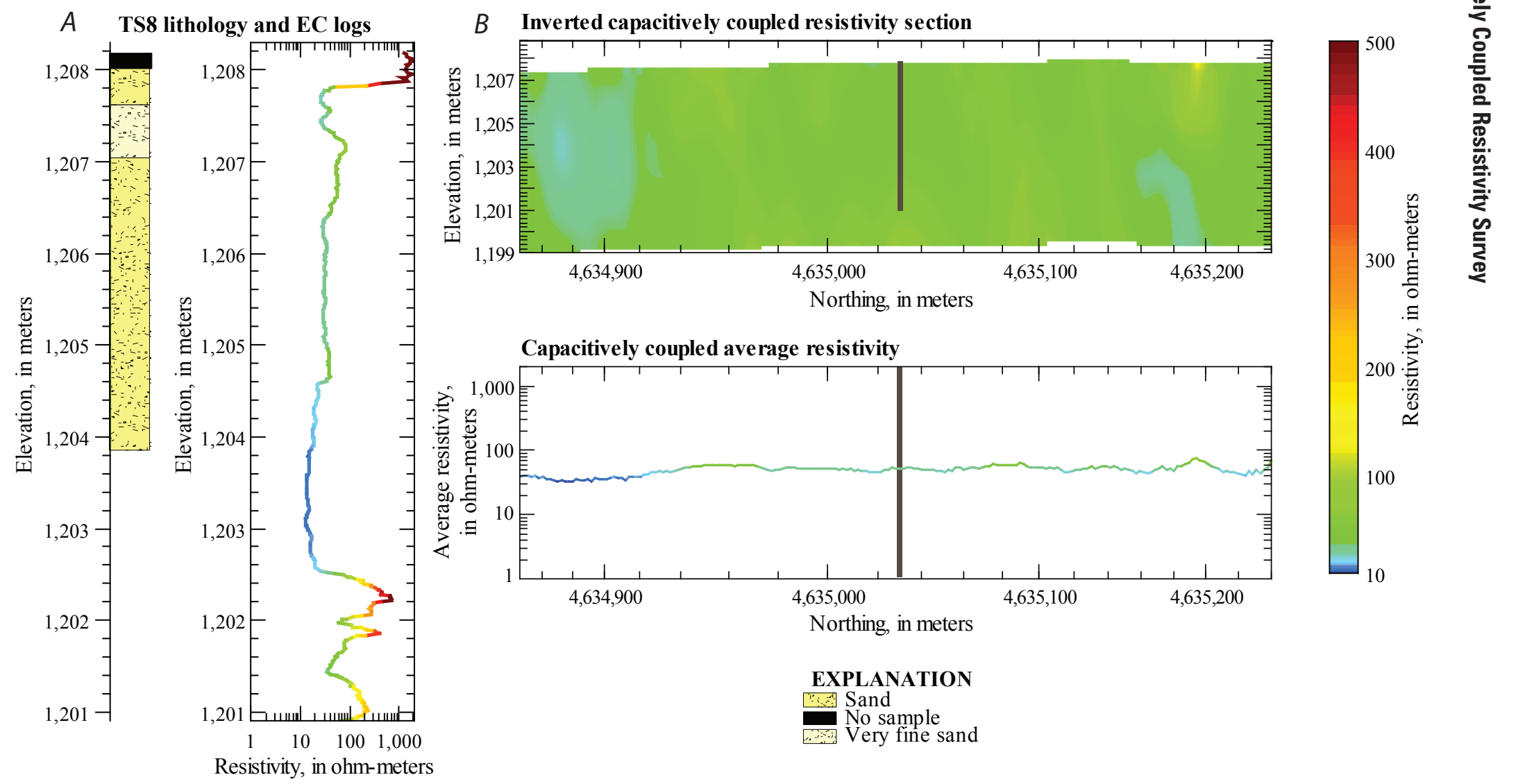

Figure 10. Comparison of (A) lithologic and electrical conductivity log data from test hole TS8 drilled in the bed of Tri-State Canal to (B) an inverted capacitively coupled resistivity section and average resistivity curve. The vertical gray line on the inverted resistivity section and average resistivity curve plots is the location of test hole TS8. 

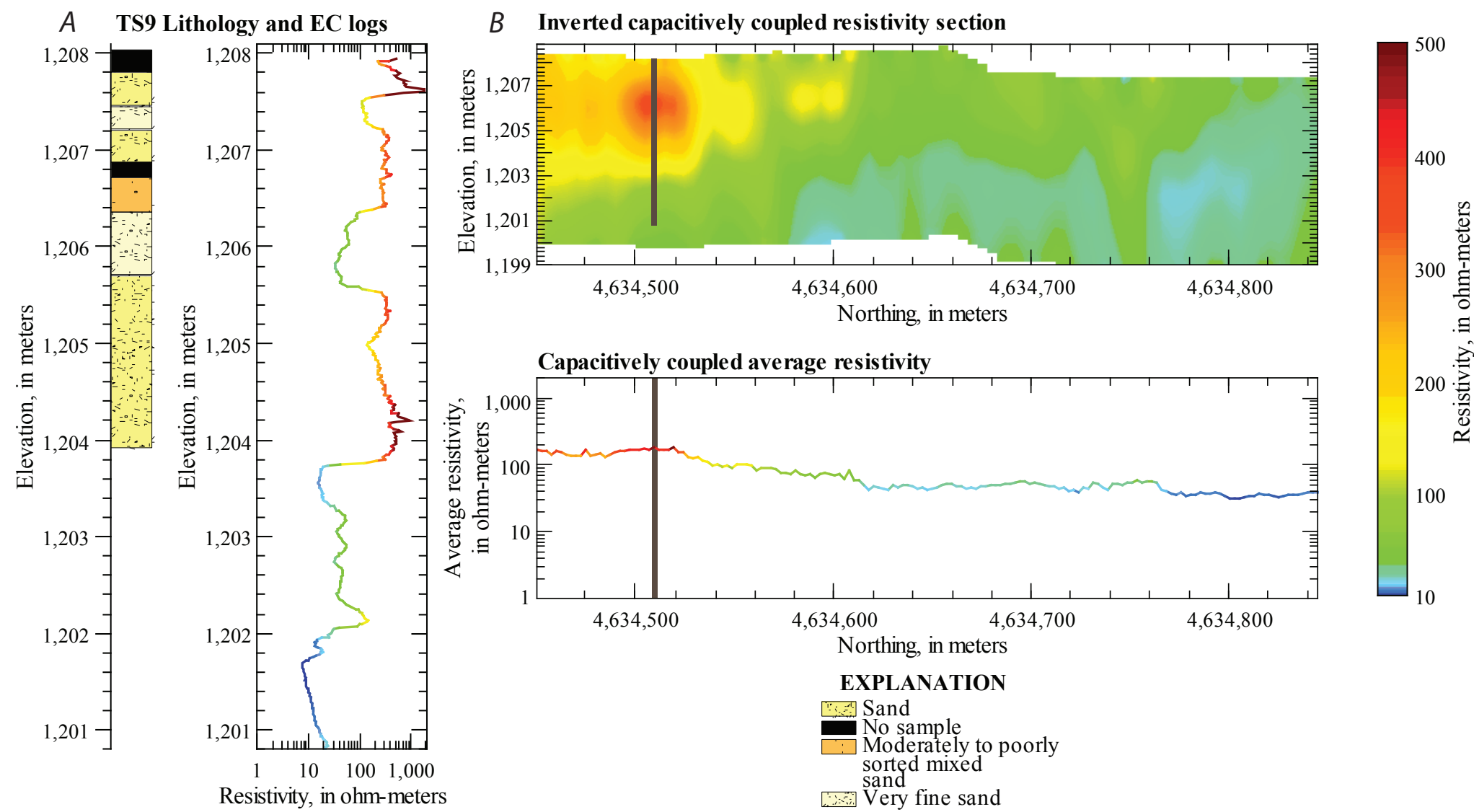

Figure 11. Comparison of $(A)$ lithologic and electrical conductivity log data from test hole TS9 drilled in the bed of Tri-State Canal to (B) an inverted capacitively coupled resistivity section and average resistivity curve. The vertical gray line on the inverted resistivity section and average resistivity curve plots is the location of test hole TS9. 

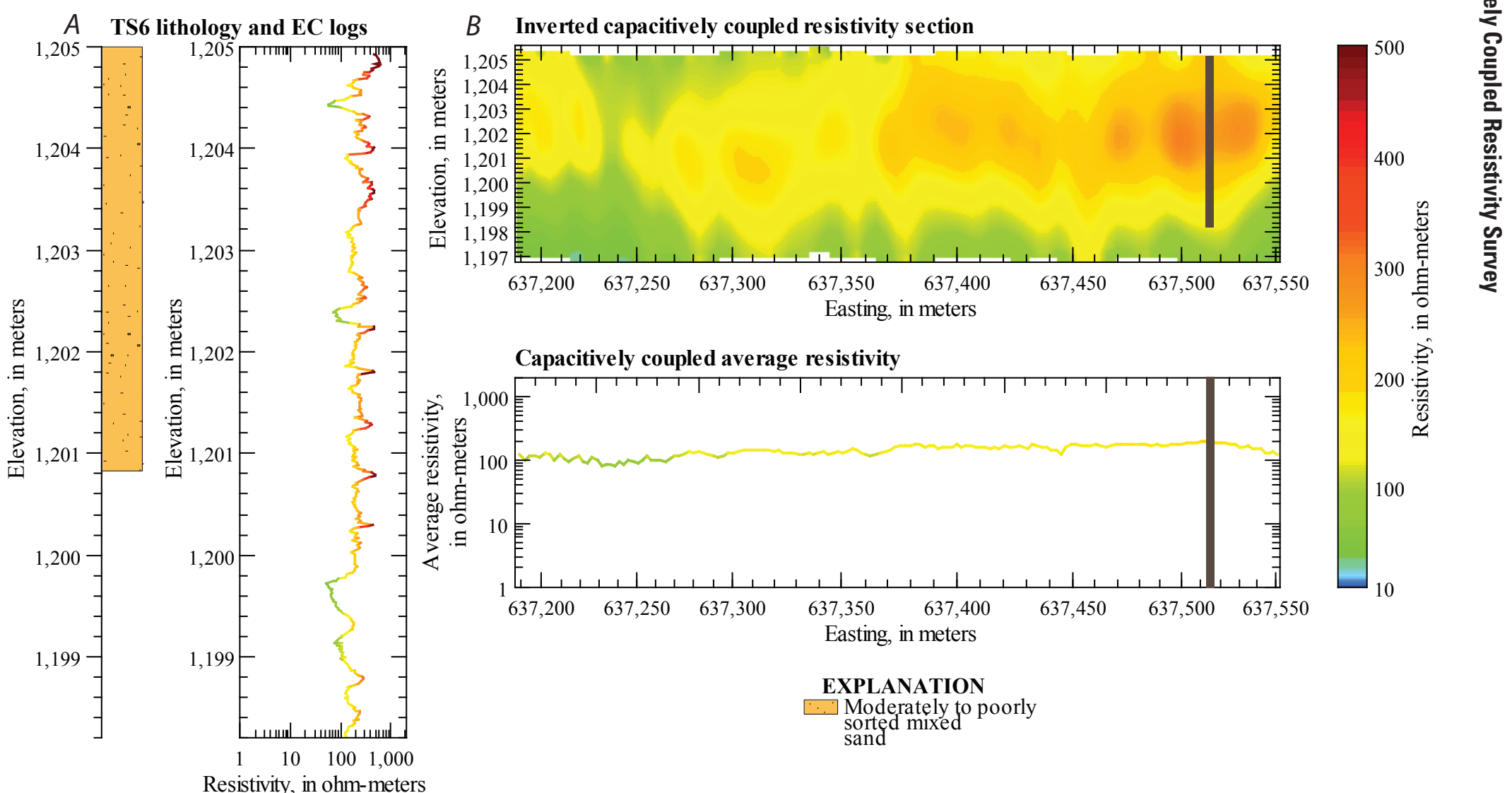

Figure 12. Comparison of $(A)$ lithologic and electrical conductivity log data from test hole TS6 drilled in the bed of Tri-State Canal to $(B)$ an inverted capacitively coupled resistivity section and average resistivity curve. The vertical gray line on the inverted resistivity section and average resistivity curve plots is the location of test hole TS6. 

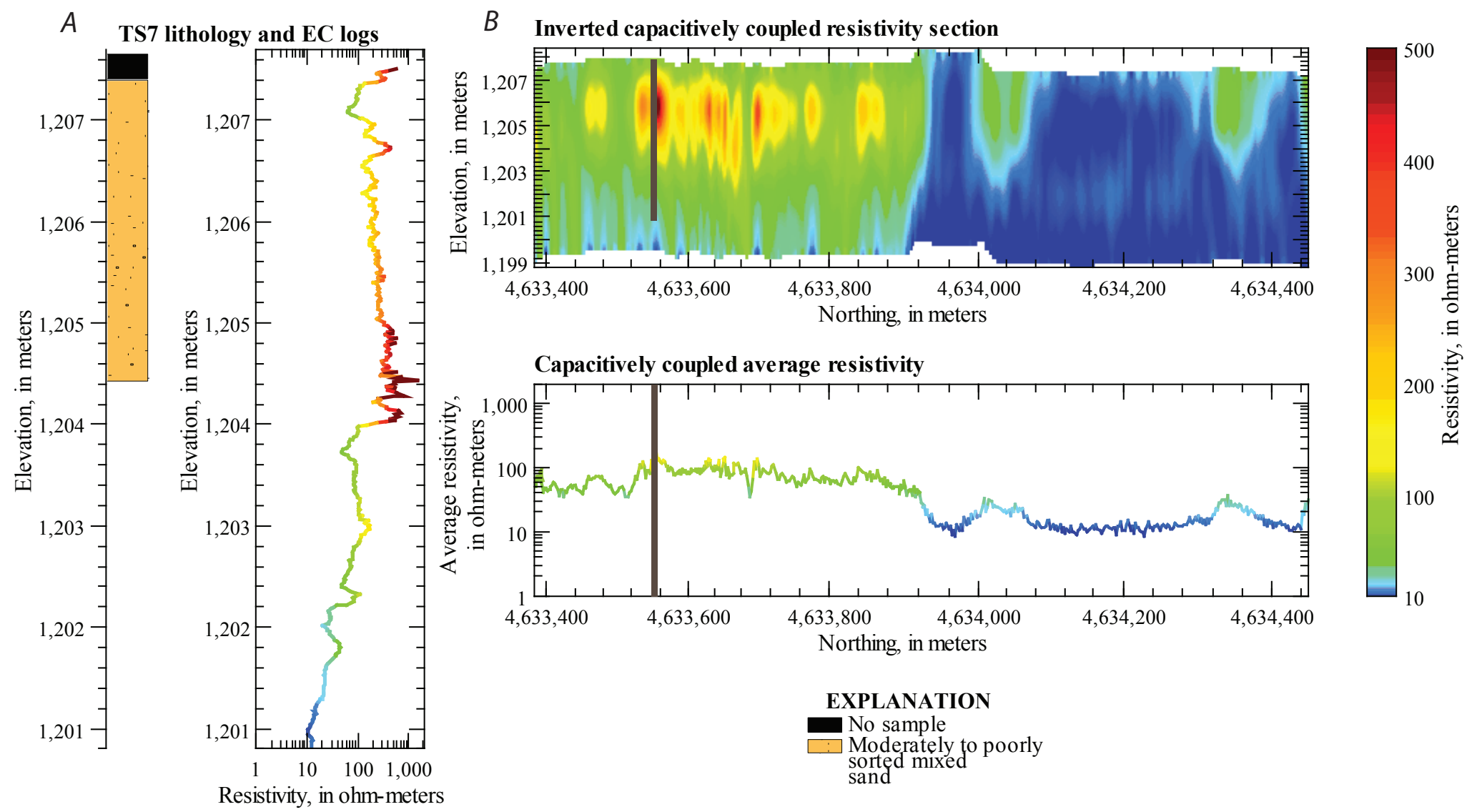

Figure 13. Comparison of (A) lithologic and electrical conductivity log data from test hole TS7 drilled in the bed of Tri-State Canal to $(B)$ an inverted capacitively coupled resistivity section and average resistivity curve. The vertical gray line on the inverted resistivity section and average resistivity curve plots is the location of test hole TS7. 
A NP38 lithology log

$B \quad$ Inverted capacitively coupled resistivity section
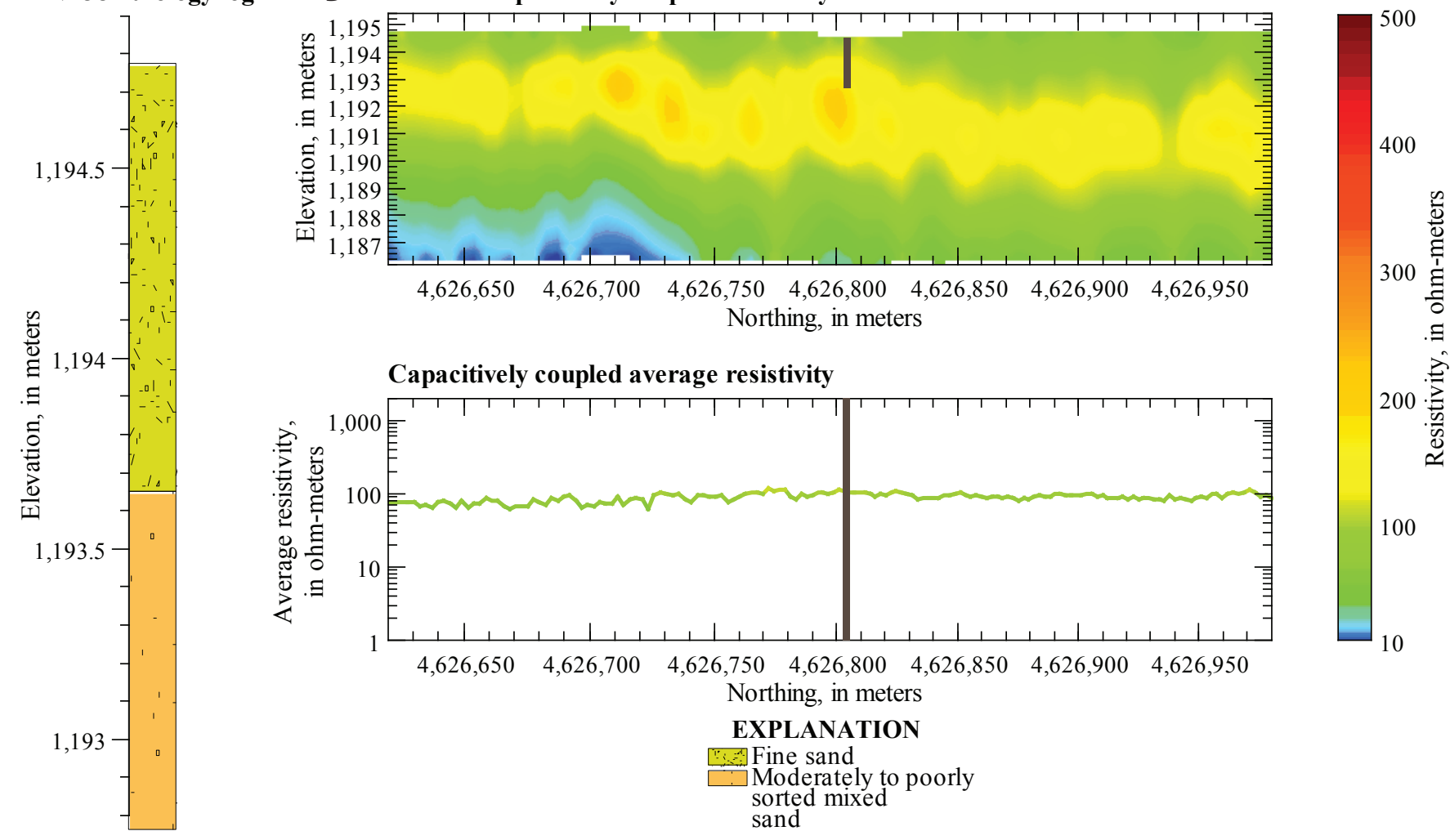

Figure 14. Comparison of $(A)$ lithologic log data from test hole NP38 drilled in the bed of Northport Canal to $(B)$ an inverted capacitively coupled resistivity section and average resistivity curve. The lithology log elevations are approximate because of the use of a handheld GPS unit with a lower vertical resolution than the typical differential GPS unit used for the test hole survey. The vertical gray line on the inverted resistivity section and average resistivity curve plots is the location of test hole NP38. 

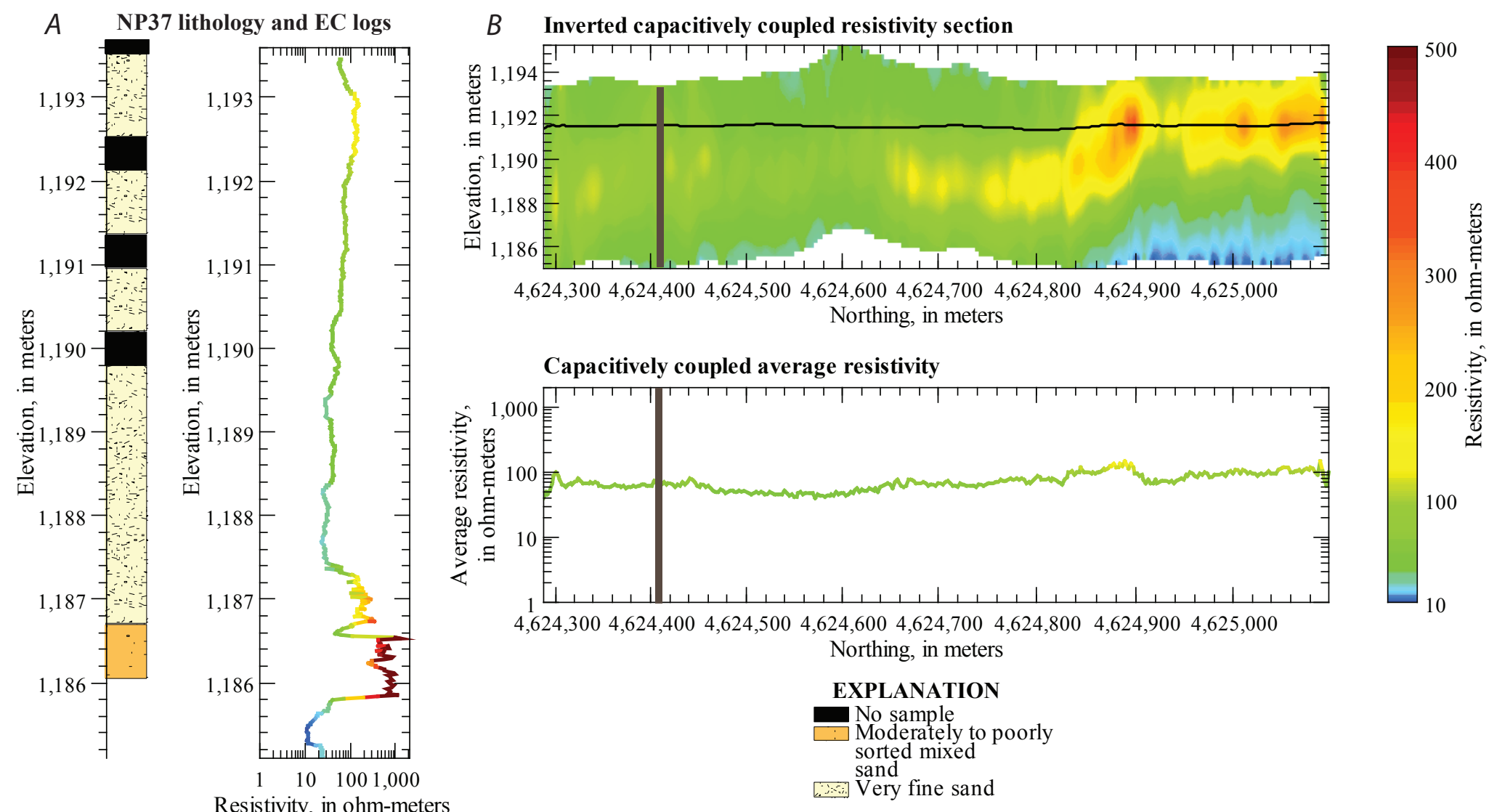

Capacitively coupled average resistivity

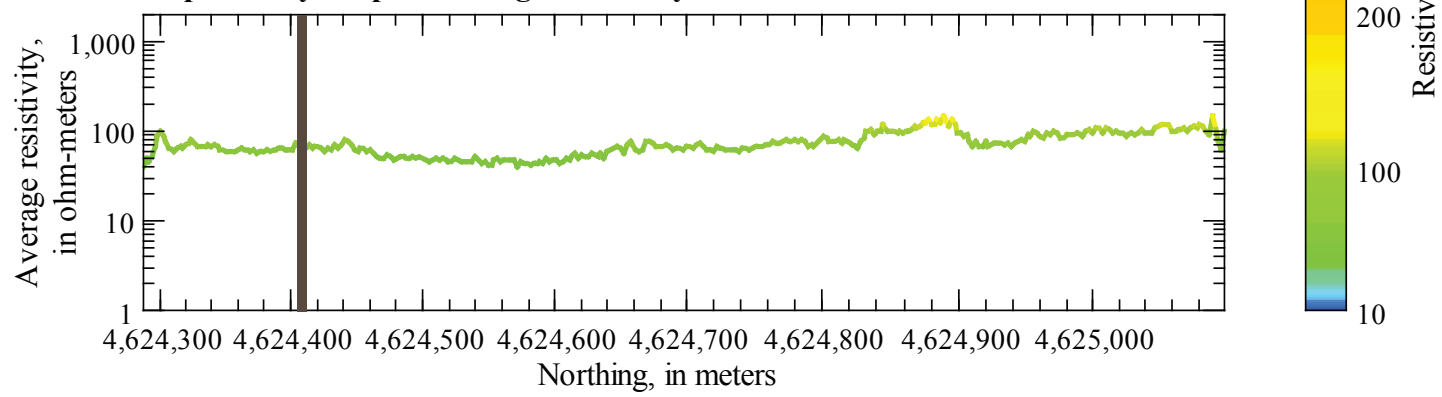

\section{Northing, in meters
No sample
Moderately to poorly sorted \\ Very fine sand}

Resistivity, in ohm-meters

Figure 15. Comparison of ( $A$ ) lithologic and electrical conductivity log data from test hole NP37 drilled along the tow road of Northport Canal to ( $B$ ) an inverted capacitively coupled resistivity section and average resistivity curve. The horizontal black line on the inverted resistivity section is the canal bed elevation, and the vertical gray line on the inverted resistivity section and average resistivity curve plots is the location of test hole NP37. 


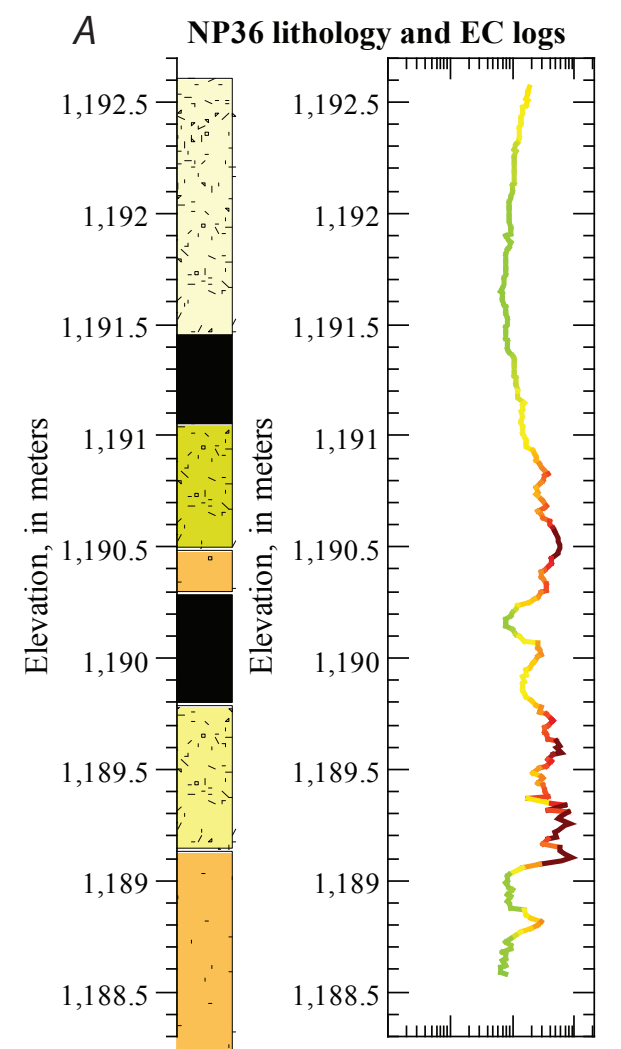

$$
110 \quad 1001,000
$$

Resistivity, in ohm-meters
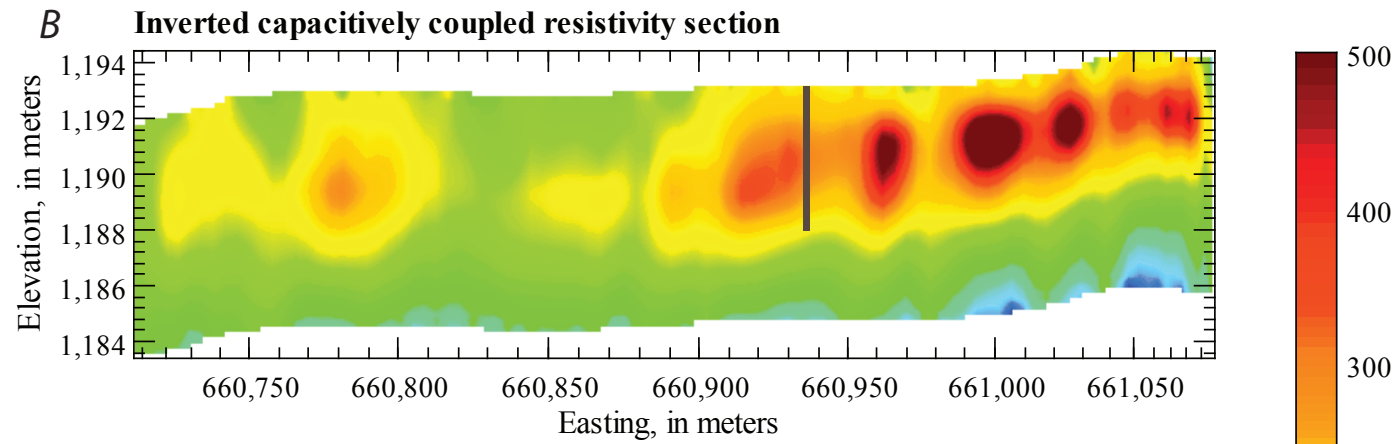

400

300

300 咅

Capacitively coupled average resistivity

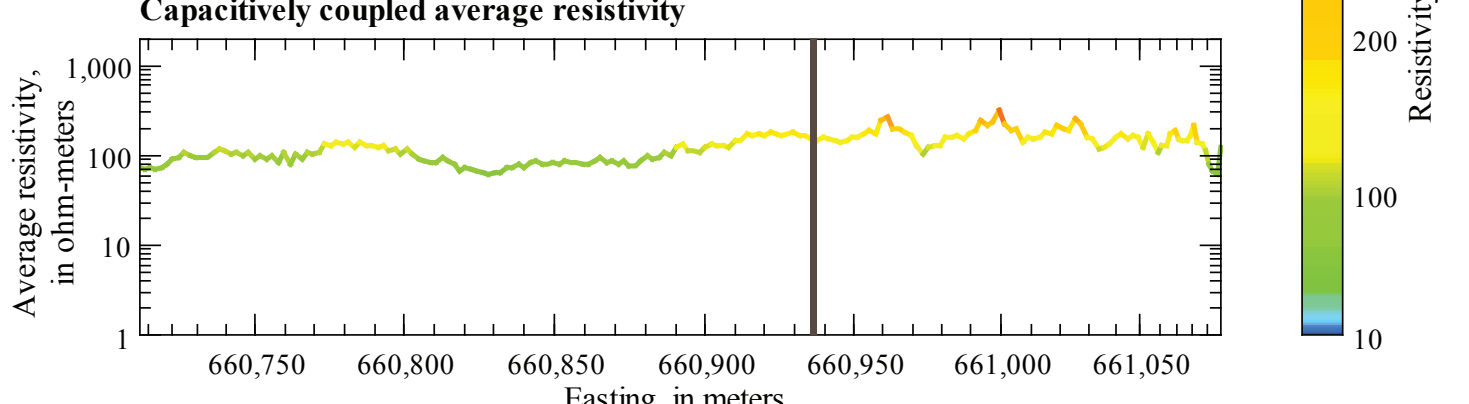

Easting, in meters

\section{EXPLANATION}

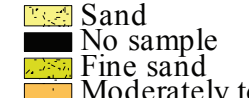

Moderately to poorly

$\rightarrow$ Very fine sand

Figure 16. Comparison of $(A)$ lithologic and electrical conductivity log data from test hole NP36 drilled along the tow road of Northport Canal to (B) an inverted capacitively coupled resistivity section and average resistivity curve. The canal bed elevations for this section are not available. The vertical gray line on the inverted resistivity section and average resistivity curve plots is the location of test hole NP36. 


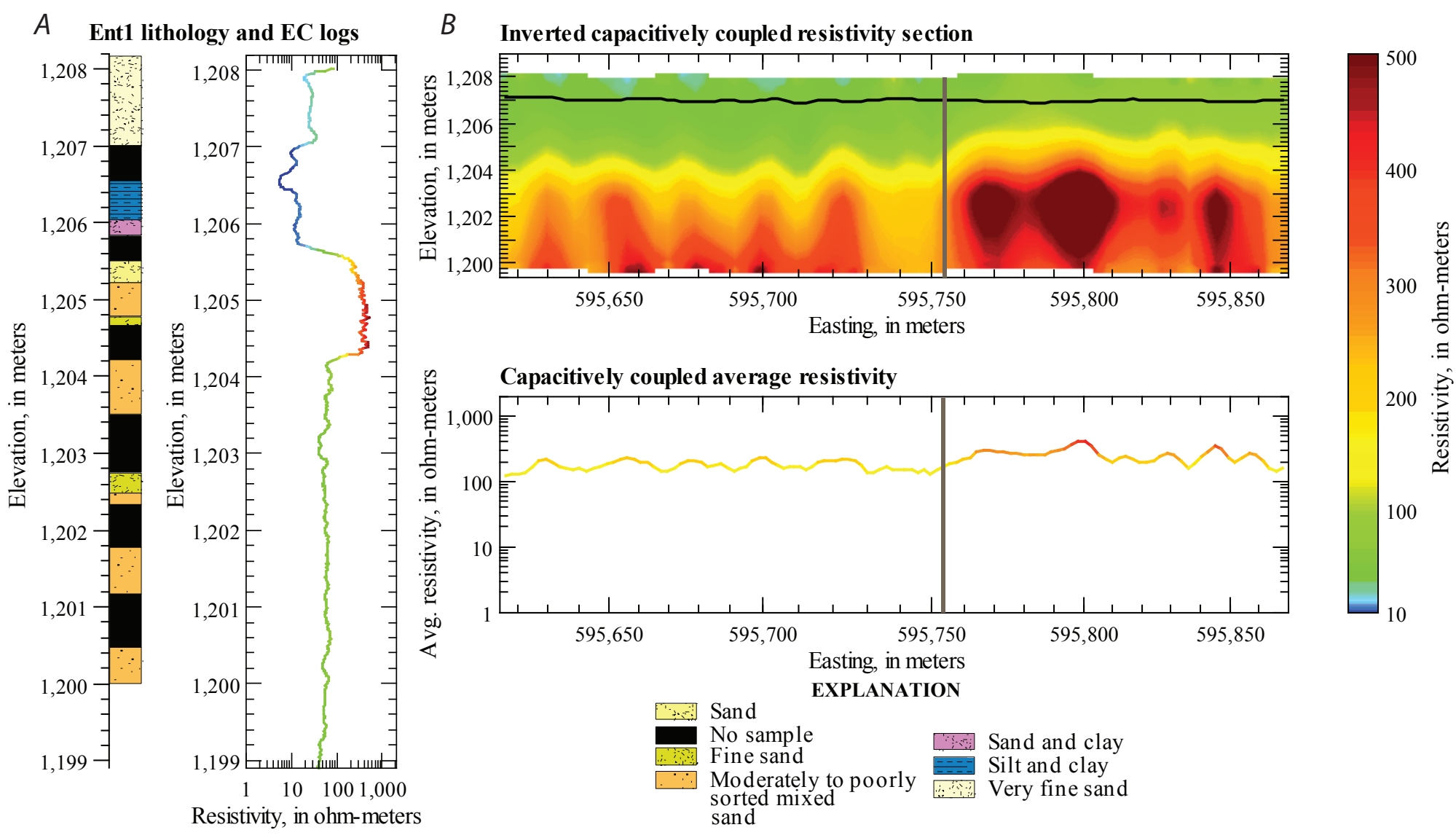

Figure 17. Comparison of (A) lithologic and electrical conductivity log data from test hole Ent1 drilled along the tow road of Enterprise Canal to $(B)$ an inverted capacitively coupled resistivity section and average resistivity curve. The horizontal black line on the inverted resistivity section is the canal bed elevation, and the vertical gray line on the inverted resistivity section and average resistivity curve plots is the location of test hole Ent1. 

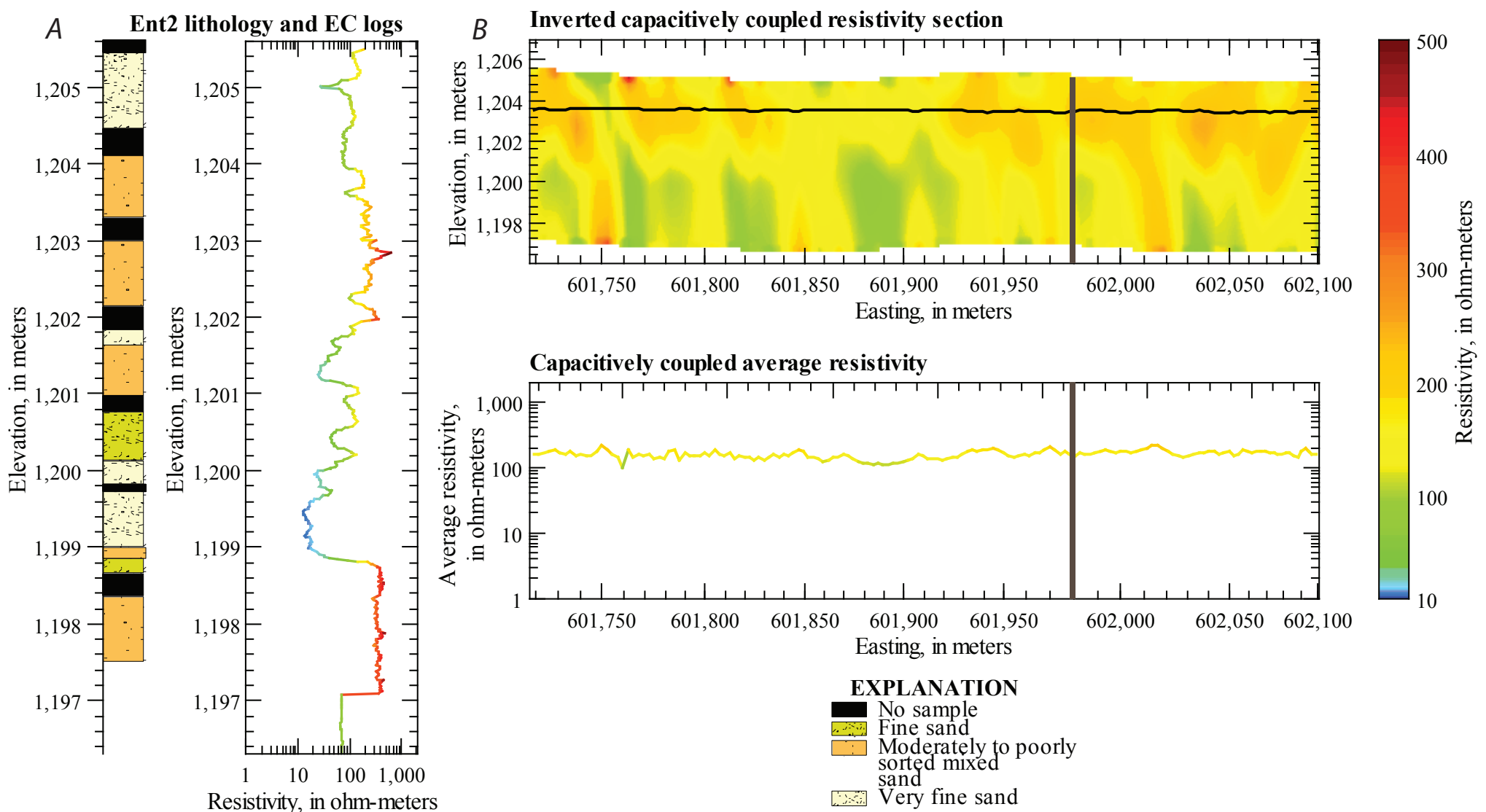

Capacitively coupled average resis tivity

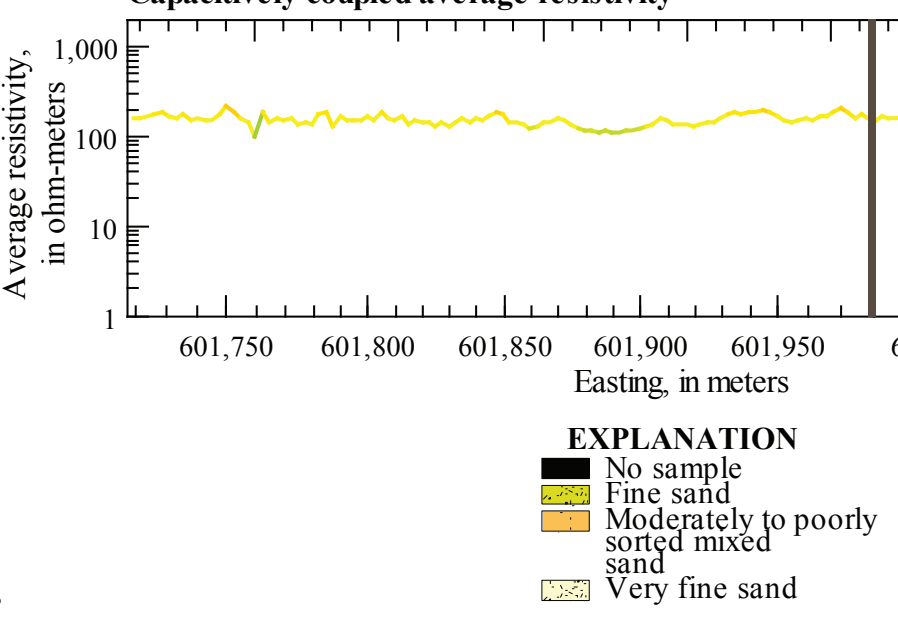

Figure 18. Comparison of ( $A$ ) lithologic and electrical conductivity log data from test hole Ent2 drilled along the tow road of Enterprise Canal to $(B)$ an inverted capacitively coupled resistivity section and average resistivity curve. The horizontal black line on the inverted resistivity section is the canal bed elevation, and the vertical gray line on the inverted resistivity section and average resistivity curve plots is the location of test hole Ent2. 

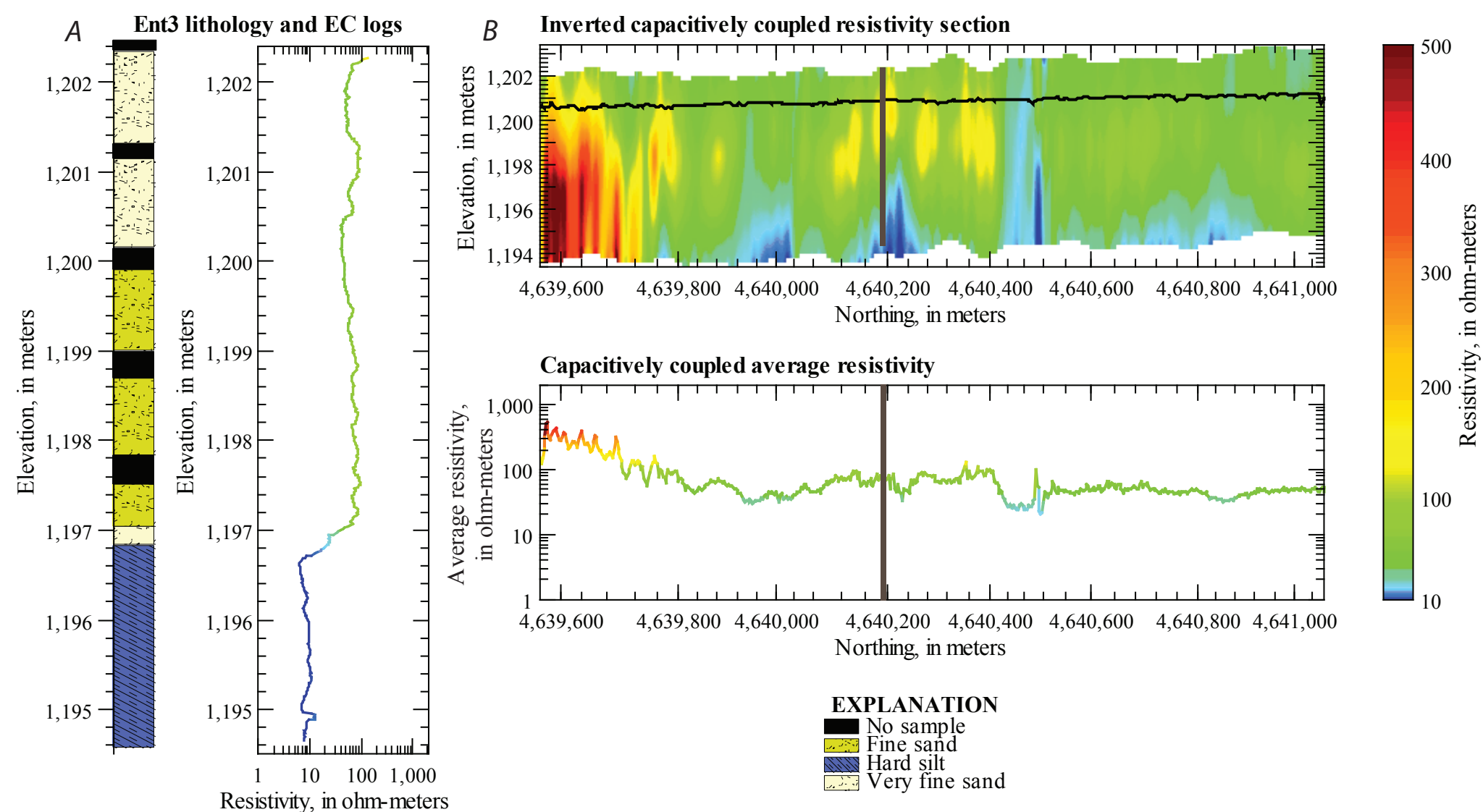

Figure 19. Comparison of $(A)$ lithologic and electrical conductivity log data from test hole Ent3 drilled along the tow road of Enterprise Canal to ( $B$ ) an inverted capacitively coupled resistivity section and average resistivity curve. The horizontal black line on the inverted resistivity section is the canal bed elevation, and the vertical gray line on the inverted resistivity section and average resistivity curve plots is the location of test hole Ent3. 

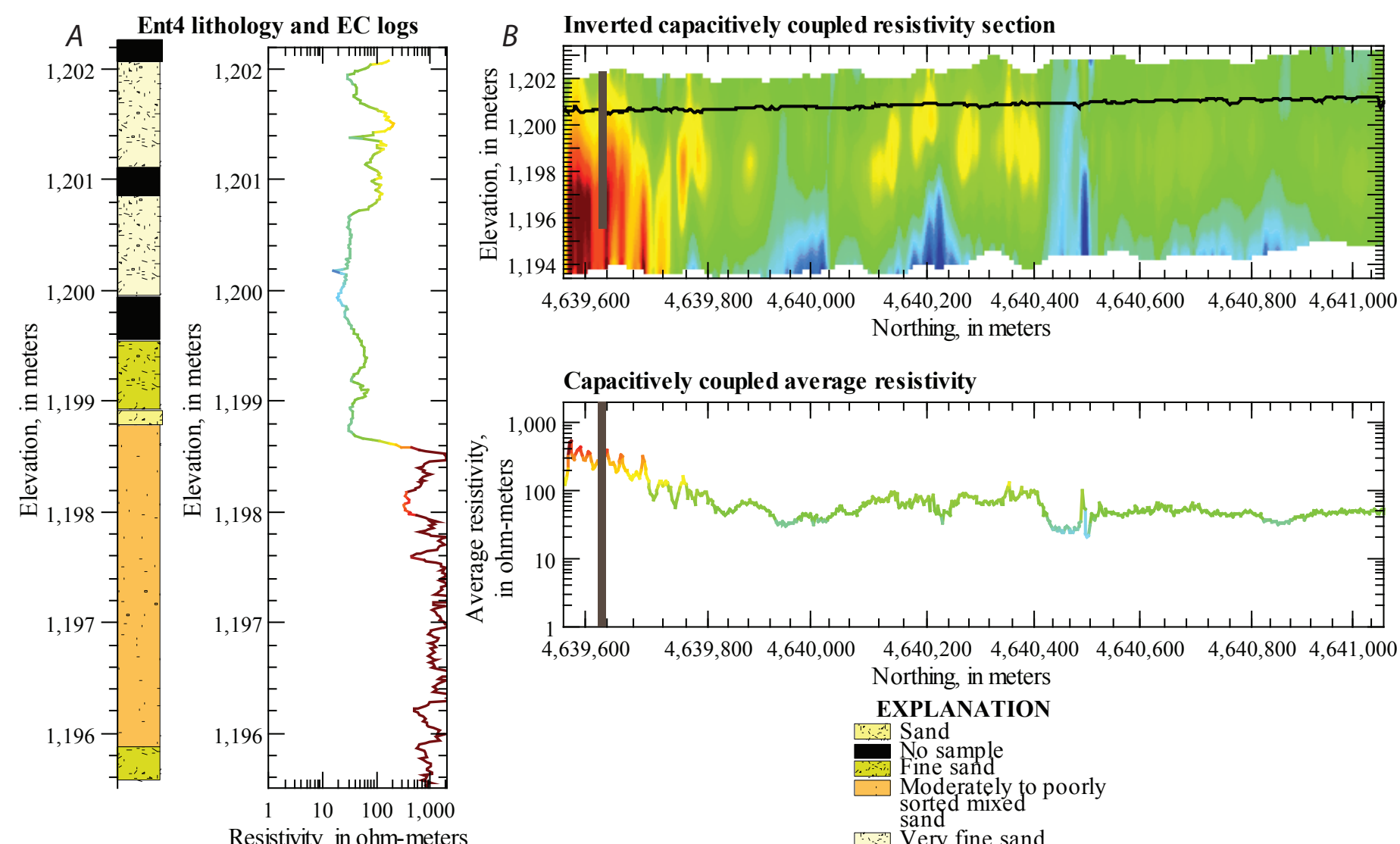

Capacitively coupled average resis tivity

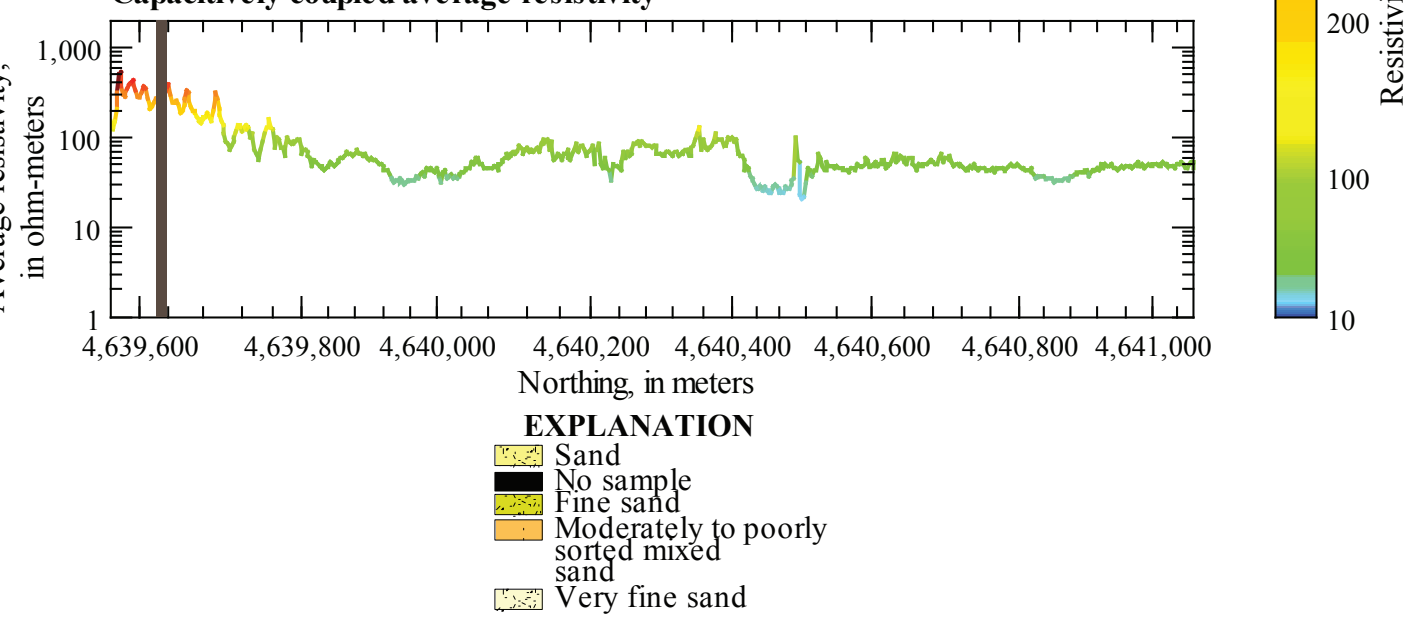

Figure 20. Comparison of $(A)$ lithologic and electrical conductivity log data from test hole Ent4 drilled along the tow road of Enterprise Canal to ( $B$ ) an inverted capacitively coupled resistivity section and average resistivity curve. The horizontal black line on the inverted resistivity section is the canal bed elevation, and the vertical gray line on the inverted resistivity section and average resistivity curve plots is the location of test hole Ent4. 

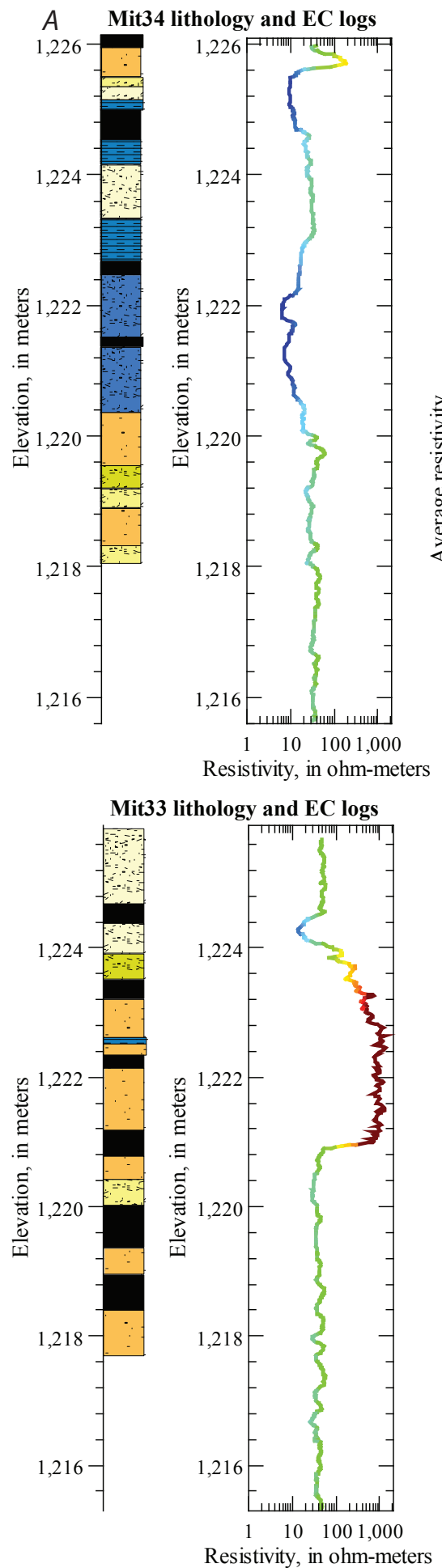

$B$ Inverted capacitively coupled resistivity section

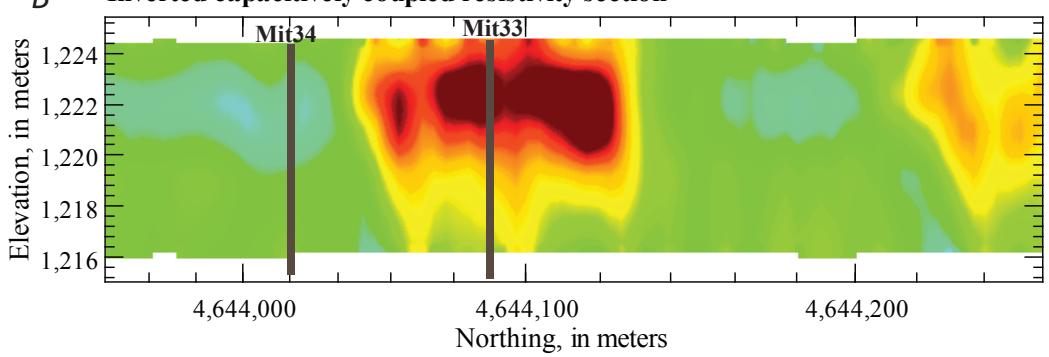

Capacitively coupled average resistivity

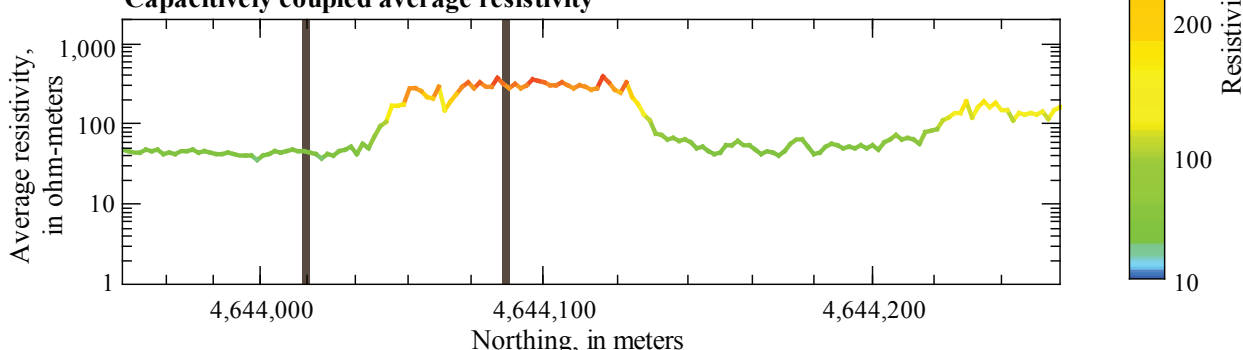

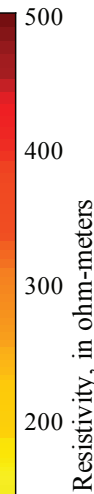

0

EXPLANATION

Sand

No sample

Moderately to poorly

sorted mixed

sand

Sand and clay

Silt and clay

Vilt and clay

Figure 21. Comparison of $(A)$ lithologic and electrical conductivity log data from test holes Mit33 and Mit34 drilled along the tow road of Mitchell Canal to $(B)$ an inverted capacitively coupled resistivity section and average resistivity curve. The capacitively coupled resistivity data in this section were acquired along the canal bed, but test holes were drilled from the tow road because steep canal walls in this area prevented access. The vertical gray lines on the inverted resistivity section and average resistivity curve plots are the locations of test holes Mit33 and Mit34. 


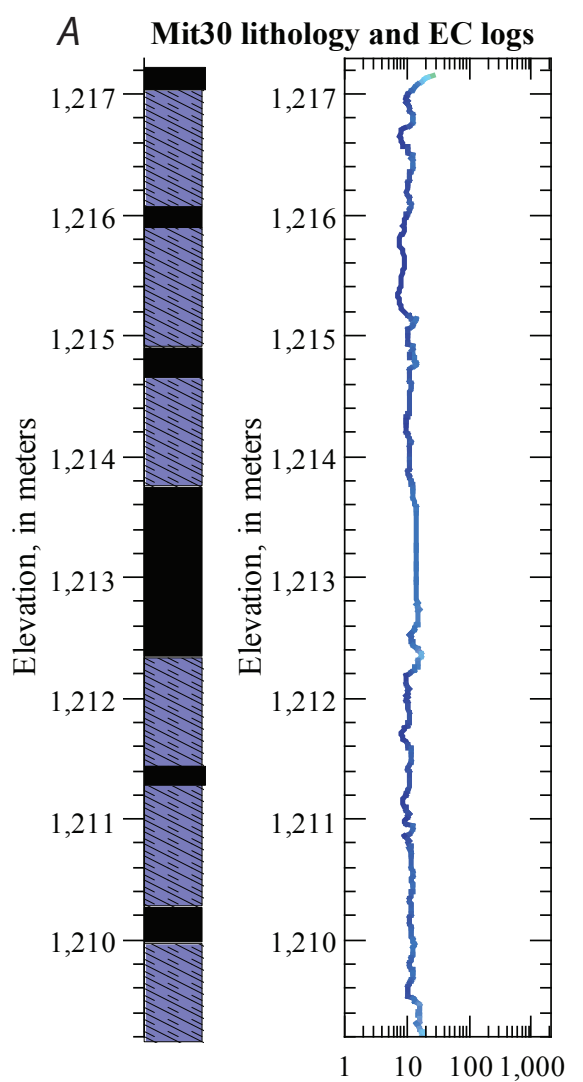

$B \quad$ Inverted capacitively coupled resistivity section
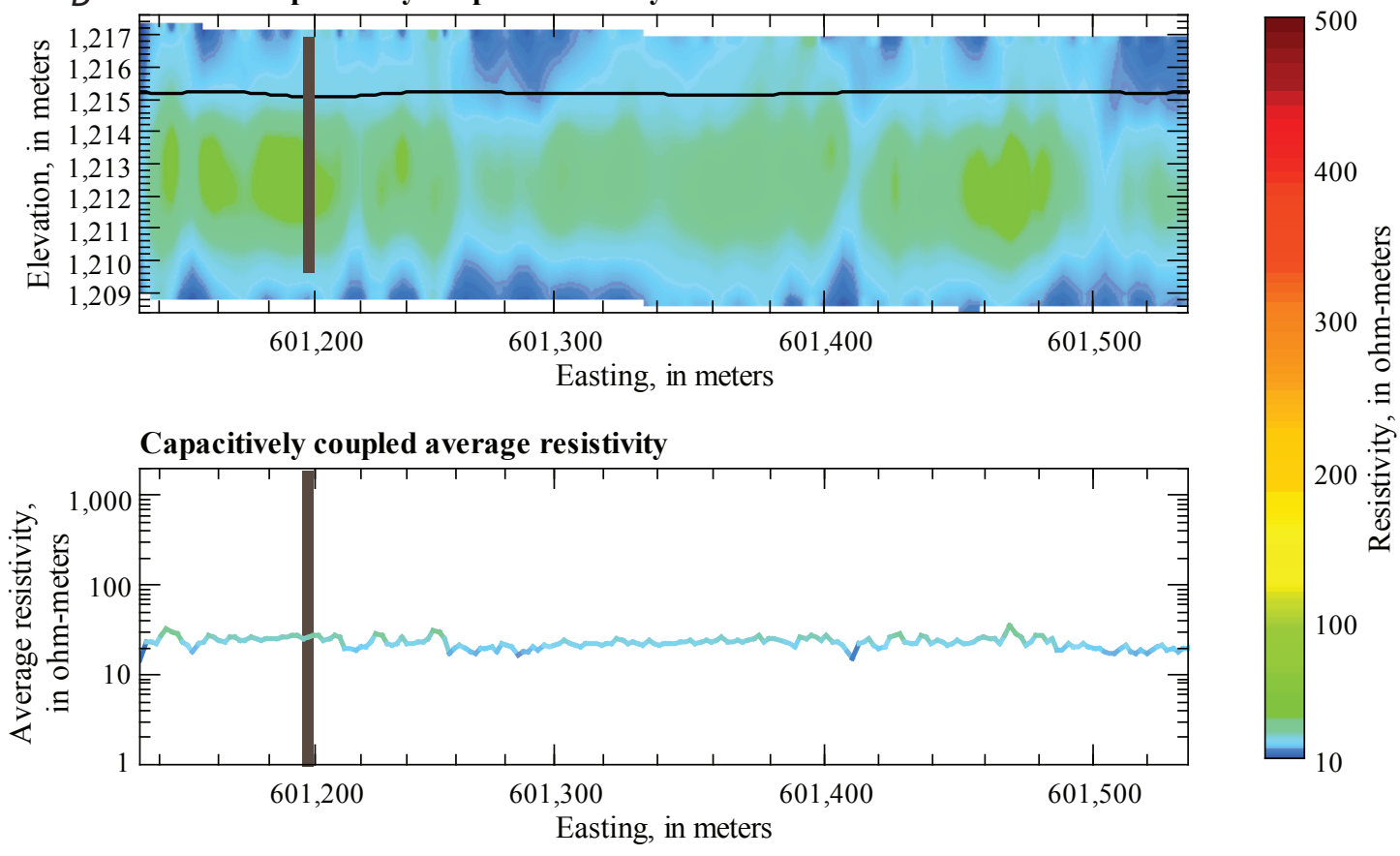

Resistivity, in ohm-meters

Figure 22. Comparison of $(A)$ lithologic and electrical conductivity log data from test hole Mit30 drilled along the tow road of Mitchell Canal to $(B)$ an inverted capacitively coupled resistivity section and average resistivity curve. The horizontal black line on the inverted resistivity section is the canal bed elevation, and the vertical gray line on the inverted resistivity section and average resistivity curve plots is the location of test hole Mit30. 


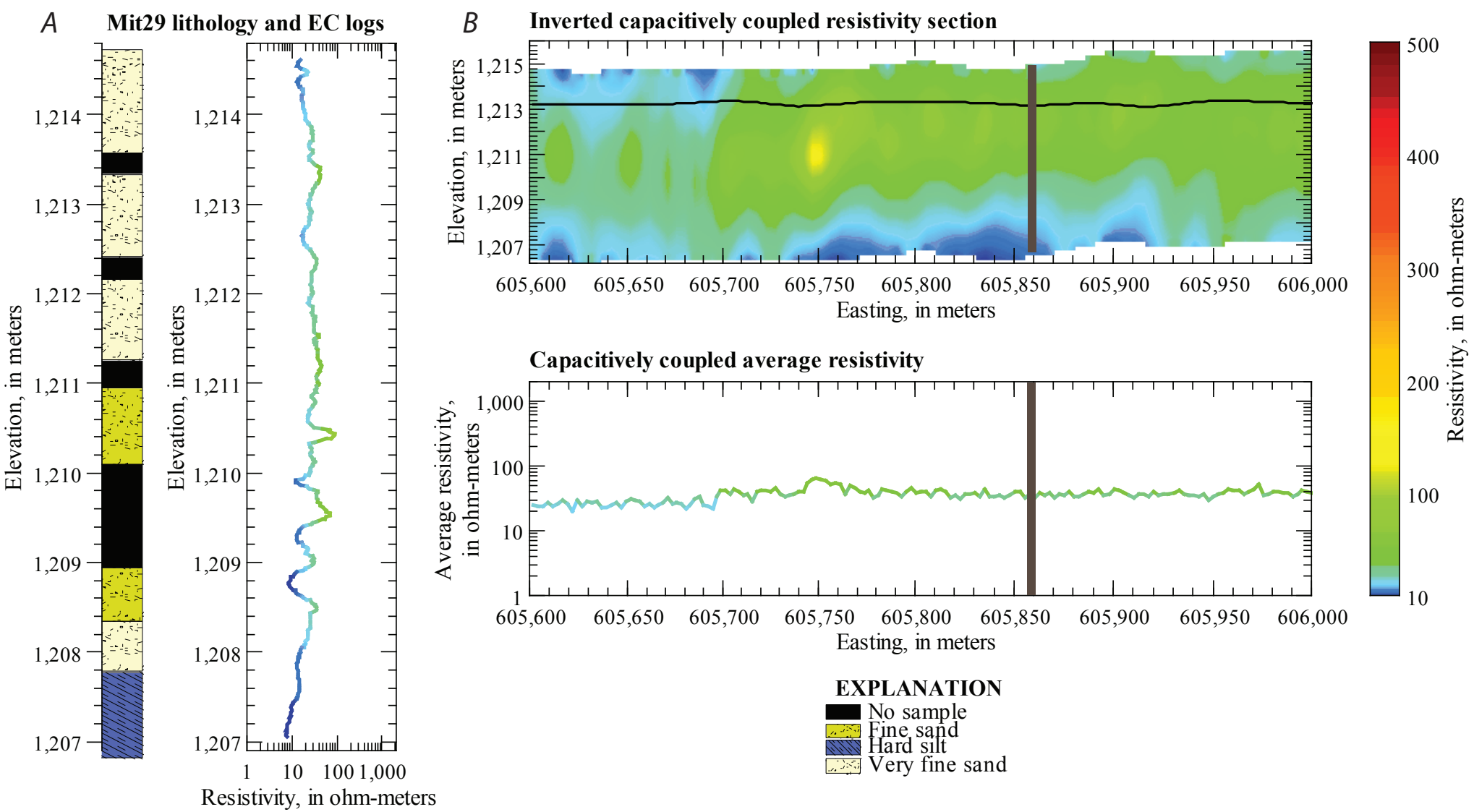

Figure 23. Comparison of $(A)$ lithologic and electrical conductivity log data from test hole Mit29 drilled along the tow road of Mitchell Canal to $(B)$ an inverted capacitively coupled resistivity section and average resistivity curve. The horizontal black line on the inverted resistivity section is the canal bed elevation, and the vertical gray line on the inverted resistivity section and average resistivity curve plots is the location of test hole Mit29. 
A Mit35 lithology and EC logs

$B \quad$ Inverted capacitively coupled resistivity section
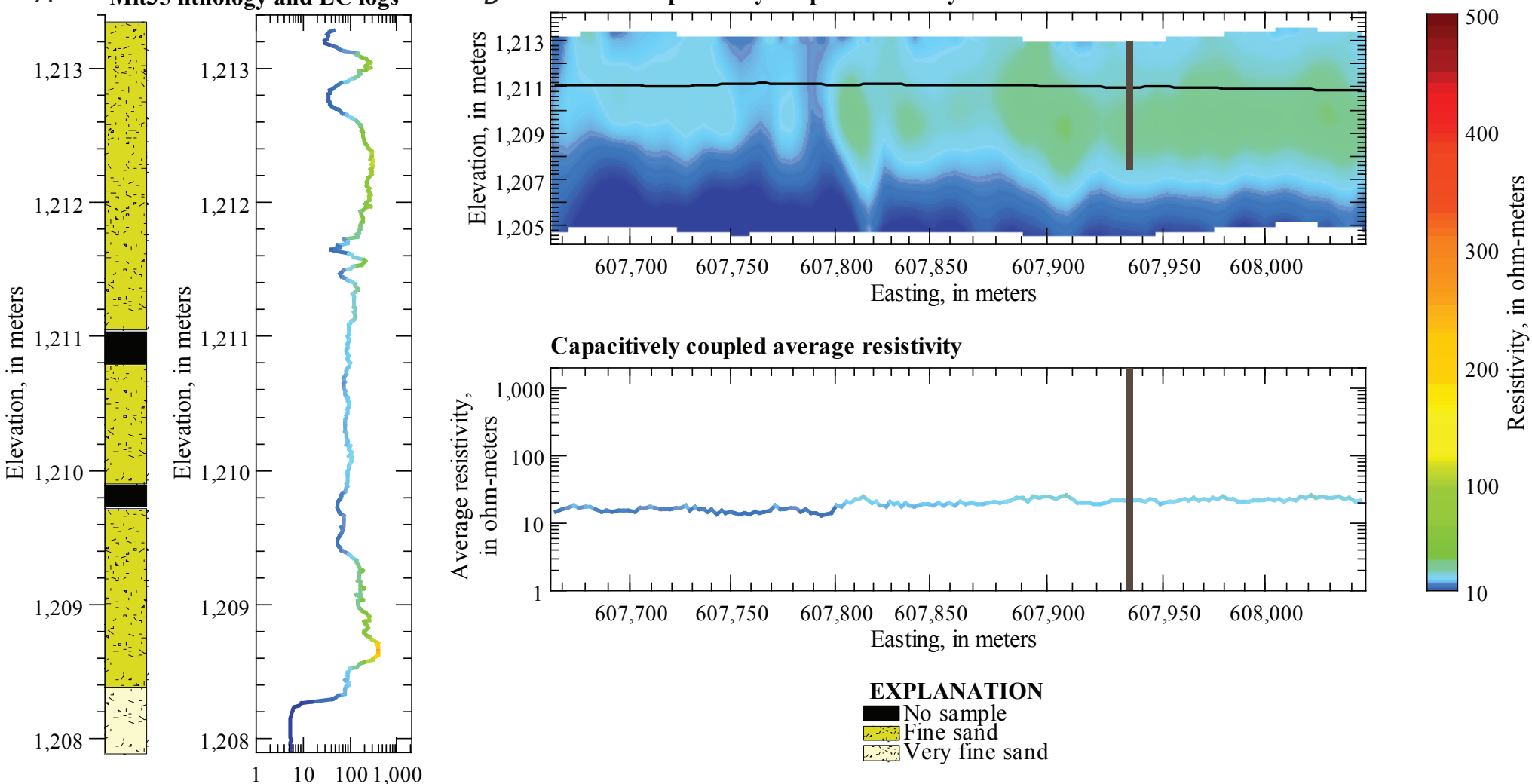

Resistivity, in ohm-meters

Figure 24. Comparison of $(A)$ lithologic and electrical conductivity log data from test hole Mit35 drilled along the tow road of Mitchell Canal to $(B)$ an inverted capacitively coupled resistivity section and average resistivity curve. The horizontal black line on the inverted resistivity section is the canal bed elevation, and the vertical gray line on the inverted resistivity section and average resistivity curve plots is the location of test hole Mit35. 


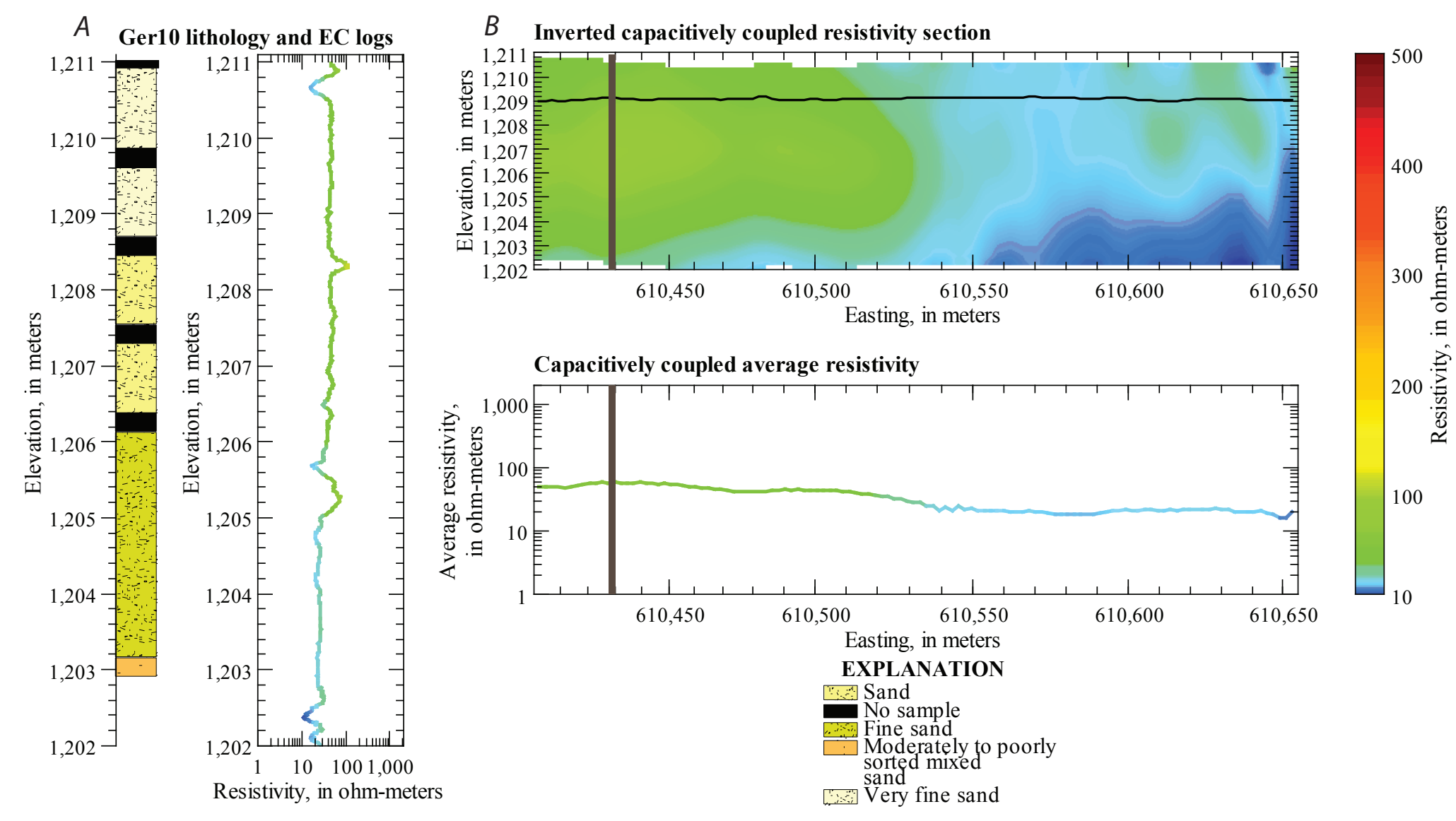

Figure 25. Comparison of $(A)$ lithologic and electrical conductivity log data from test hole Ger10 drilled along the tow road of Gering Canal to $(B)$ an inverted capacitively coupled resistivity section and average resistivity curve. The horizontal black line on the inverted resistivity section is the canal bed elevation, and the vertical gray line on the inverted resistivity section and average resistivity curve plots is the location of test hole Ger10. 

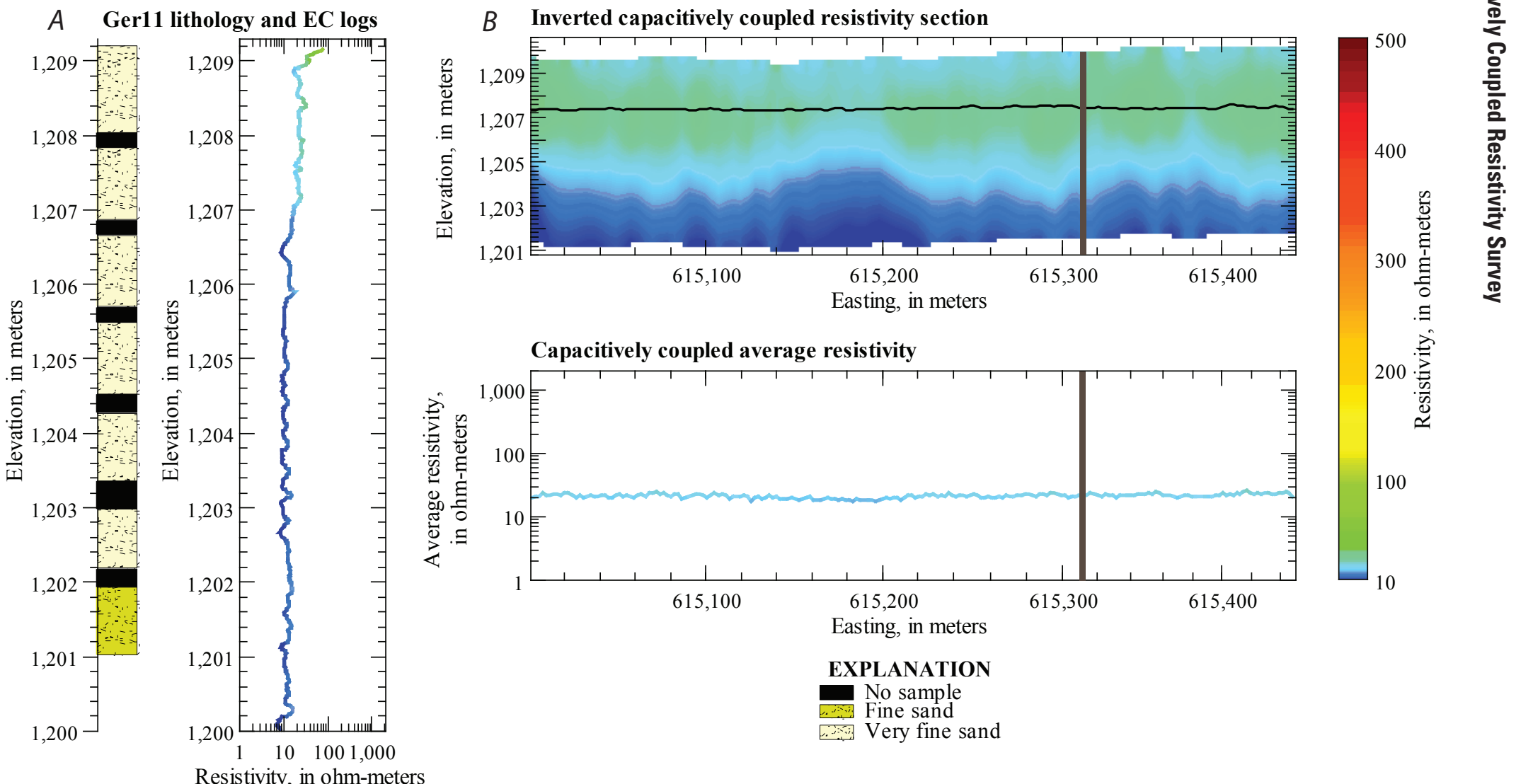

Figure 26. Comparison of (A) lithologic and electrical conductivity log data from test hole Ger11 drilled along the tow road of Gering Canal to $(B)$ an inverted capacitively coupled resistivity section and average resistivity curve. The horizontal black line on the inverted resistivity section is the canal bed elevation, and the vertical gray line on the inverted resistivity section and average resistivity curve plots is the location of test hole Ger11. 

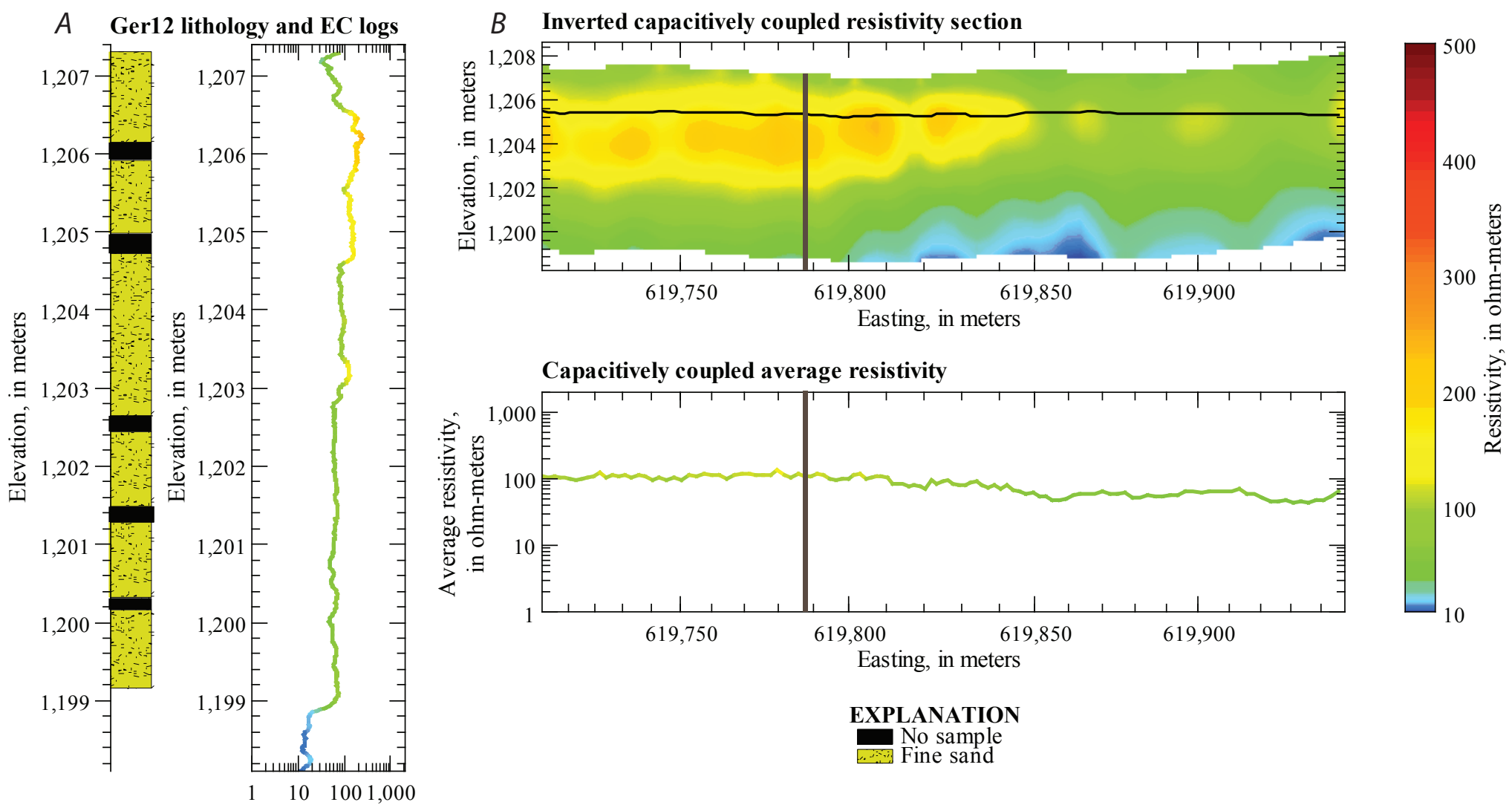

Resistivity, in ohm-meters

Figure 27. Comparison of $(A)$ lithologic and electrical conductivity log data from test hole Ger12 drilled along the tow road of Gering Canal to (B) an inverted capacitively coupled resistivity section and average resistivity curve. The horizontal black line on the inverted resistivity section is the canal bed elevation, and the vertical gray line on the inverted resistivity section and average resistivity curve plots is the location of test hole Ger12.

\section{EXPLANATION}

No sample 

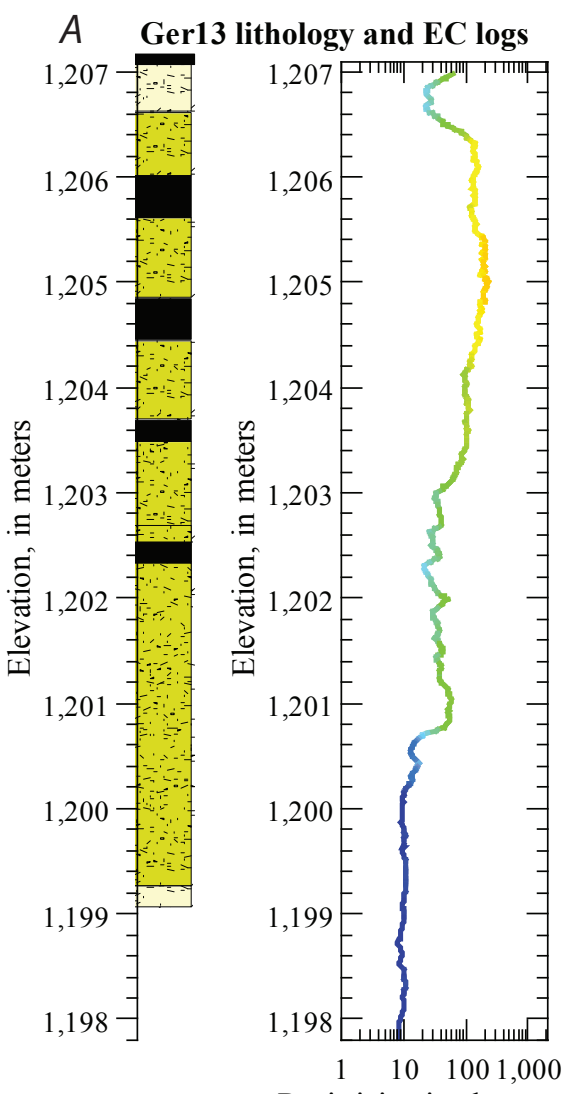

$B$ Inverted capacitively coupled resistivity section
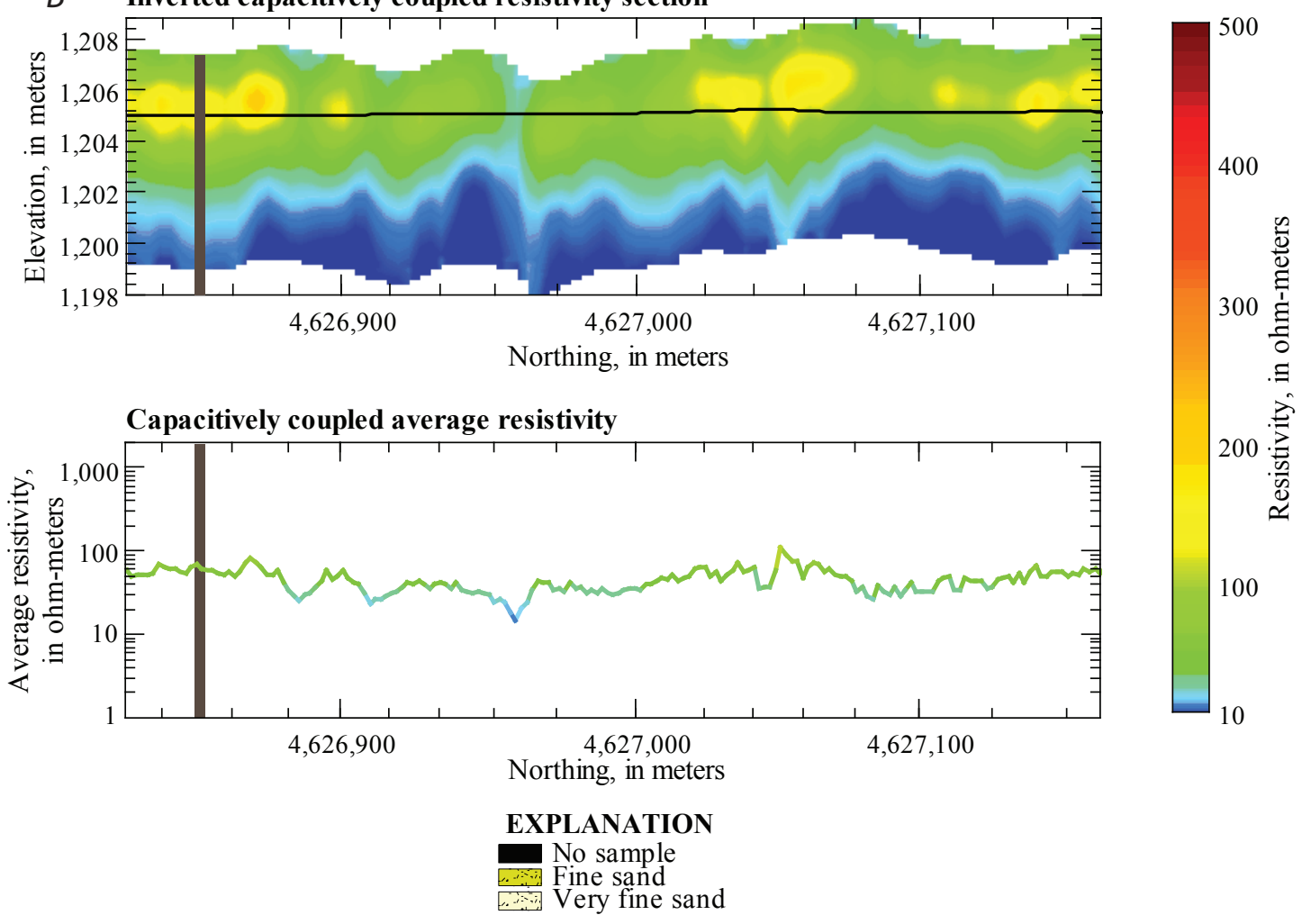

Resistivity, in ohm-meters

Figure 28. Comparison of ( $A$ ) lithologic and electrical conductivity log data from test hole Ger13 drilled along the tow road of Gering Canal to (B) an inverted capacitively coupled resistivity section and average resistivity curve. The horizontal black line on the inverted resistivity section is the canal bed elevation, and the vertical gray line on the inverted resistivity section and average resistivity curve plots is the location of test hole Ger13. 

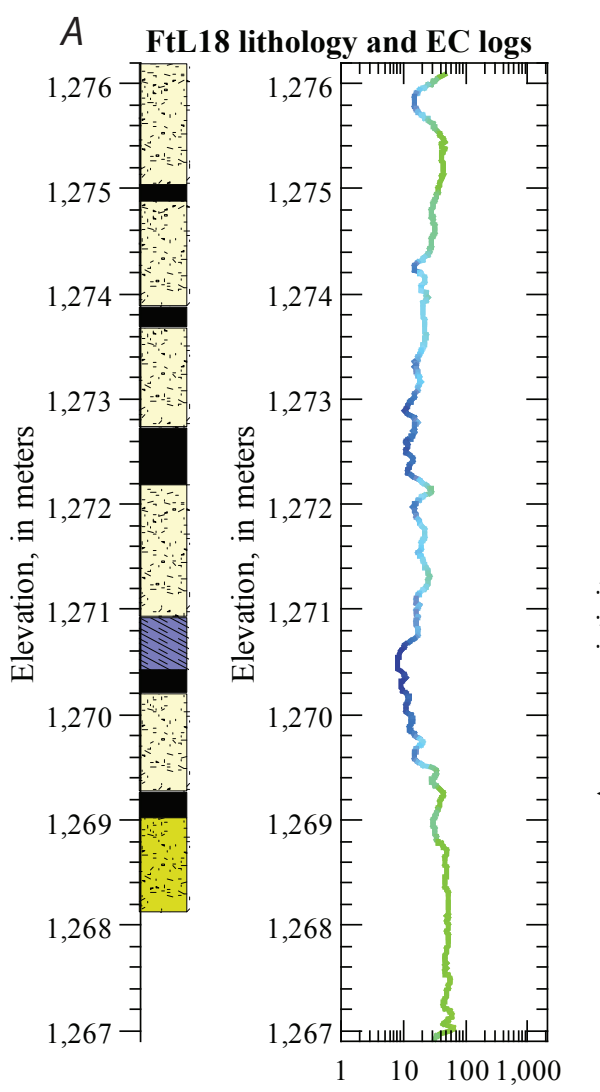

$B \quad$ Inverted capacitively coupled resistivity section
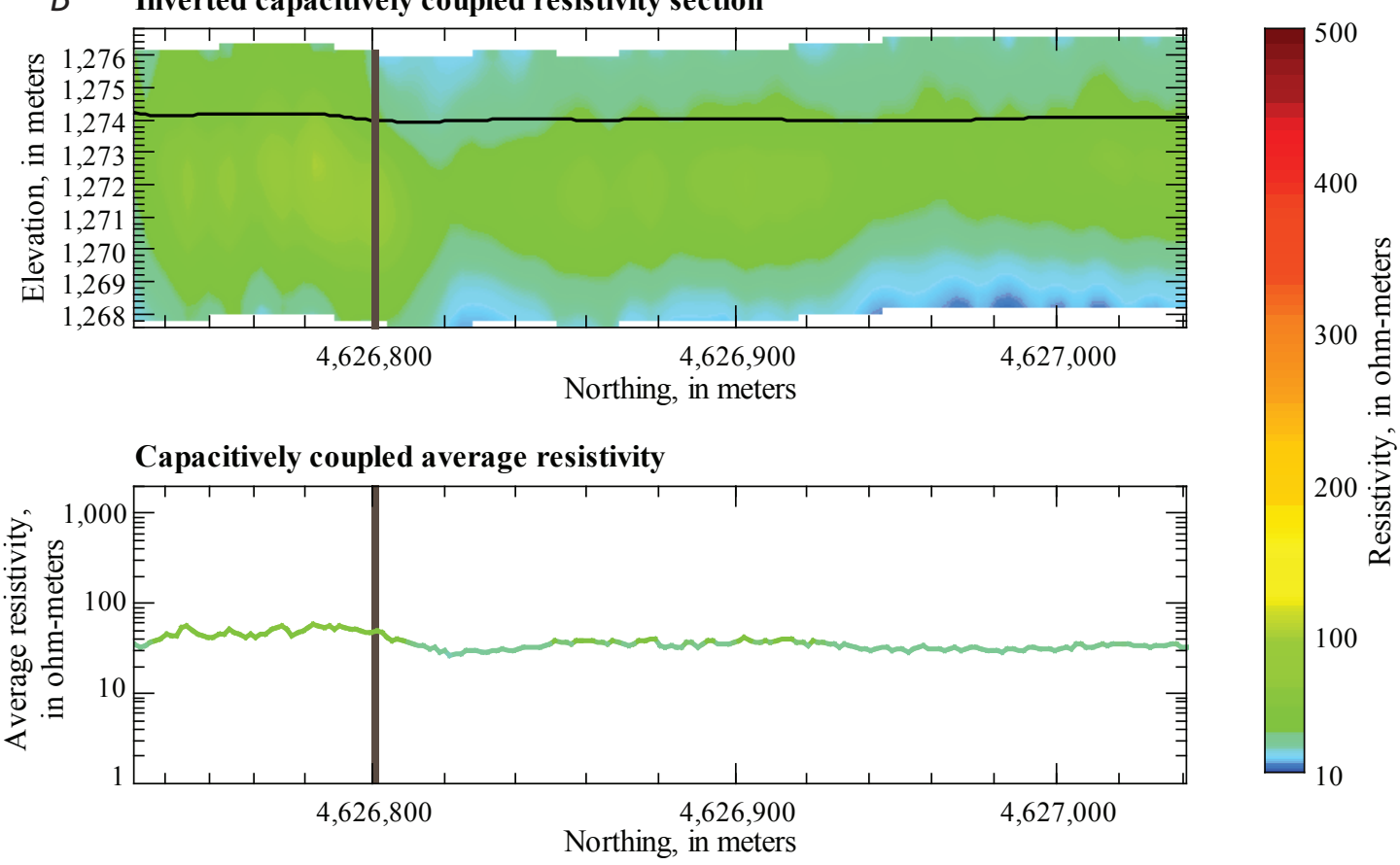

Resistivity, in ohm-meters

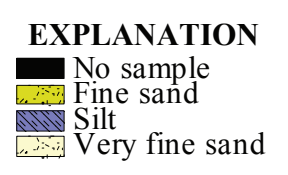

Figure 29. Comparison of $(A)$ lithologic and electrical conductivity log data from test hole FtL18 drilled along the tow road of Fort Laramie Canal to ( $B$ ) an inverted capacitively coupled resistivity section and average resistivity curve. The horizontal black line on the inverted resistivity section is the canal bed elevation, and the vertical gray line on the inverted resistivity section and average resistivity curve plots is the location of test hole FtL18. 


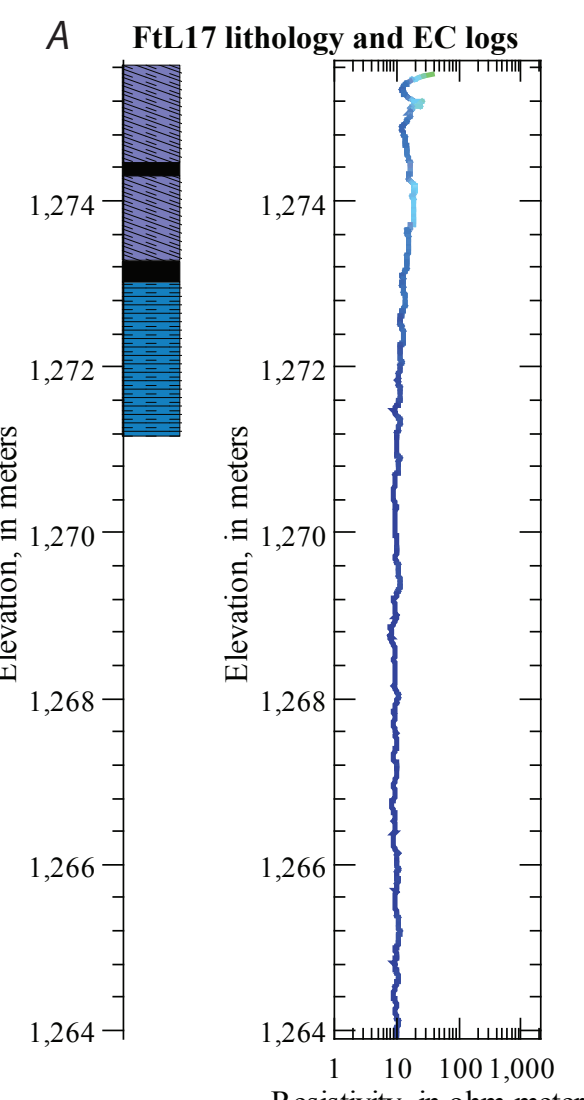

$B \quad$ Inverted capacitively coupled resistivity section

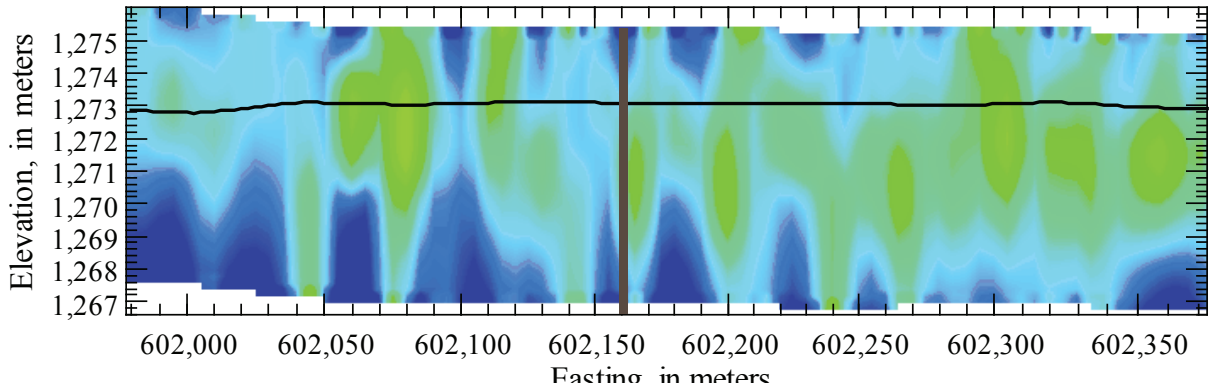

Resistivity, in ohm-meters

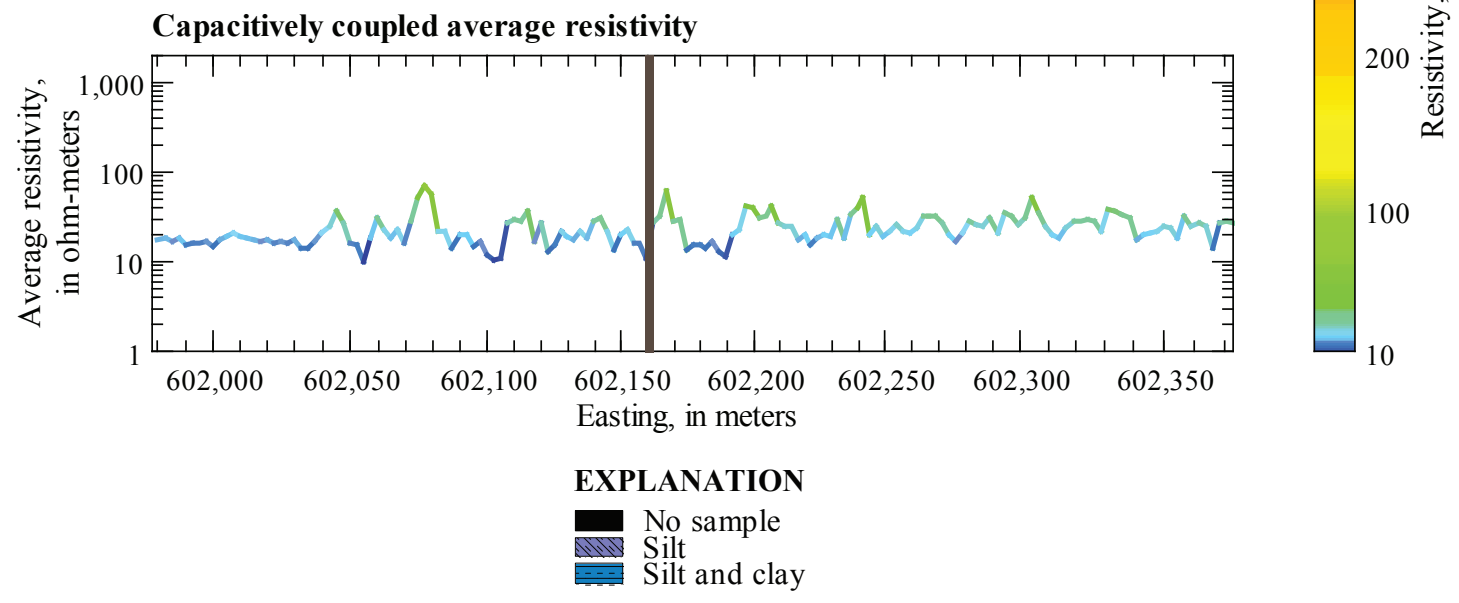

Figure 30. Comparison of $(A)$ lithologic and electrical conductivity log data from test hole FtL17 drilled along the tow road of Fort Laramie Canal to $(B)$ an inverted capacitively coupled resistivity section and average resistivity curve. The horizontal black line on the inverted resistivity section is the canal bed elevation, and the vertical gray line on the inverted resistivity section and average resistivity curve plots is the location of test hole FtL17. 

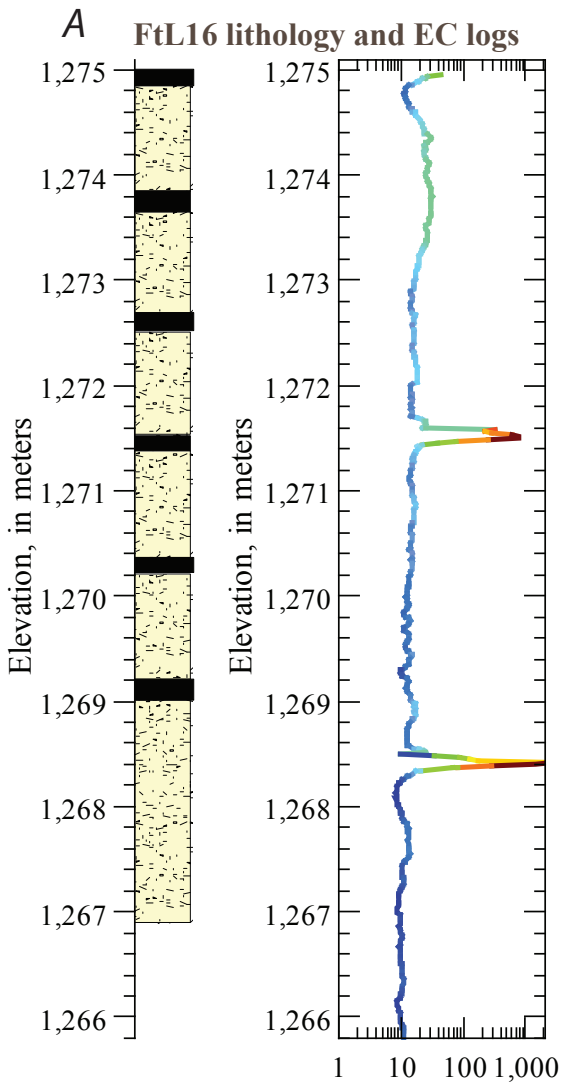

\section{$B \quad$ Inverted capacitively coupled resistivity section}
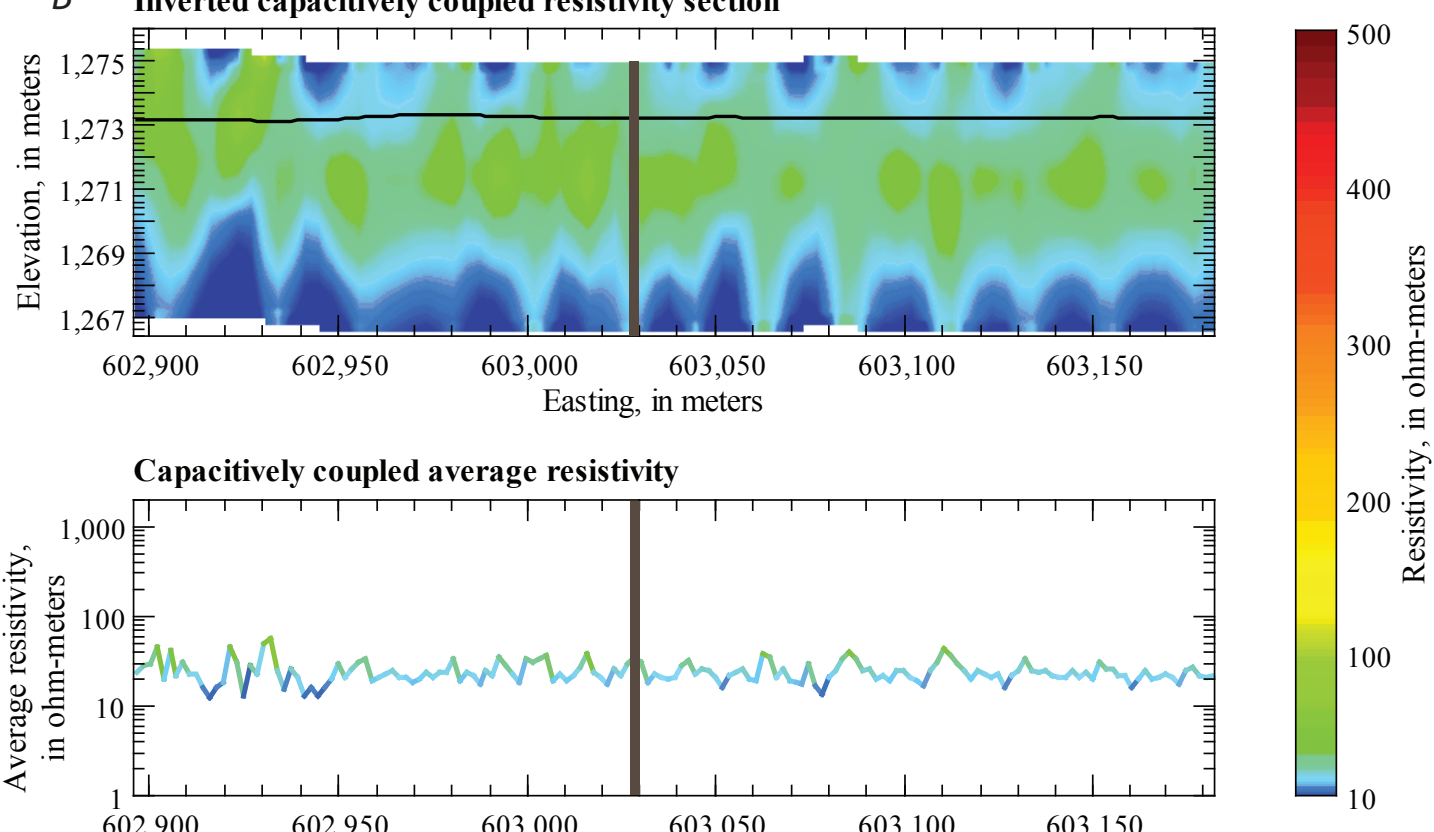

Resistivity, in ohm-meters

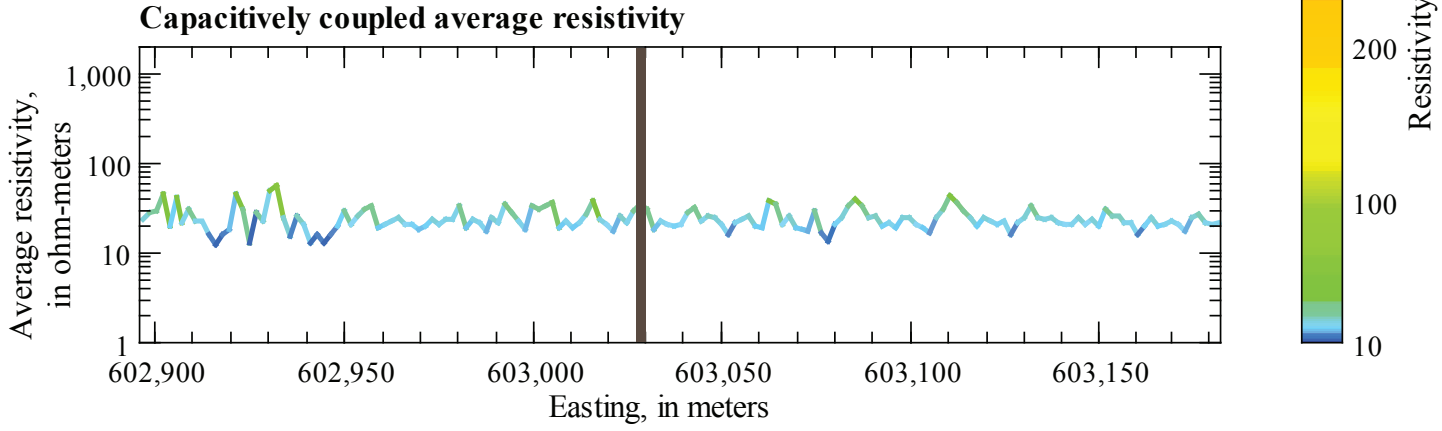

\section{EXPLANATION}

No sample

Figure 31. Comparison of $(A)$ lithologic and electrical conductivity log data from test hole FtL16 drilled along the tow road of Fort Laramie Canal to (B) an inverted capacitively coupled resistivity section and average resistivity curve. The horizontal black line on the inverted resistivity section is the canal bed elevation, and the vertical gray line on the inverted resistivity section and average resistivity curve plots is the location of test hole FtL16. 

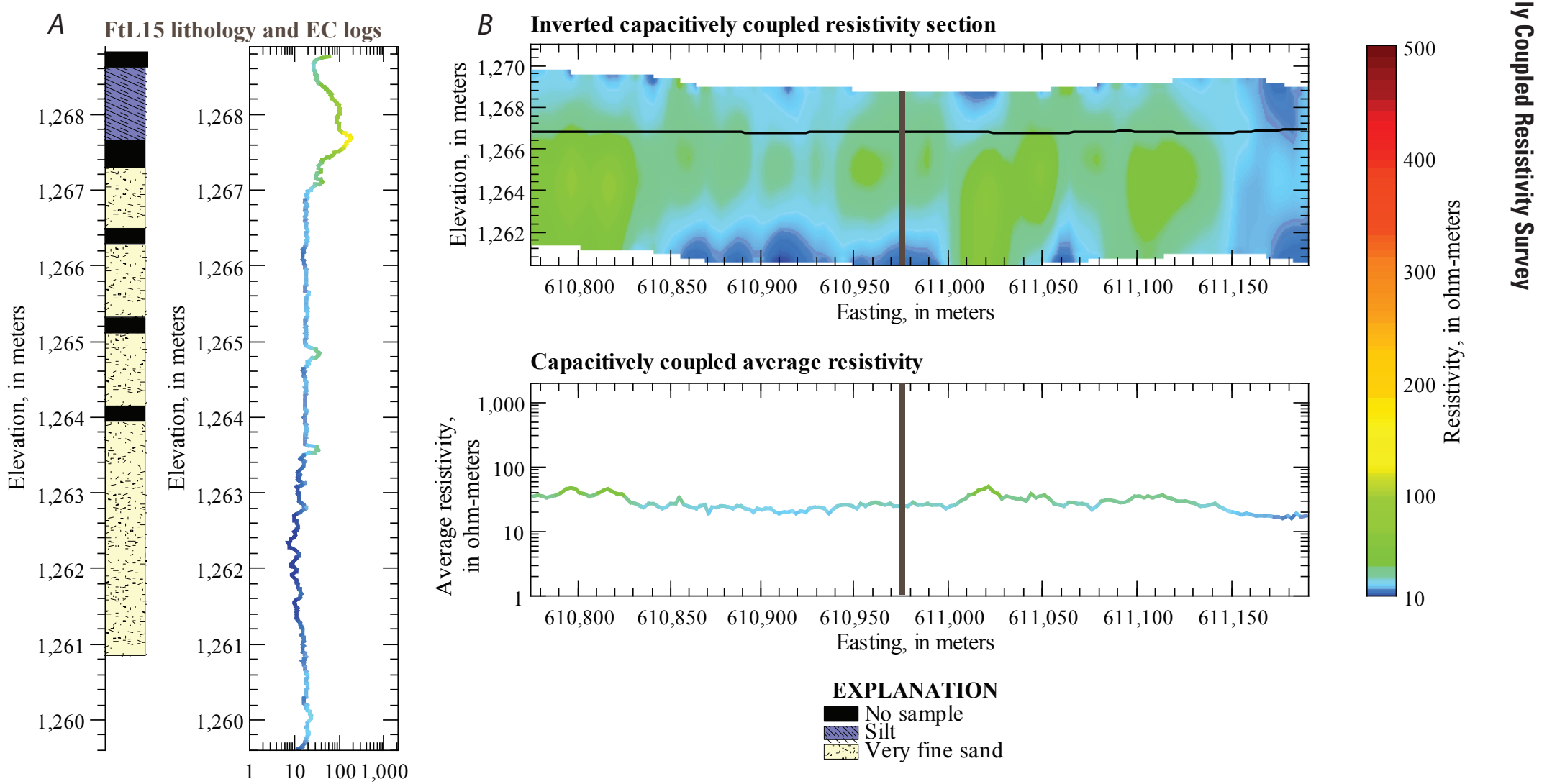

Easting, in meters

\section{EXPLANATION}

No sample

Very fine sand

Figure 32. Comparison of $(A)$ lithologic and electrical conductivity log data from test hole FtL15 drilled along the tow road of Fort Laramie Canal to $(B)$ an inverted capacitively coupled resistivity section and average resistivity curve. The horizontal black line on the inverted resistivity section is the canal bed elevation, and the vertical gray line on the inverted resistivity section and average resistivity curve plots is the location of test hole FtL15. 

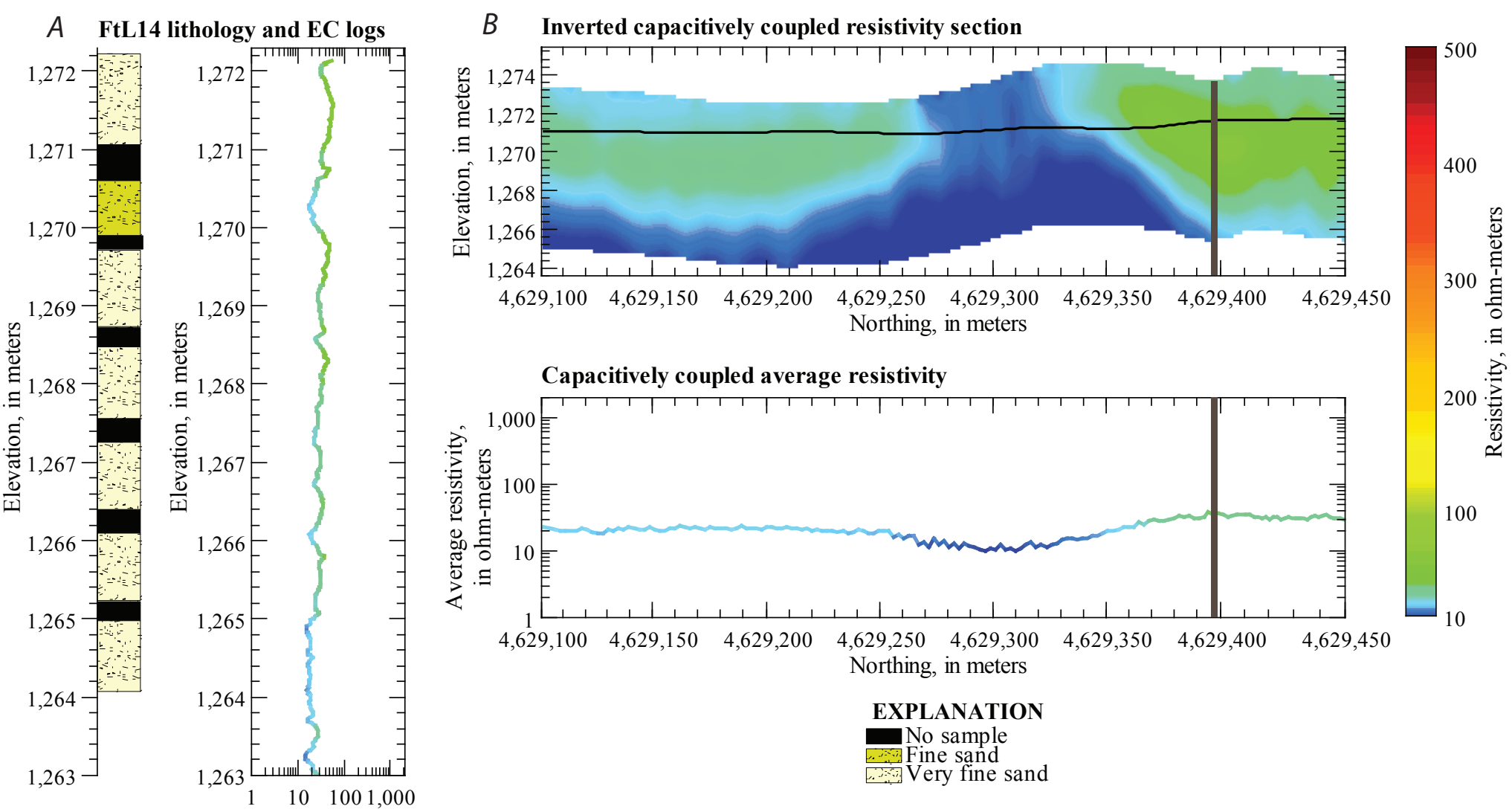

EXPLANATION

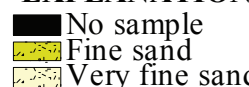

Resistivity, in ohm-meters

Figure 33. Comparison of $(A)$ lithologic and electrical conductivity log data from test hole FtL14 drilled along the tow road of Fort Laramie Canal to $(B)$ an inverted capacitively coupled resistivity section and average resistivity curve. The horizontal black line on the inverted resistivity section is the canal bed elevation, and the vertical gray line on the inverted resistivity section and average resistivity curve plots is the location of test hole FtL14. 


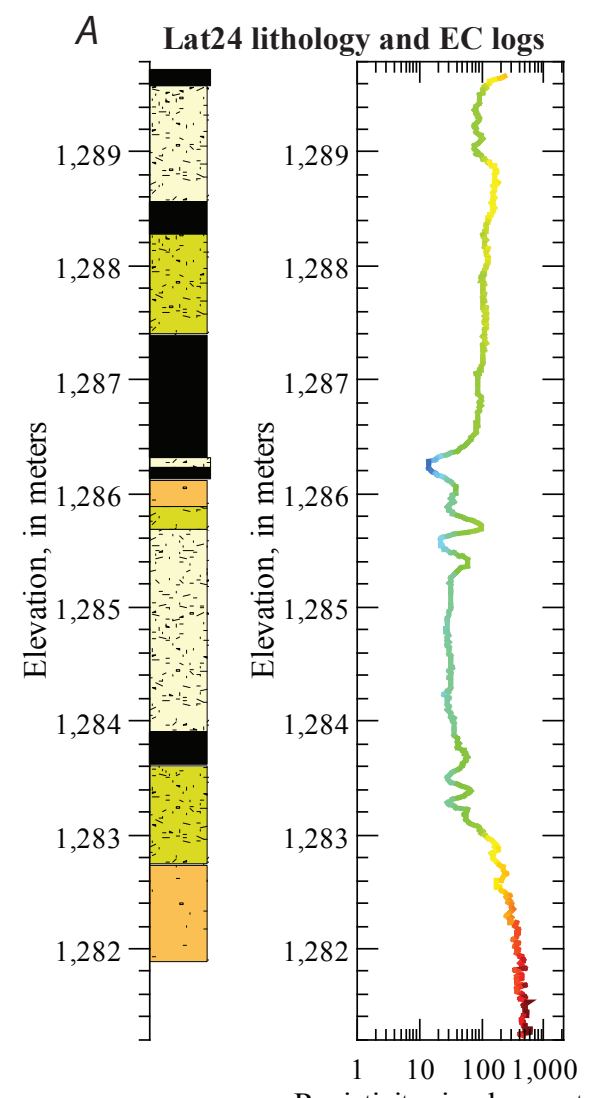

Resistivity, in ohm-meter

\section{B Inverted capacitively coupled resistivity section}

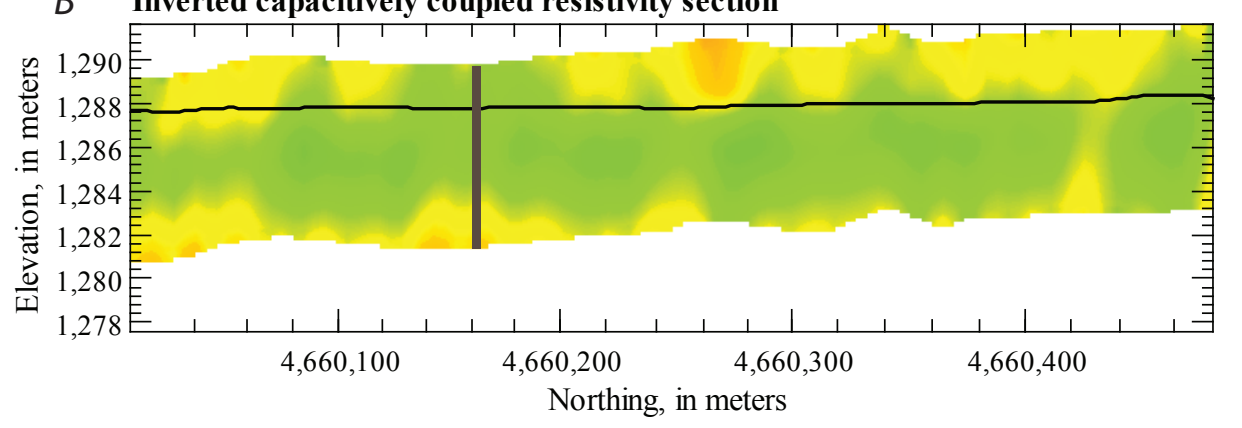

400

$300 \stackrel{1}{\Xi}$

Northing, in meters

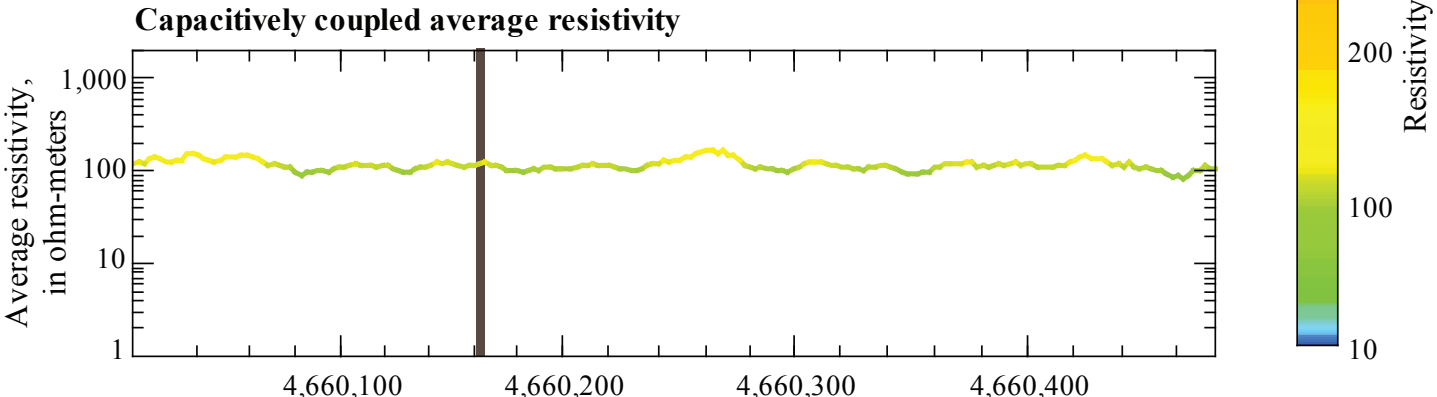

Northing, in meters

EXPLANATION

No sample

Moderately to poorly

sorted mixed

Very fine sand

Figure 34. Comparison of $(A)$ lithologic and electrical conductivity log data from test hole Lat24 drilled along the tow road of Lateral Number 1 to $(B)$ an inverted capacitively coupled resistivity section and average resistivity curve. The horizontal black line on the inverted resistivity section is the canal bed elevation, and the vertical gray line on the inverted resistivity section and average resistivity curve plots is the location of test hole Lat24. 


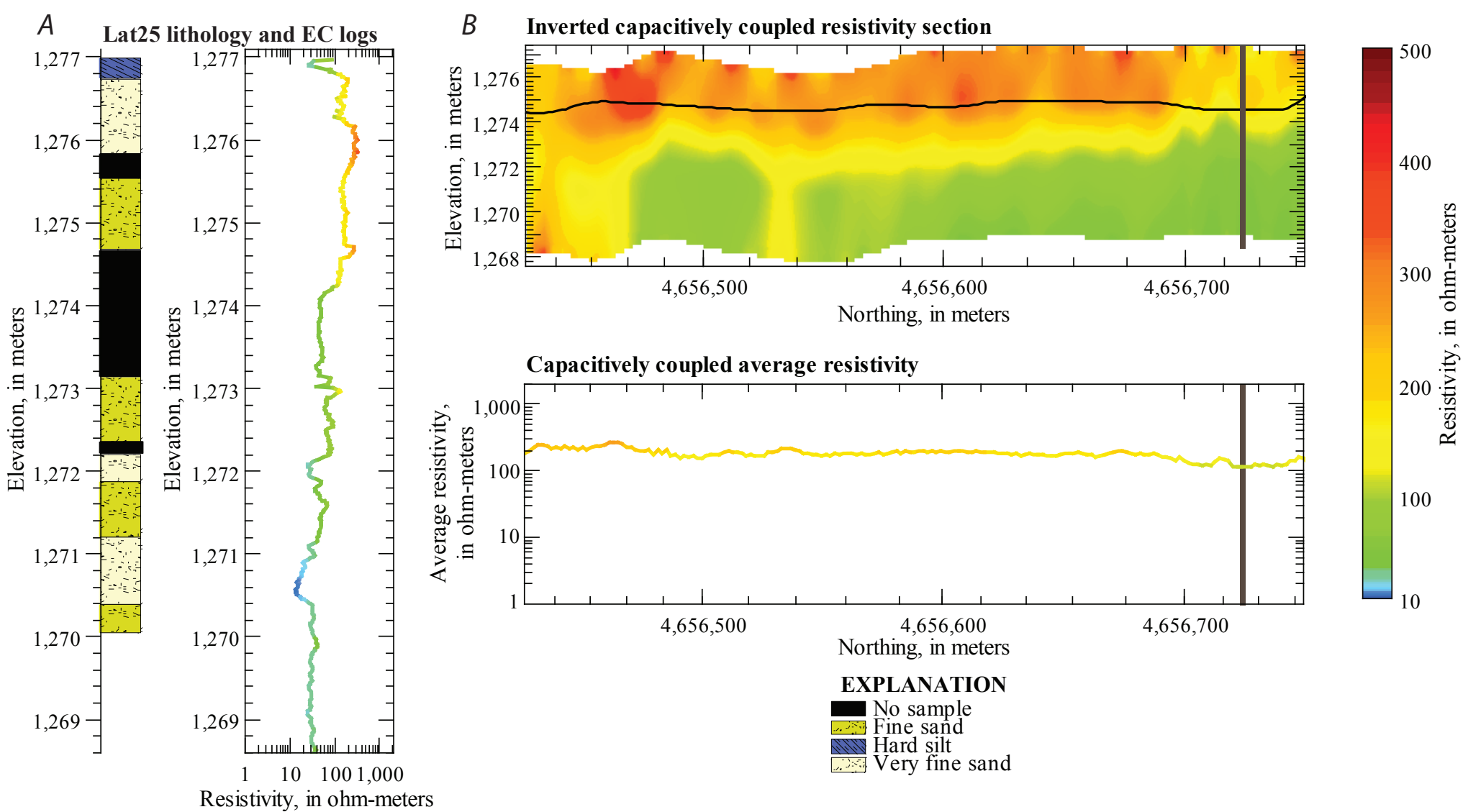

Figure 35. Comparison of $(A)$ lithologic and electrical conductivity log data from test hole Lat25 drilled along the tow road of Lateral Number 1 to $(B)$ an inverted capacitively coupled resistivity section and average resistivity curve. The horizontal black line on the inverted resistivity section is the canal bed elevation, and the vertical gray line on the inverted resistivity section and average resistivity curve plots is the location of test hole Lat25. 


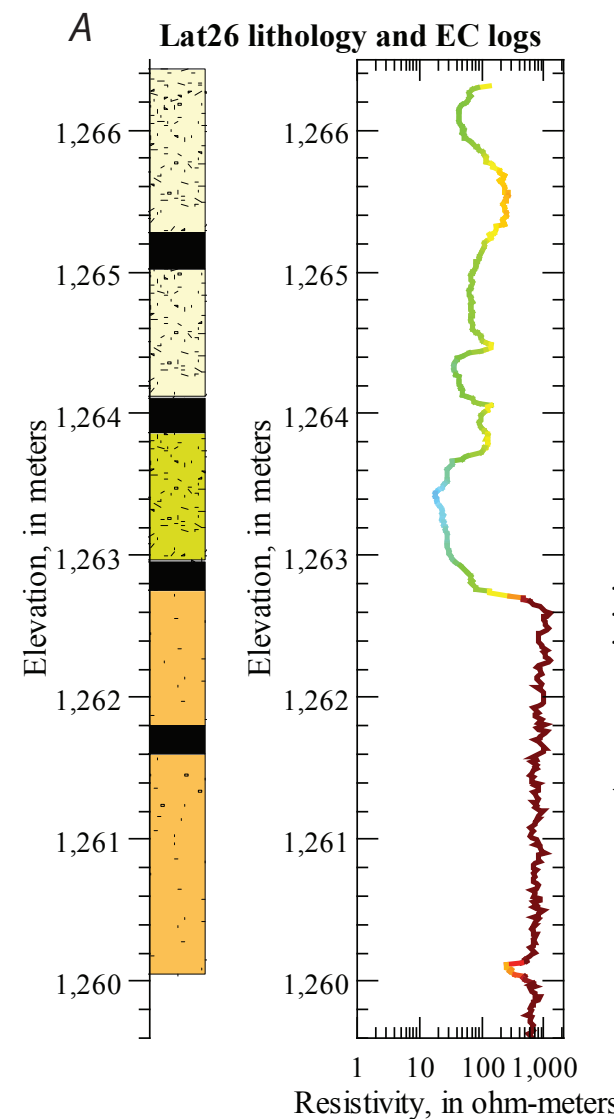

\section{B Inverted capacitively coupled resistivity section}

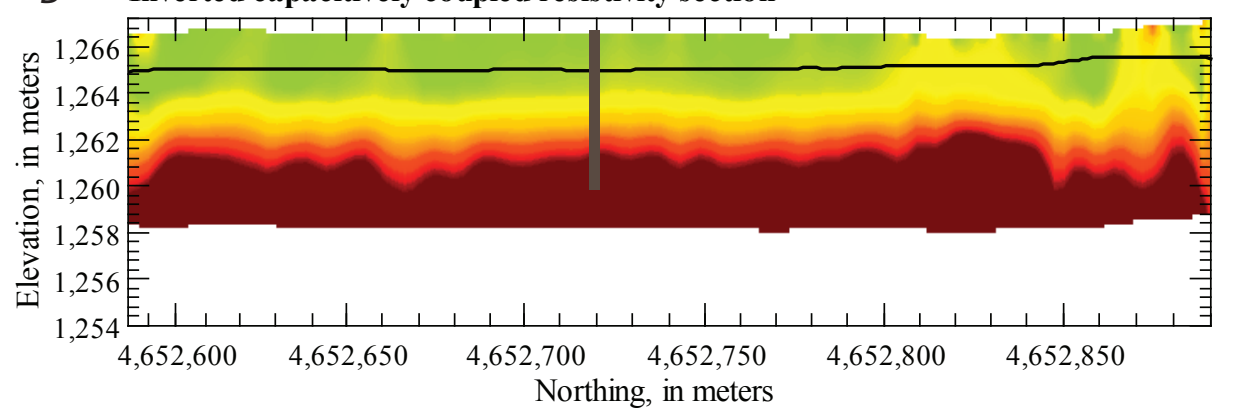

Capacitively coupled average resistivity
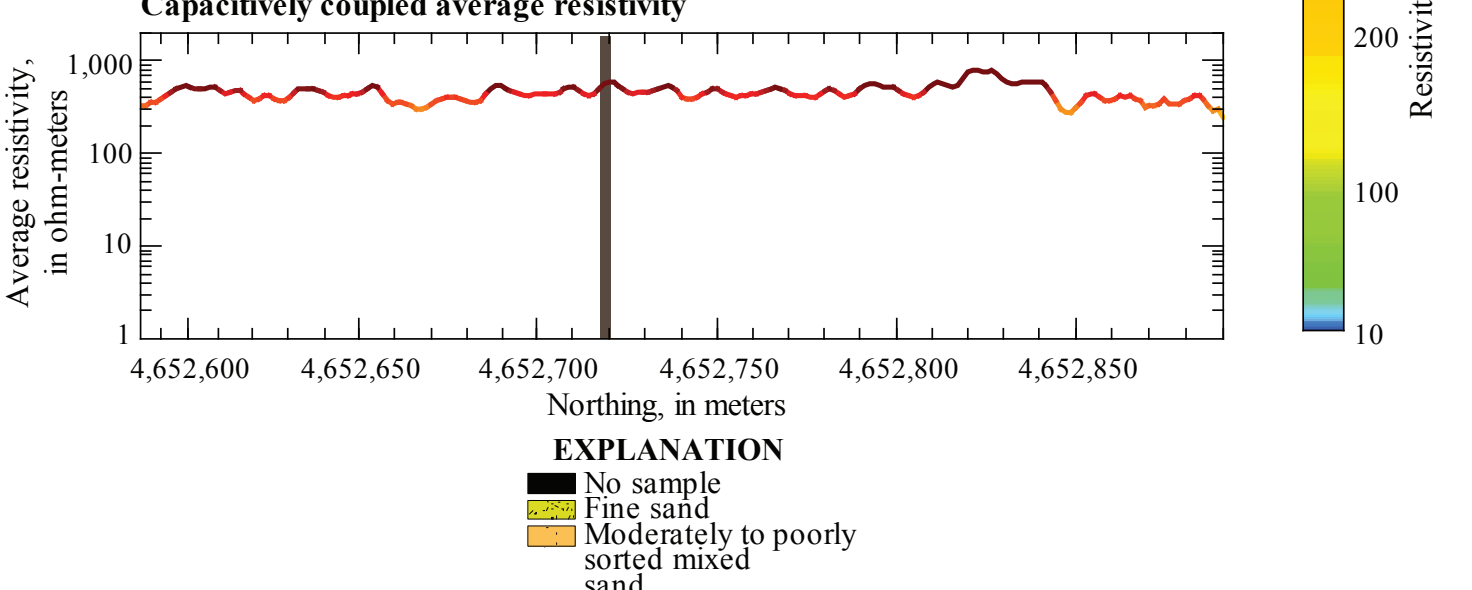

Figure 36. Comparison of $(A)$ lithologic and electrical conductivity log data from test hole Lat26 drilled along the tow road of Lateral Number 1 to $(B)$ an inverted capacitively coupled resistivity section and average resistivity curve. The horizontal black line on the inverted resistivity section is the canal bed elevation, and the vertical gray line on the inverted resistivity section and average resistivity curve plots is the location of test hole Lat26. 

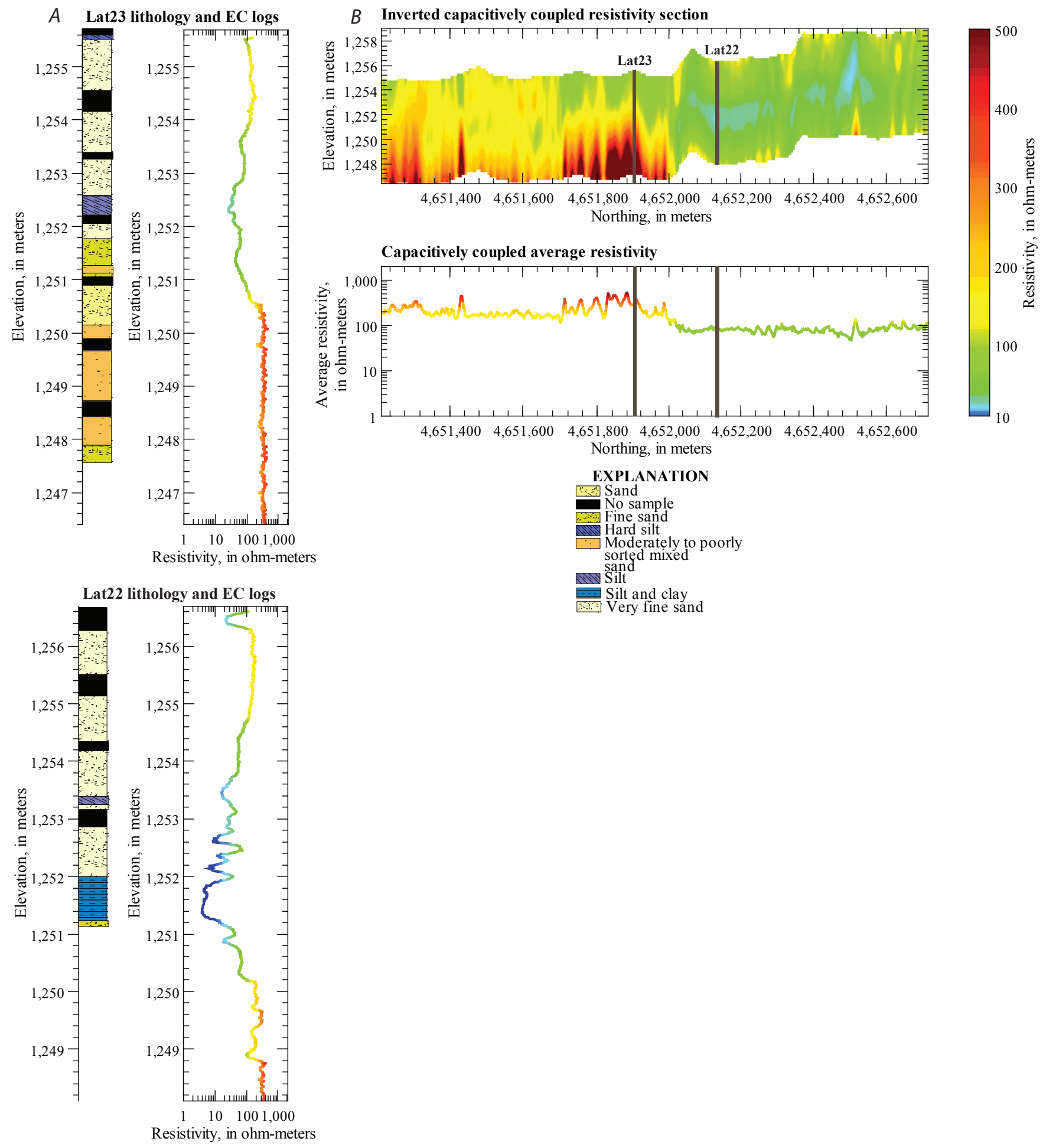

Figure 37. Comparison of $(A)$ lithologic and electrical conductivity log data from test holes Lat22 and Lat23 drilled along the tow road of Lateral Number 10 to $(B)$ an inverted capacitively coupled resistivity section and average resistivity curve. The vertical gray lines on the inverted resistivity section and average resistivity curve plots are the locations of test holes Lat22 and Lat23. The canal bed elevations are not available for this section. 

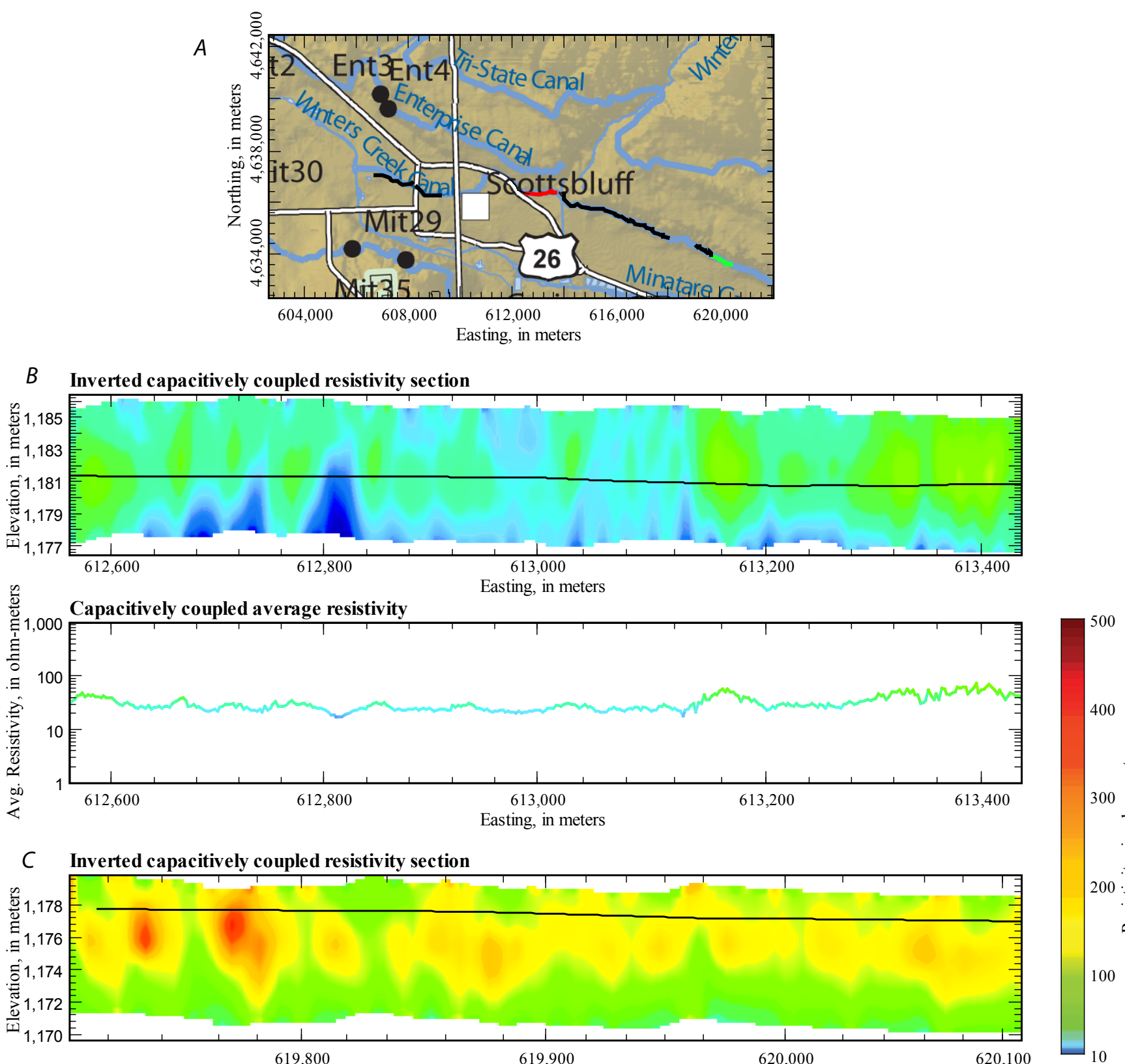

C Inverted capacitively coupled resistivity section

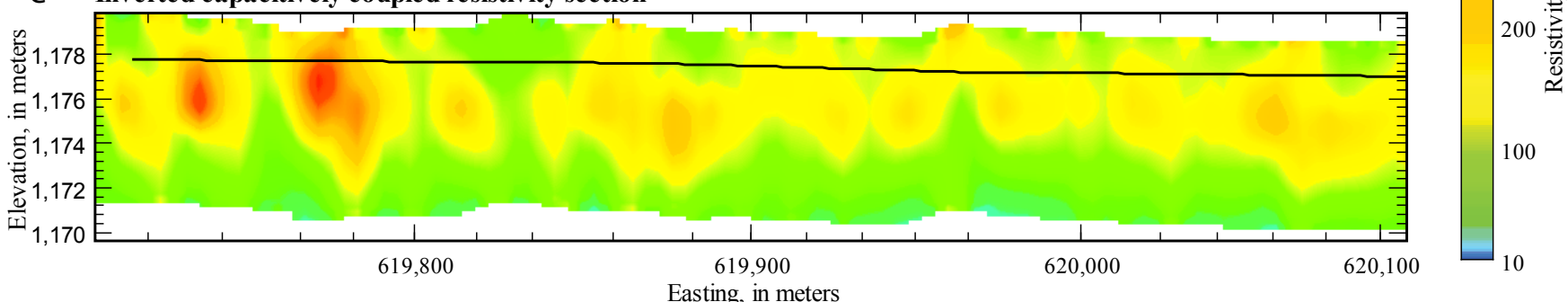

Capacitively coupled average resistivity

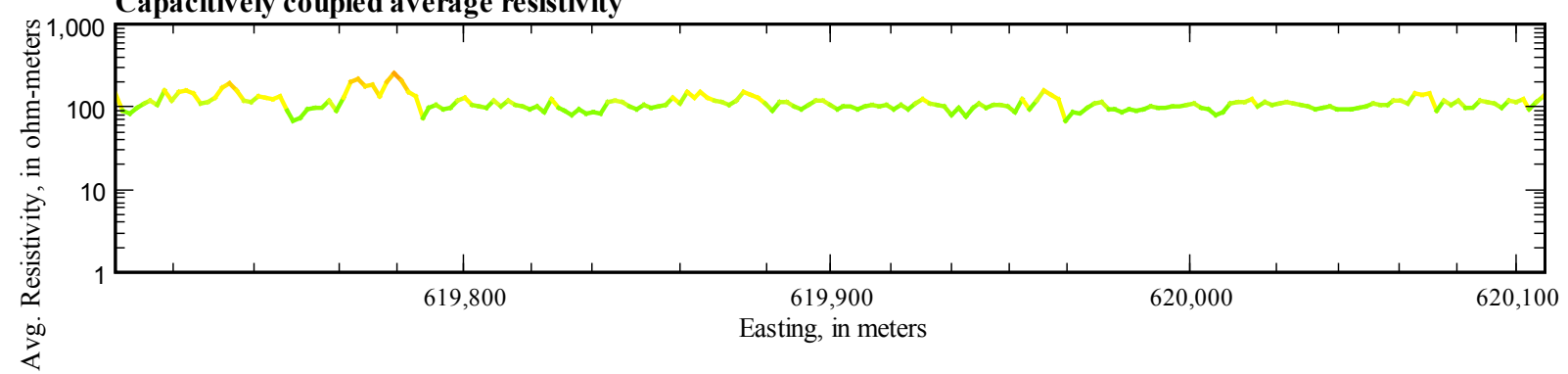

Figure 38. Map $(A)$ showing the location of two sample inverted capacitively coupled resistivity sections and average resistivity curves from Winters Creek Canal. All surveyed sections of Winters Creek Canal are shown in black on the map. The western displayed section $(B)$ is shown in red on the map, and the eastern displayed section $(C)$ is shown in green on the map. Both sections were acquired along the tow road, and the horizontal black line on the inverted resistivity sections is the canal bed elevation. 

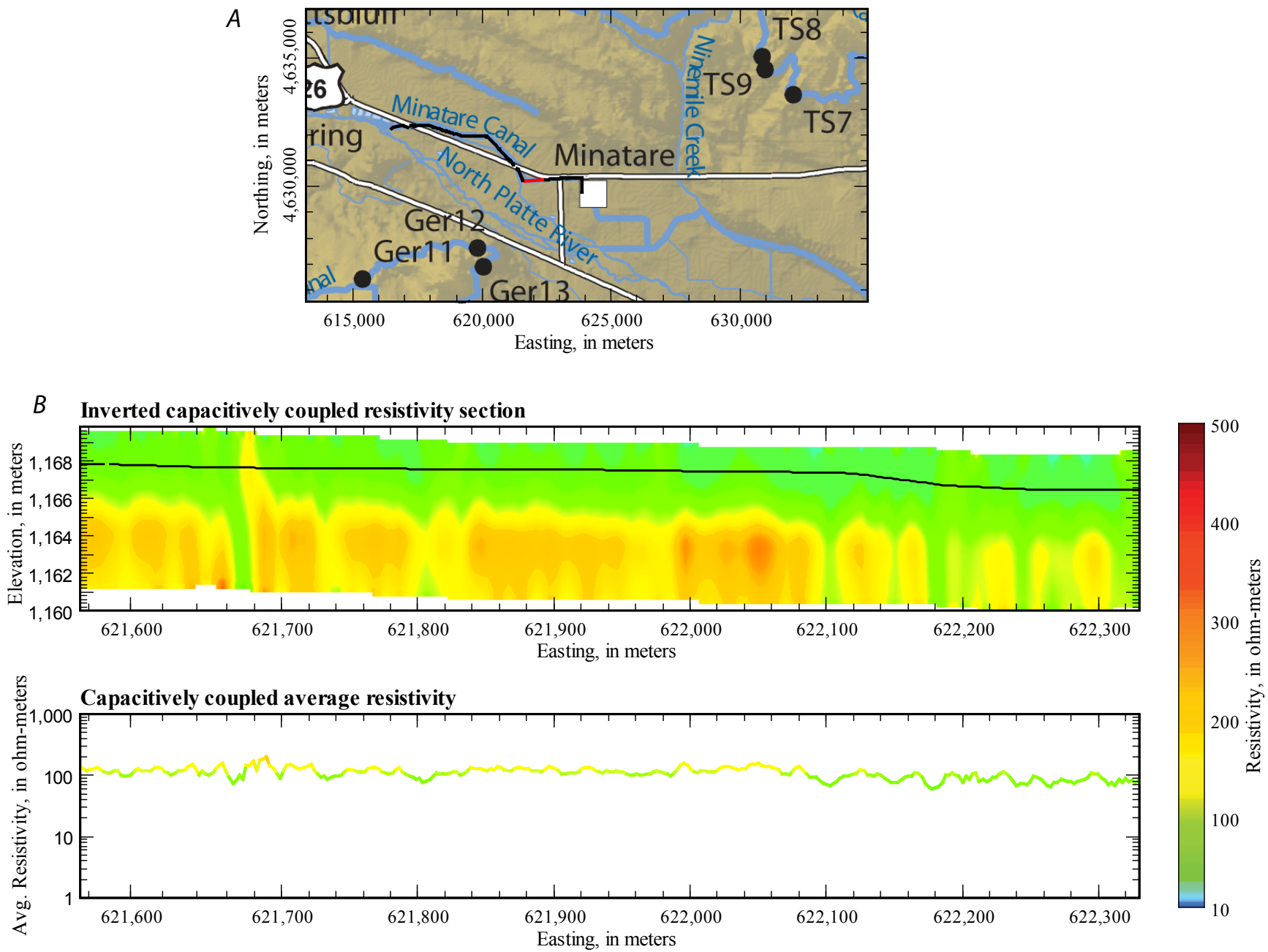

Figure 39. Map $(A)$ showing the location of a sample inverted capacitively coupled resistivity section and average resistivity curve from Minatare Canal. All surveyed sections of Minatare Canal are shown in black on the map. The displayed section $(B)$ is shown in red on the map. This section was acquired along the tow road, and the horizontal black line on the inverted resistivity section is the canal bed elevation. 
$A$

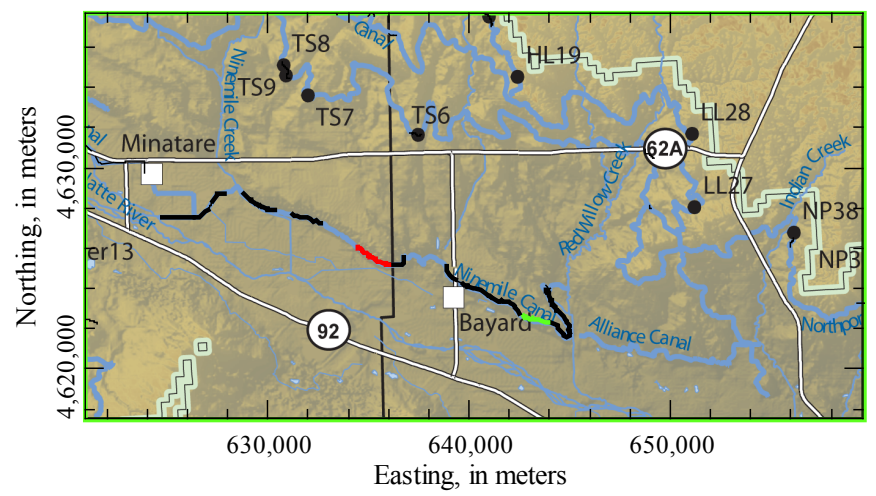

$B \quad$ Inverted capacitively coupled resistivity section
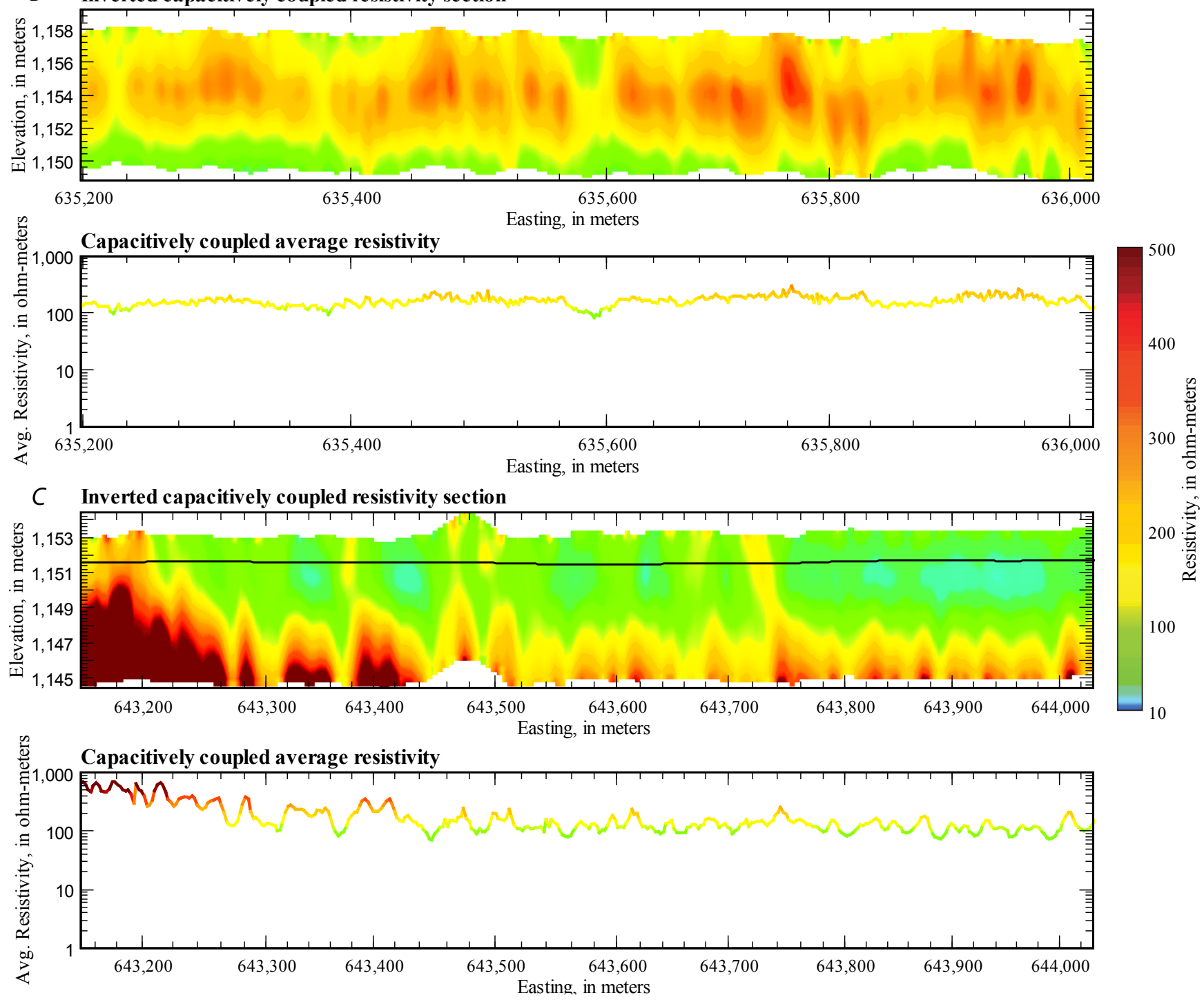

Figure 40. Map $(A)$ showing the location of two sample inverted capacitively coupled resistivity sections and average resistivity curves from Ninemile Canal. All surveyed sections of Ninemile Canal are shown in black on the map. The western displayed section $(B)$ is shown in red on the map, and the eastern displayed section $(C)$ is shown in green on the map. Both sections were acquired along the tow road, and the horizontal black line on the inverted resistivity section $(C)$ is the canal bed elevation. The canal bed along section $(B)$ was not surveyed due to the presence of water in the canal. 


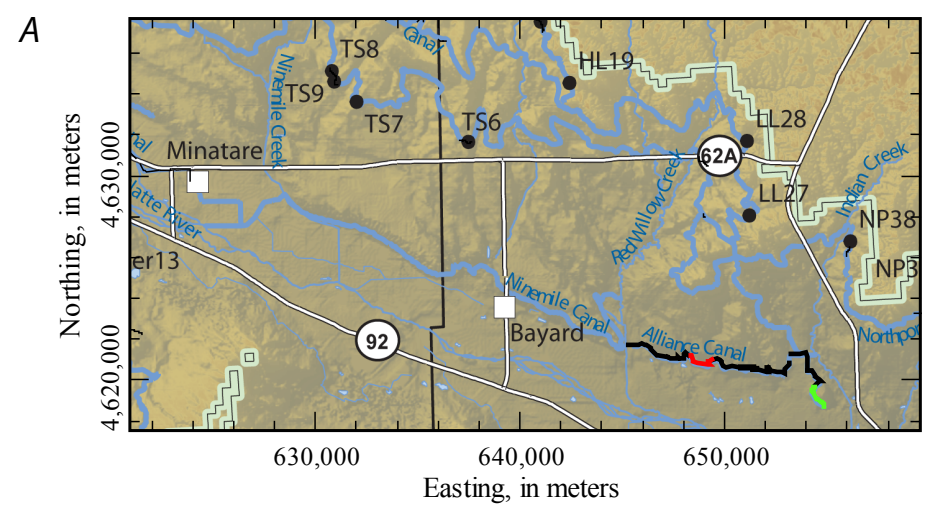

$B \quad$ Inverted capacitively coupled resistivity section

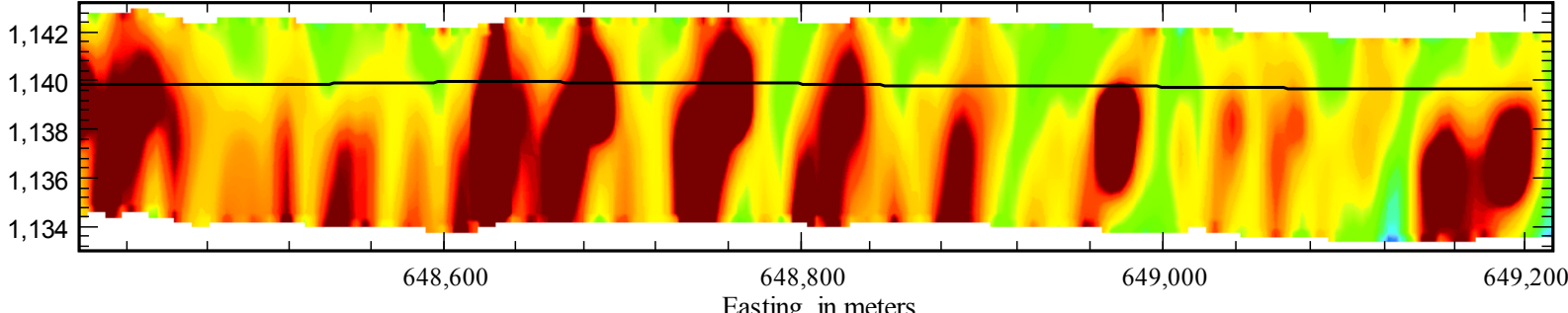

Capacitively coupled average resistivity

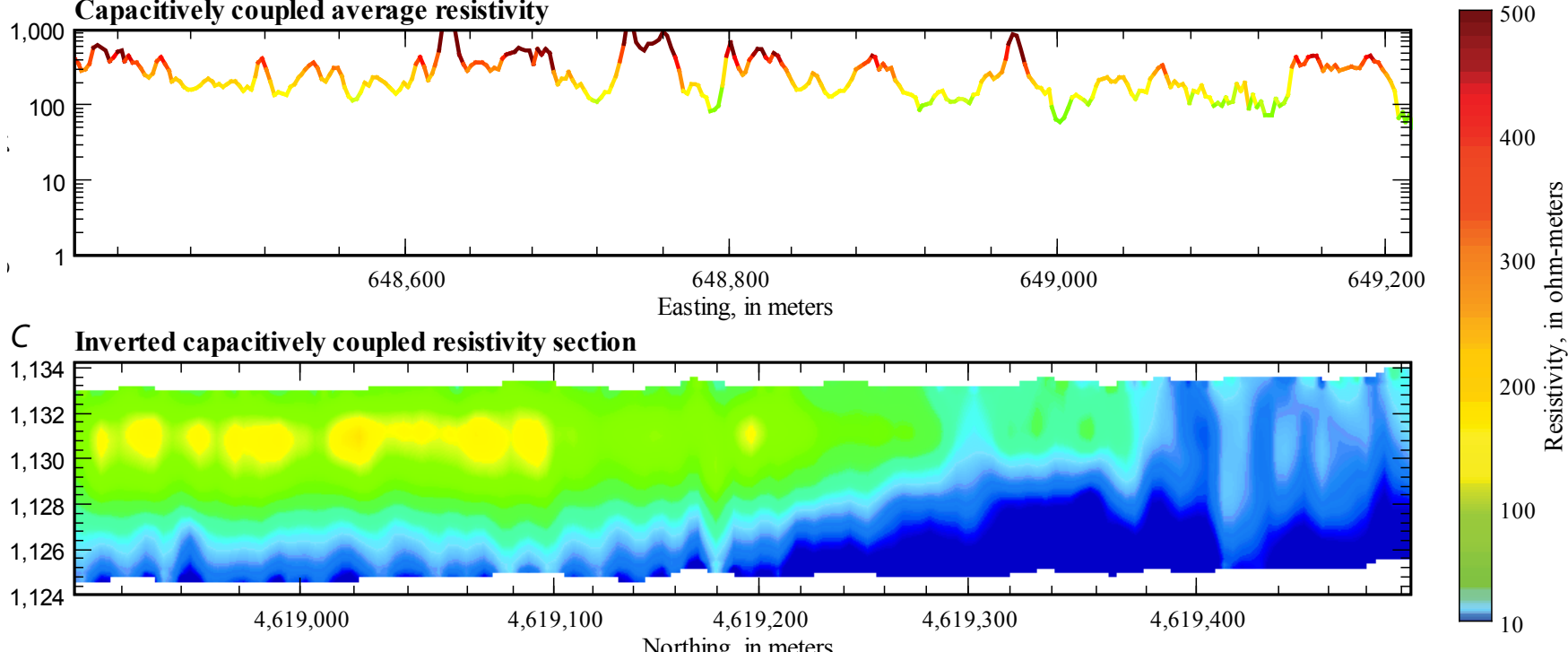

Capacitively coupled average resistivity

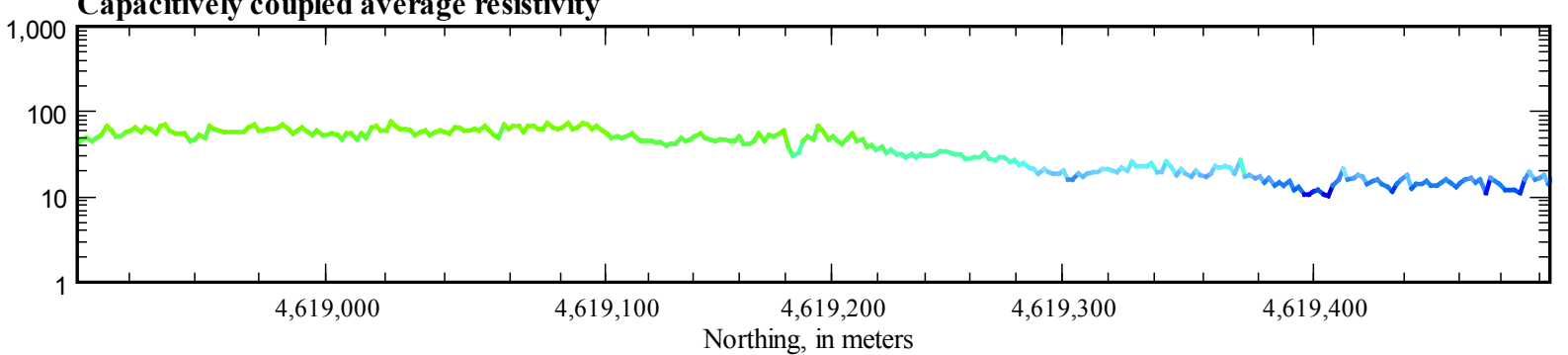

Figure 41. Map $(A)$ showing the location of two sample inverted capacitively coupled resistivity sections and average resistivity curves from Alliance Canal. All surveyed sections of Alliance Canal are shown in black on the map. The western displayed section $(B)$ is shown in red on the map, and the eastern displayed section $(C)$ is shown in green on the map. Both sections were acquired along the tow road, and the horizontal black line on the inverted resistivity section $(B)$ is the canal bed elevation. The canal bed along section $(C)$ was not surveyed due to limited access. 


\section{Appendix-Digital Data}

\section{Capacitively Coupled Resistivity Data}

Digital capacitively coupled resistivity data are provided in two compressed files:

1. Binned data: processed, binned (5-m bin size) data, and

2. Inverted data: processed, inverted model (2.5-m cell size) data.

Each compressed file contains 4 files, one for each year of data acquisition: 2004, 2007, 2008, and 2009:

All data are provided in an ASCII array, comma-separated format. Unavailable or null data are denoted by -9999.00 value. The data headings are as follows:

- Line: line name, format varies based on data acquisition year,

- $X$ and $Y$ : easting and northing coordinates of acquired $\mathrm{CC}$ resistivity data in NAD83, UTM zone $13 \mathrm{~N}$, in meters,

- Z: elevation of acquired $\mathrm{CC}$ resistivity data in NAVD88, in meters,

- Dist_m: local downline distance, in meters,

- Depth_m[\#]: depth below surface horizontal array containing \# values, in meters,

- Res_ohmm[\#]: resistivity value horizontal array containing \# values, in ohm-m,

Publishing support provided by:

Denver Publishing Service Center

For more information concerning this publication, contact:

Team Chief Scientist, USGS Crustal Imaging and Characterization Box 25046, Mail Stop 964

Denver, CO 80225

(303) 236-1312

Or visit the Crustal Imaging and Characterization Team Web site at: http://crustal.usgs.gov/
- Canal: canal name in which data were acquired,

- Location: location of acquired CC resistivity data, either in "CANAL" or on "TOW ROAD", and

- $R T K G P S \_Z \_m$ : canal bed elevations from RTK GPS survey, in NAVD88 meters.

In the Binned data files, the Depth_m[\#] and Res_ ohmm[\#] headings are array values containing 5 elements each for every X and Y location. The Res_ohmm[\#] heading contains apparent resistivities, in ohm-m.

In the Inverted data files, the Depth_m[\#] and Res_ ohmm[\#] headings are array values that contain a varying number of elements for every $\mathrm{X}$ and $\mathrm{Y}$ location depending on the acquisition year: 2004 (10 elements), 2007 (5 elements), 2008 (7 elements), and 2009 (7 elements). The Res_ohmm[\#] heading contains modeled resistivities, in ohm-m.

\section{Electrical Conductivity Log Data}

The electrical conductivity (EC) log data from the 2008 and 2009 test holes are provided in an ASCII, comma-separated format. The data headings are as follows:

- TH_ID: test hole name,

- Depth_m: depth below land surface, in meters,

- Elev_m: elevation in NAVD88, in meters,

- EC_mSm: electrical conductivity, in millisiemens per meter,

- Res_ohmm: resistivity, in ohm-meters, and

- ROP_mmin: rate of push, in meters per minute. 
